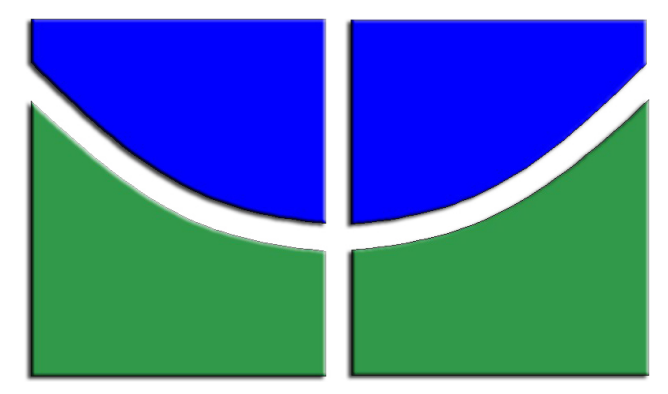

\author{
UNIVERSIDADE DE BRASÍLIA \\ INSTITUTO DE FÍSICA \\ PROGRAMA DE PÓS-GRADUAÇÃO EM FÍSICA
}

DISSERTAÇÃO DE MESTRADO

Impacto do Átomo de Metal nas Propriedades Eletrônicas e Ópticas de Ftalocianinas

Antonio Marcos Silva Santos

Brasília

Junho de 2016 


\title{
Impacto do Átomo de Metal nas Propriedades Eletrônicas e Ópticas de Ftalocianinas
}

\author{
Antonio Marcos Silva Santos \\ Orientador: Dr. Demétrio Antônio da Silva Filho \\ Dissertação de Mestrado apresen- \\ tada ao Instituto de Física da Uni- \\ versidade de Brasília como parte \\ dos requisitos necessários para a \\ obtenção do título de Mestre em \\ Física.
}

Banca Examinadora:

Prof. Dr. Demétrio Antônio da Silva Filho (Orientador - IF - UnB)

Prof. Dr. Luiz Antonio Ribeiro Junior (IF - UnB)

Prof. Dr. Luciano Almeida Leal (CMB-DF)

Brasília

Junho de 2016 
Ficha catalográfica elaborada automaticamente, com os dados fornecidos pelo(a) autor(a)

Silva Santos, Antonio Marcos

Impacto do Átomo de Metal nas Propriedades

Eletrônicas e ópticas de Ftalocianinas / Antonio

Marcos Silva Santos; orientador Demétrio Antônio da Silva Filho. -- Brasília, 2016.

$112 \mathrm{p}$.

Dissertação (Mestrado - Mestrado em Física) -Universidade de Brasília, 2016.

1. Ftalocianinas. 2. Propriedades Eletrônicas. I. da Silva Filho, Demétrio Antônio, orient. II. Título. 


\section{"Impacto do Átomo de Metal nas Propriedades Eletrônicas e Ópticas de Ftalocianinas."}

\section{Por}

\section{Antônio Marcos Silva Santos.}

Dissertação submetida ao Instituto de Física da Universidade de Brasília como parte dos requisitos para a obtenção do grau de Mestre em Física.

Aprovada por:

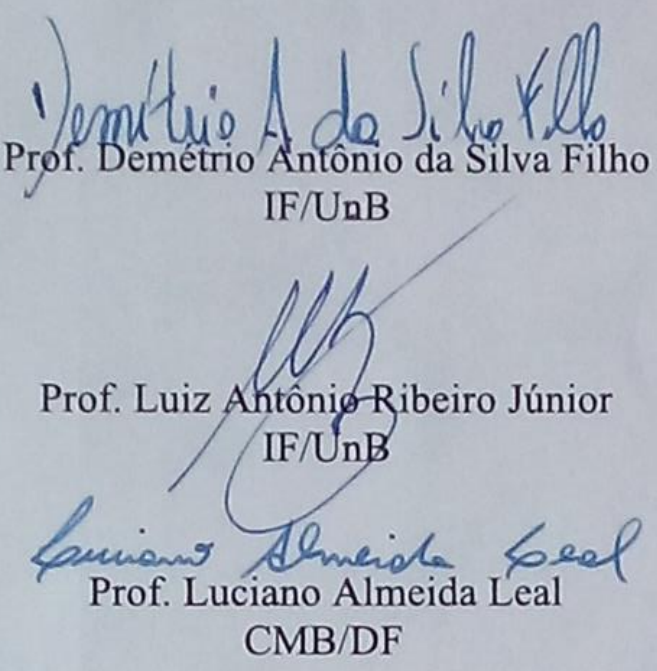

Prof. Dr. Fernando de Oliveira Albuquerque

Coordenador de Pós-Graduação

Instituto de Física 
O coração do que tem discernimento adquire conhecimento; os ouvidos dos sábios saem à sua procura. (Provérbios $18: 15)$ 
Às minhas irmãs, Maria Silva Santos Barbosa e Marizete Silva Santos, à minha esposa Sandra Maria Oliveira Santos. 


\section{Agradecimentos}

Agradeço a DEUS por sempre me manter firme nos momentos mais difíceis da minha vida, me dando mais esta vitória.

Às minhas irmãs Maria Silva Santos Barbosa e Marizete Silva Santos pelo amor incondicional, por serem sempre a minha principal coluna de sustentação, por estarem ao meu lado todas as vezes que precisei e por terem feito de mim o que sou hoje.

Aos meus irmãos Vivaldo Silva Santos e Iracildo Silva Santos por sempre estarem ao meu lado e me apoiarem em todas as minhas decisões.

Ao meu irmão Odeto Silva Santos pelo carinho que sempre mostrou ter por $\operatorname{mim}$.

À minha esposa Sandra Maria Oliveira Santos pelo apoio, incentivo, dedicação e amor em todos os momentos.

À toda minha família pelo apoio, incentivo e orações.

À minha grande amiga Tamires Lima Pereira que me acompanhou desde o começo, contribuindo de maneira significativa durante todo este processo.

Ao amigo Arthur Silva Aguiar pela a amizade e incentivo.

Ao meu orientador Prof. Demétrio Antônio da Silva Filho pelas orientações, compreensão e oportunidade de desenvolver este trabalho.

Aos colegas do Instituto de Física Arthur Akira Mamiya e Leonardo Evaristo de Sousa pelas contribuições neste trabalho.

Ao Conselho Nacional de Desenvolvimento Científico e Tecnológico (CNPq) pela concessão da bolsa de estudos. 


\section{Lista de Abreviaturas}

B3LYP - Funcional Híbrido de Correlação e Troca da DFT (do inglês, Beck, Three Parameter Lee-Young-Parr)

CCDC - Cambridge Crystallographic Data Centre

CM - Centro Médio

Co - Cobalto

Cr - Cromo

$\mathbf{C u}-$ Cobre

DFT - Teoria do Funcional da Densidade (do inglês, Density Functional Theory)

DMF - Dimetilformamida

F.O. - Força de Oscilador

Fe - Ferro

Ftc - Ftalocianina

Ftc-Co - Ftalocianina de Cobalto

Ftc-Cu - Ftalocianina de Cobre

Ftc-Fe - Ftalocianina de Ferro

Ftc- $\mathbf{H}_{2}-$ Ftalocianina Base Livre

Ftc-Li - Ftalocianina de Lítio

Ftc-Ni - Ftalocianina de Níquel

Ftc-Ti - Ftalocianina de Titânio

Ftc-V - Ftalocianina de Vanádio

Ftc-Zn - Ftalocianina de Zinco

GO - Geometria Otimizada

HF - Hartree Fock 
HOMO - Orbital Molecular mais Alto Ocupado (do inglês, highest occupied molecular orbital)

LDA - Aproximação da Densidade Local (do inglês, Local Density Approximation)

$\mathbf{L i}$ - Lítio

LUMO - Orbital Molecular mais Baixo Desocupado (do inglês, Lowest Unoccupied Molecular Orbital)

LYP - Lee-Yang-Parr

M - Metal

MFtcs - Metaloftalocianinas

Mo - Molibdênio

Ni - Níquel

OFETs - Transistores Orgânicos de Efeito de Campo (do inglês, Organic Field-Effect Transistors)

OLEDs - Diodos Orgânicos Emissores de Luz (do inglês, Organic Light Emitting Diodes) OPVs - Fotovoltaicos Orgânicos (do inglês, Organic Photovoltaics)

PDT - Terapia Fotodinâmica (do inglês, Photodynamic Therapy)

$\mathbf{p O}_{2}$ - Pressão Parcial de Oxigênio

RHF - Hartree-Fock Restrito

ROHF - Hartree-Fock Restrito para Camada Aberta

$\mathbf{r}_{v d w}$ - raio de van der Walls

Si - Silício

TDDFT - Teoria do Funcional da Densidade Dependente do Tempo (do inglês, Time Dependent Density Functional Theory)

Ti - Titânio

UHF - Hartree-Fock não Restrito

UV-VIS - Ultravioleta Vísivel 
V - Vanádio

$\mathbf{V}_{c}$ - Diferença de potencial crítica

VWN - Vosko-Wilk-Nusair

W - Tungstênio

$\mathbf{Z}$ - Distância do CM ao metal

Zn - Zinco 


\section{Sumário}

Lista de Figuras $\quad$ viii

Lista de Tabelas $\quad$ xi

Resumo $\quad$ xiii

Abstract $\quad$ xiv

1 Introdução 1

1.1 História das Ftalocianinas . . . . . . . . . . . . . . . . . . . 2

2 Fundamentação Teórica $\quad 6$

2.1 Raios-X ............................. 6

2.2 Difração de Raios-X . . . . . . . . . . . . . . . . . . . . . . . 9

2.3 Métodos aproximativos da Química Quântica . . . . . . . . . . . . . . 11

2.3.1 Aproximação de Born-Oppenheimer . . . . . . . . . . . . . . . . . 12

2.3.2 Determinante de Slater . . . . . . . . . . . . . . . . . . 15

2.3.3 A Equação de Hartree-Fock . . . . . . . . . . . . . . . . . . . . . . 18

2.3.4 Teorema de Koopmans . . . . . . . . . . . . . . . . . . . . 20

2.3.5 Teoria do Funcional da Densidade . . . . . . . . . . . . . . . . . 23

3 Resultados e Discussões 28

3.1 Propriedades Geométricas . . . . . . . . . . . . . . . . . . . 28

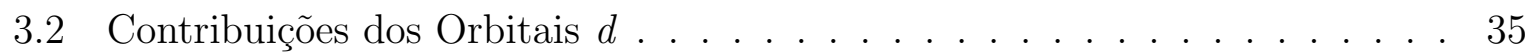

3.3 Energia de Excitação . . . . . . . . . . . . . . . . . . . . . . . 45 
3.4 Espectroscopia UV-VIS . . . . . . . . . . . . . . . . . . . . . 46

$3.4 .1 \quad \mathrm{Ftc}^{-} \mathrm{H}_{2} \ldots \ldots \ldots \ldots \ldots \ldots$

$3.4 .2 \mathrm{Ftc}-\mathrm{Ti} \ldots \ldots \ldots \ldots \ldots \ldots \ldots$

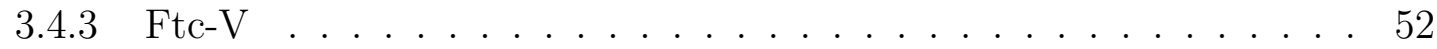

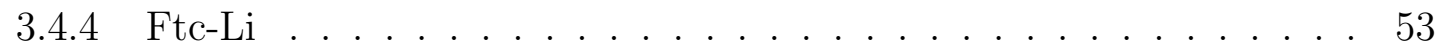

$3.4 .5 \quad \mathrm{Ftc}-\mathrm{Fe} \ldots \ldots \ldots \ldots \ldots \ldots \ldots \ldots$

3.4 .6 Ftc-Co . . . . . . . . . . . . . . . 56

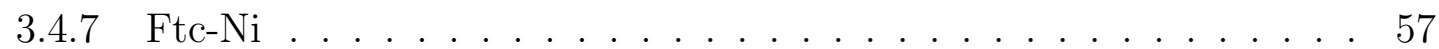

$3.4 .8 \quad \mathrm{Ftc}-\mathrm{Si} \ldots \ldots \ldots \ldots \ldots \ldots$

$3.4 .9 \mathrm{Ftc}-\mathrm{Cu} \ldots \ldots \ldots \ldots \ldots \ldots$

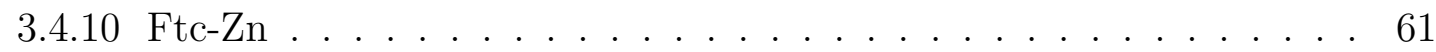

4 Considerações Finais $\quad 65$

$\begin{array}{lr}\text { Referências Bibliográficas } & 67\end{array}$

$\begin{array}{ll}\text { A Ftalocianinas } & 73\end{array}$

A.1 Ftalocianina de Base Livre . . . . . . . . . . . . . . . . . . 73

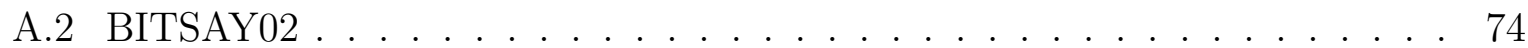

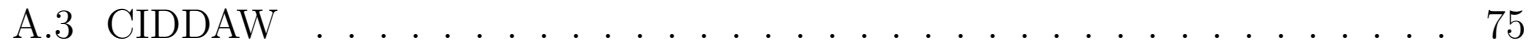

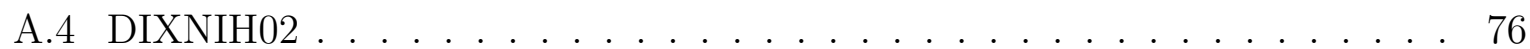

A.5 LUWNUM . . . . . . . . . . . . . . . . . . . 77

A.6 LUWPAU . . . . . . . . . . . . . . . . . . . . . . . . 78

A.7 NIPHTC . . . . . . . . . . . . . . . . . . . . . . . 79

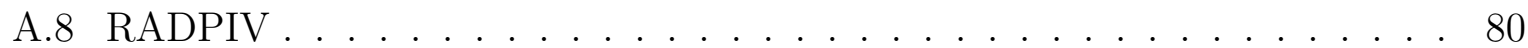

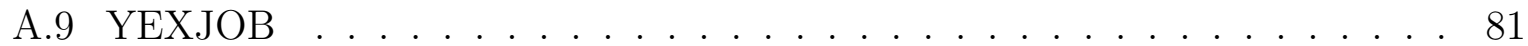

B Script para o Cálculo das Contribuições do Orbital d 82 
C Contribuições do Orbital d

D Descrição dos Estados Excitados das Ftcs 


\section{Lista de Figuras}

1.1 Moléculas de Ftalocianina $\left(\mathrm{C}_{32} \mathrm{H}_{18} \mathrm{~N}_{8}\right)$ (a) e Metaloftalocianina $\left(\mathrm{MeC}_{32} \mathrm{H}_{16} \mathrm{~N}_{8}\right)$

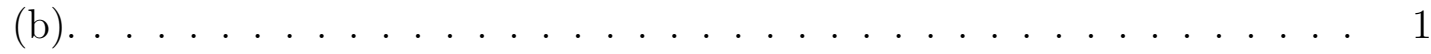

1.2 Estratégias gerais para a síntese de Ftcs. Figura adaptada da referência [24]. 4

2.1 Espectro eletromagnético de radiação. . . . . . . . . . . . . . . . . 7

2.2 Obtenção de radiação $K_{\alpha}$ e $K_{\beta} \ldots \ldots \ldots \ldots \ldots$. . . . . . . . . . 7

2.3 Relação entre as intensidades por cada comprimento de onda produzido. 8

2.4 Reflexão de um feixe de Raios-X pelos planos (h k l) de um cristal. . . . . 10

2.5 Sistema de coordenadas molecular. . . . . . . . . . . . . . . . 12

3.1 Distância do centro médio da molécula ao metal para os casos Raios-X e geometria otimizada. . . . . . . . . . . . . . . 30

3.2 (a) raio da gaiola e (b) raio de van der Walls. . . . . . . . . . . . . . 32

3.3 Representação do arqueamento da MFtc decorrente da presença do metal na gaiola central. . . . . . . . . . . . . . . . . . . . 34

3.4 Representação dos orbitais $d . \ldots \ldots \ldots \ldots$. . . . . . . . . . . . 35

3.5 Contribuições dos orbitais d acima de $10 \%$ para as moléculas de Ftcs. . . . 37

3.6 Orbitais moleculares para a $\mathrm{Ftc}-\mathrm{H}_{2} \ldots \ldots \ldots \ldots \ldots$

3.7 Orbitais moleculares para a Ftc-Ti. . . . . . . . . . . . . . . . . 39

3.8 Orbitais moleculares para a Ftc-V . . . . . . . . . . . . . . . . . 39

3.9 Orbitais moleculares para a Ftc-Li. . . . . . . . . . . . . . . . . . . 39

3.10 Orbitais moleculares para a Ftc-Fe. . . . . . . . . . . . . . . . 40

3.11 Orbitais moleculares para a Ftc-Co. . . . . . . . . . . . . . . 40

3.12 Orbitais moleculares para a Ftc-Ni. . . . . . . . . . . . . . . 40 
3.13 Orbitais moleculares para a Ftc-Si. . . . . . . . . . . . . . . . 41

3.14 Orbitais moleculares para a Ftc-Cu. . . . . . . . . . . . . . . . . 41

3.15 Orbitais moleculares para a Ftc-Zn. . . . . . . . . . . . . . . . 41

3.16 Energia dos Orbitais HOMO, HOMO-1, HOMO-2 e LUMO, LUMO+1, LUMO+2 para Raios-X e geometria otimizada. . . . . . . . . . . . . . 46

3.17 Possíveis tipos de transições eletrônicas permitidos. . . . . . . . . . . . . . 48

3.18 A banda $\mathrm{Q}$ corresponde a transição $\left(\mathrm{a}_{1 u} \rightarrow \mathrm{e}_{g}\right)$, a banda $\mathrm{B}_{1}$ corresponde a transição $\left(\mathrm{a}_{2 u} \rightarrow \mathrm{e}_{g}\right)$ e a banda $\mathrm{B}_{2}$ corresponde a transição $\left(\mathrm{b}_{2 u} \rightarrow \mathrm{e}_{g}\right)$. . . 49

3.19 Espectro de absorção da Ftc-H $\ldots$. . . . . . . . . . . . . . 50

3.20 Espectro de absorção da Ftc-Ti. . . . . . . . . . . . . . . . . . . . . . 51

3.21 Espectro de absorção da Ftc-V . . . . . . . . . . . . . . . . . . 52

3.22 Espectro de absorção da Ftc-Li. . . . . . . . . . . . . . . . . . . . . . . 54

3.23 Espectro de absorção da Ftc-Fe. . . . . . . . . . . . . . . . . . . . 55

3.24 Espectro de absorção da Ftc-Co. . . . . . . . . . . . . . . . 56

3.25 Espectro de absorção da Ftc-Ni. . . . . . . . . . . . . . . . . . 57

3.26 Espectro de absorção da Ftc-Si. . . . . . . . . . . . . . . . . . . . . . . 59

3.27 Espectro de absorção da Ftc-Cu. . . . . . . . . . . . . . . . . . 60

3.28 Espectro de absorção da Ftc-Zn. . . . . . . . . . . . . . . . . . . . 61

3.29 Espectro de absorção das MFtcs e da Ftc-H $\mathrm{H}_{2}$. . . . . . . . . . . . . . . 63

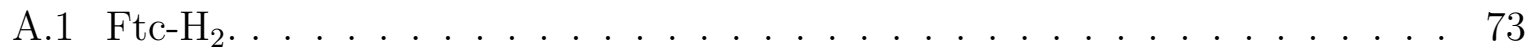

A.2 BITSAY02 (Ftc-Ti.) . . . . . . . . . . . . . . 74

A.3 CIDDAW $(\mathrm{Ftc}-\mathrm{V}) . \ldots \ldots \ldots \ldots \ldots \ldots \ldots$

A.4 DIXNIH02 (Ftc-Li) . . . . . . . . . . . . . 76

A.5 LUWNUM (Ftc-Co). . . . . . . . . . . . . . . . . . 77

A.6 LUWPAU $(\mathrm{Ftc}-\mathrm{Fe}) \ldots \ldots \ldots \ldots \ldots \ldots \ldots$

A.7 NIPHTC $(\mathrm{Ftc}-\mathrm{Ni}) . \quad \ldots \ldots \ldots \ldots \ldots$ 
A.8 RADPIV $(\mathrm{Ftc}-\mathrm{Cu}) \ldots \ldots \ldots \ldots \ldots \ldots$

A.9 YEXJOB $($ Ftc-Zn) . . . . . . . . . . . . . . . . . 81 


\section{Lista de Tabelas}

2.1 Radiações características dos principais materiais utilizados em tubos de

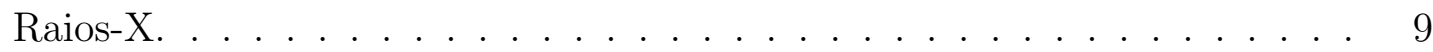

3.1 Raio médio da gaiola central das Ftcs e raio de van der Walls. . . . . . . . 31

3.2 Maior contribuição do orbital $d$, número de elétrons da camada $d$, posição do metal central e orbital molecular ocupado de maior contribuição $d$. . . . 38

3.3 Maior contribuição do orbital $d$, número de elétrons da camada $d$, posição do metal central e orbital molecular desocupado de maior contribuição $d$. . 42

3.4 Energias $\Delta_{H O M O}$ e $\Delta_{L U M O}$, contribuição do orbital $d$ na formação do orbital molecular ocupado, contribuição do orbital $d$ na formação do orbital molecular desocupado, posição do metal central, orbital molecular ocupado de maior contribuição $d$ e orbital molecular desocupado de maior

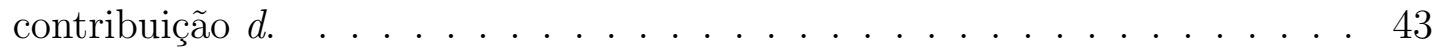

3.5 Descrição dos Estados Excitados da Ftc-H

3.6 Descrição dos Estados Excitados da Ftc-Ti. . . . . . . . . . . . . . . . . . 52

3.7 Descrição dos Estados Excitados da Ftc-V. . . . . . . . . . . . . . . . . . 53

3.8 Descrição dos Estados Excitados da Ftc-Li. . . . . . . . . . . . . . . . . . . 54

3.9 Descrição dos Estados Excitados da Ftc-Fe. . . . . . . . . . . . . . . . 55

3.10 Descrição dos Estados Excitados da Ftc-Co. . . . . . . . . . . . . . . 57

3.11 Descrição dos Estados Excitados da Ftc-Ni. . . . . . . . . . . . . . . 58

3.12 Descrição dos Estados Excitados da Ftc-Si. . . . . . . . . . . . . . . . . . 59

3.13 Descrição dos Estados Excitados da Ftc-Cu. . . . . . . . . . . . . . . . . 61

3.14 Descrição dos Estados Excitados da Ftc-Zn. . . . . . . . . . . . . . . . 62 


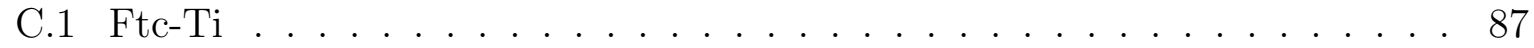

C.2 $\mathrm{Ftc}-\mathrm{Cu} \ldots \ldots \ldots \ldots \ldots \ldots \ldots \ldots$

C.3 Ftc-Ni . . . . . . . . . . . . . . . . . . 88

C.4 Ftc-V . . . . . . . . . . . . . . . . . . . 88

C.5 Ftc-Co . . . . . . . . . . . . . . . . . . . . 89

C.6 $\mathrm{Ftc}-\mathrm{Fe} \ldots \ldots \ldots \ldots \ldots \ldots$

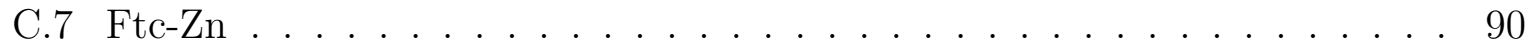

D.1 Descrição dos Estados Excitados das Ftcs . . . . . . . . . . . . . . . 92 


\section{Resumo}

As ftalocianinas compõem uma fantástica classe de moléculas aromáticas que tem sido utilizadas principalmente como corantes ou pigmentos pela indústria química. Recentemente, fazendo-se uso da flexibilidade de síntese inerente das moléculas orgânicas, diferentes derivados foram sintetizados e tem sido utilizados com muito sucesso como materiais ativos em inúmeras aplicações da Eletrônica Orgânica. Dentre as formas de funcionalizar estas moléculas encontra-se a inserção de diferentes metais em sua região central. Neste trabalho, analisamos os efeitos deste átomo central sobre as propriedades eletrônicas e ópticas da ftalocianina resultante, tais como: i) a geometria da molécula ii) a energia dos orbitais de fronteira; e iii) a primeira energia de excitação. Neste estudo, utilizamos o pacote computacional Gaussian 09 com o funcional B3LYP e a base 6-31G** na realização dos cálculos teóricos. O ponto de partida do nosso estudo foi o banco de estruturas cristalográficas CCDC (do inglês, Cambridge Crystallographic Data Centre) de onde extraímos a geometria de diferentes ftalocianinas já sintetizadas e caracterizadas via difração de Raios-X. Realizamos cálculos TD-DFT (do inglês, Time Dependent Den-

sity Functional Theory) para obter as energias de excitações verticais $\left(\mathrm{S}_{0} \rightarrow \mathrm{S}_{1}\right)$, tanto utilizando a geometria experimental (Raios-X) quanto as geometrias otimizadas. Este estudo tem como objetivo entender o papel deste tipo de funcionalização das ftalocianinas a fim de possibilitar a síntese racional de novos derivados mais apropriados para aplicações específicas da Eletrônica Orgânica. 


\section{Abstract}

Phthalocyanines constitute an interesting class of aromatic molecules, which has been used widely as dyes or pigments by the chemical industry. Recently, taking advantage of the synthetic flexibility that is inherent to the organic molecules, different derivatives have been synthesized and have been used with great success as active materials in several organic electronic devices. Among the ways to functionalize these molecules the addition of a central atom. Here we analize the effects of this central atom in the electronic and optical properties of the resulting phthalocyanine, such as the impact on: i) the molecular geometry; ii) the frontier orbitals; and iii) the first excitation energy. Calculations have been carried out using Gaussian 09 program suite together with the B3LYP functional and the $6-31 \mathrm{G}^{* *}$ basis set. The starting point was the Cambridge Crystallographic Data Centre from where we obtained the geometry of different phthalocyanines already synthesized and characterized by X-Rays diffraction. Using TD-DFT we computed vertical excitation energies $\left(\mathrm{S}_{0} \rightarrow \mathrm{S}_{1}\right)$ using both the experimental (X-Rays) geometry and the optimized geometries. The goal of this study is to understand the hole of this kind of functionalization on the phthalocianines in order to make possible the rational synthesis of new molecules more appropriate to specific applications of the Organic Electronics. 


\section{Introdução}

Materiais orgânicos tem despontado no cenário tecnológico nacional e internacional como fortes candidatos para uma nova geração de dispositivos eletrônicos. Tanto a indústria quanto a academia tem mostrado grande interesse nesses materiais por serem flexíveis, quimicamente desenháveis e de baixo-custo de produção.

Compostos orgânicos, como as ftalocianinas por exemplo, tem sido utilizados como materiais ativos em inúmeras aplicações, tais como: displays eletrocrômicos [1], diodos orgânicos emissores de luz (OLED - do inglês, Organic Light Emitting Diodes) [2], transistores orgânicos de efeito de campo (OFETs - do inglês, Organic Field-Effect Transistors) [3, 4] e fotovoltaicos orgânicos (OPVs - do inglês, Organic Photovoltaics) [5].

As ftalocianinas (Figura 1.1a) compreendem uma grande classe de compostos com propriedades de grande interesse para a industria, dentre elas: a estabilidade térmica e química e a estrutura eletrônica altamente conjugada.

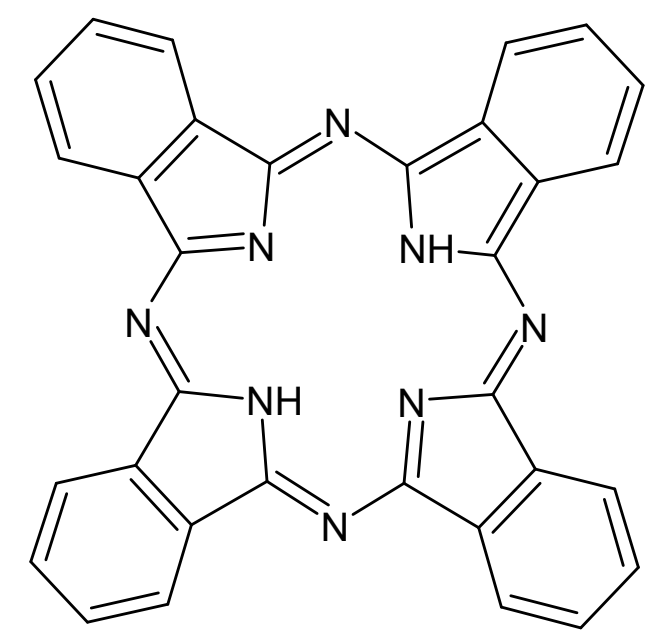

(a)

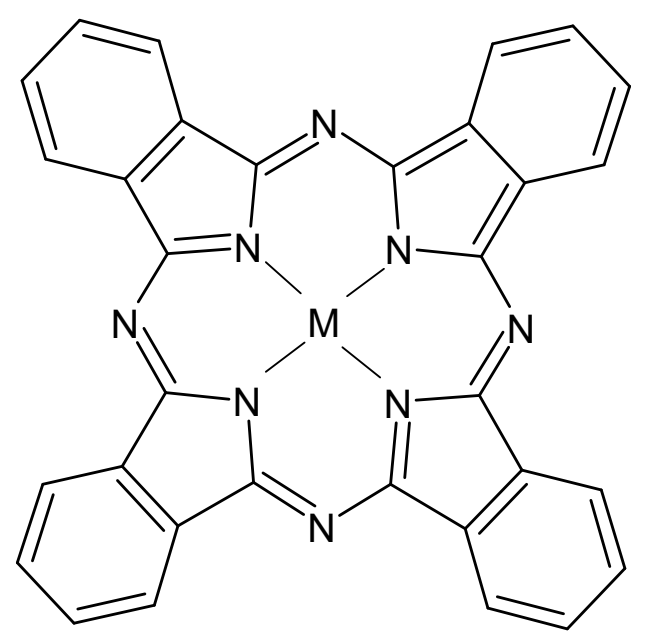

(b)

Figura 1.1: Moléculas de Ftalocianina $\left(\mathrm{C}_{32} \mathrm{H}_{18} \mathrm{~N}_{8}\right)$ (a) e Metaloftalocianina $\left(\mathrm{MeC}_{32} \mathrm{H}_{16} \mathrm{~N}_{8}\right)(\mathrm{b})$. 
As metaloftalocianinas são assim chamadas pois no centro da molécula há um átomo de metal. Este átomo confere a esta molécula não só várias propriedades interessantes, como também uma grande variedade de aplicações na eletrônica orgânica. Vários estudos tem avaliado o impacto da existência do átomo de metal central na ftalocianina e a possibilidade de explorar o uso de diferentes metais em aplicações na eletrônica orgânica $[6,7,8]$. Este átomo de metal tem orbitais $d$ que podem ou não interagir com o sistema de elétrons $\pi$ da molécula, podendo contribuir tanto para as propriedades geométricas quanto para as propriedades eletrônicas da molécula.

Neste trabalho, investigaremos para um conjunto de derivados da ftalocianina, o impacto do átomo central em algumas das propriedades eletrônicas e estruturais da molécula resultante. Antes, apresentaremos uma breve história das ftalocianinas (Ftcs) e suas propriedades.

\subsection{História das Ftalocianinas}

A ftalocianina (Ftc) foi descoberta acidentalmente por Braun e Tchermiac em 1907. Acreditavam tratar-se de uma impureza de uma reação na produção de ortocianobenzamida. Somente em 1927 que dois químicos suíços, Von der Weid e de Diesbach, obtiveram a Ftc de cobre (Ftc-Cu) $\left[\mathrm{C}_{32} \mathrm{H}_{16} \mathrm{CuN}_{8}\right]$. Já em 1928 foi descoberta, também de forma involuntária, a Ftc de ferro (Ftc-Fe), $\left[\mathrm{C}_{32} \mathrm{H}_{16} \mathrm{FeN}_{8}\right]$, pela Scottish Dyes Ltd. [9, 10]. Tratava-se de uma substância azul escuro, estável, cristalina e que era insolúvel em solventes orgânicos típicos e em água [10]. No ano seguinte a descoberta foi patenteada $[9]$.

Com o estudo de Raios-X das Ftcs feito por Robertson em 1936, foi possível determinar sua estrutura e de vários de seus derivados [11]. As Ftcs são compostos policíclicos orgânicos formados por quatro anéis de benzenos, ligados por nitrogênios na posição aza. Nas Ftcs de base livre são acomodados dois átomos de hidrogênio, que quando substituídos por determinados metais, originam as MFtcs [9], como representado na Figura 1.1b. Outra característica dessa classe de moléculas é a "gaiola central" em sua 
estrutura sendo formada pelos quatro átomos de nitrogênio mais internos da molécula.

As Ftcs compreendem uma grande classe de compostos aromáticos com propriedades interessantes, tais como estabilidade térmica e química, simetria e estrutura eletrônica altamente conjugadas, conferidas pelos seus 18 elétrons $\pi$ [12]. Estas estruturas podem inclusive acomodar mais de 70 diferentes íons metálicos em seu centro [12, 13, 14]. É possível também modificar quimicamente a estrutura das Ftcs, dando origem a vários de seus derivados, tais como: sub ftalocianas, Ftcs três-quartos e porfirinas aza expandidas $[12]$.

Uma característica das metaloftalocianinas neutras é sua insolubilidade em solventes polares como a água, mas substituições nos seus anéis benzênicos por grupos sulfônicos, podem dar origem as Ftcs tetrassulfonadas. Sendo esse grupo solúvel em solventes polares [15]. Essas modificações possíveis nas Ftcs faz com que seu uso se torne ainda maior em vários outros campos de pesquisa. Em especial, as Ftcs de metal tem mostrado ter propriedades semicondutoras [16]. O que desperta grande interesse da indústria eletrônica, entre outros.

A indústria tem utilizado as ftalocianinas em várias aplicações. Inicialmente estas moléculas foram aplicadas na fabricação de corantes, devido a sua cor azul intenso para a coloração de tecidos, plásticos e couros [17]. Com o desenvolvimento da eletrônica orgânica, estas moléculas passaram a ser usadas em displays eletrocrômicos [1], materiais semicondutores [18], sensores de gás [18], displays de cristais líquidos [19], catálise [20], OLED (do inglês, Organic Light Emitting Diode) [2], OPV (do inglês, Organic Photovoltaic) [5], OFETs (do inglês, Organic Field-Effect Transistors) [3], terapia fotodinâmica (PDT - do inglês, Photodynamic Therapy) [21], dentre outras [22].

Apesar de suas características serem muito parecidas com as porfirinas (encontrada na natureza) [10, 23], as Ftcs são moléculas que só existem de forma sintética. São quatro os principais monômeros envolvidos na formação das Ftcs: ftalonitrilo, anídrido ftálico, ftalimida e derivado de isoindol [24] (ver Figura 1.2).

O espectro de absorção da Ftc na região do visível é composto aproximadamente por sete bandas, sendo que a principal absorção ocorre entre 600 e $700 \mathrm{~nm}[9,14]$. Apesar das MFtcs e Ftcs terem suas características próprias em alguns aspectos, pode-se perceber que ambas tem em comum uma ou duas bandas intensas na faixa de 560-700 nm 


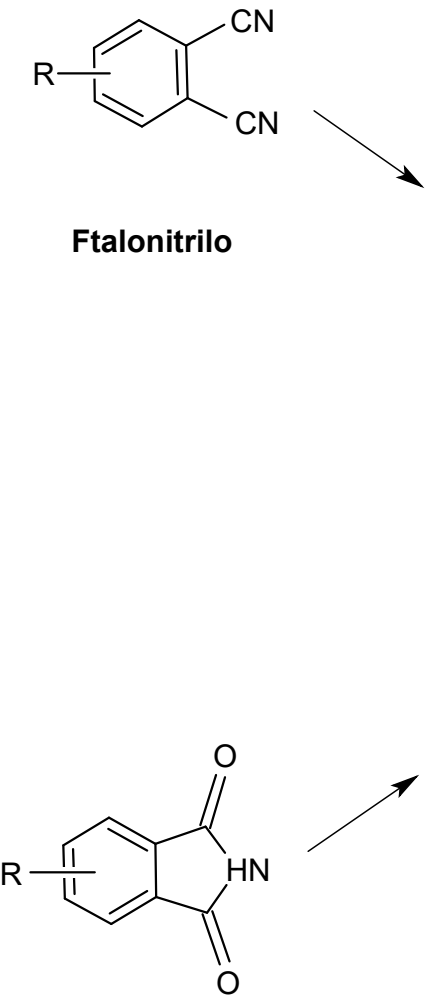

Ftalimida

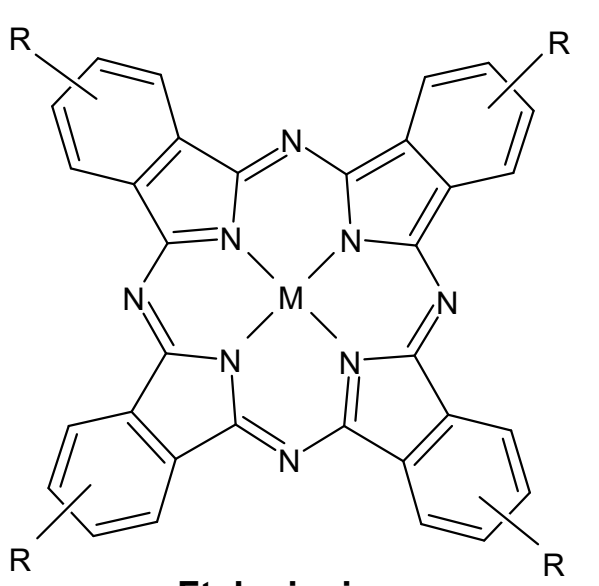

Ftalocianina

$M=$ metal

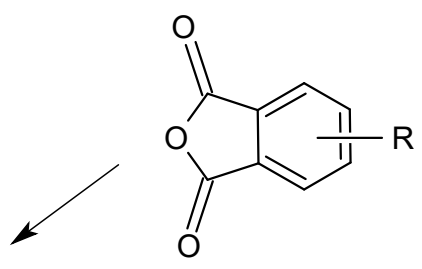

Anidrido Ftálico

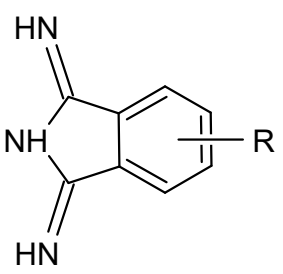

Derivado de Isoindol

Figura 1.2: Estratégias gerais para a síntese de Ftcs. Figura adaptada da referência [24].

e uma banda que se destaca em $600 \mathrm{~nm}[9]$.

Neste trabalho, fizemos uma análise dos efeitos do metal sobre as propriedades geométricas e eletrônicas da molécula, tais como: o tamanho da gaiola central, a energia dos orbitais de fronteira e a energia das primeiras excitações eletrônicas. Para os cálculos teóricos utilizamos o pacote computacional Gaussian 09 [25]. Em nossos cálculos de energia e otimização de geometria utilizamos a teoria do funcional densidade (DFT do inglês, Density Functional Theory) juntamente com o funcional B3LYP e com a base 6-31G** Esta combinação tem sido utilizada na literatura com sucesso na descrição das propriedades eletrônicas e estruturais de metaloftalocianinas [26].

Nesta dissertação, os capítulos que seguirão estão distribuídos da seguinte forma: no Capítulo 2 é apresentada a fundamentação teórica, fazendo uma breve discussão sobre os Raios-X e difração de Raios-X. Também serão abordados os métodos aproxima- 
tivos de Hartree-Fock (HF) e pós-HF. Essa abordagem será concluída com a Teoria do Funcional da Densidade; no Capítulo 3 serão apresentados os resultados e discussões do trabalho. Finalmente a dissertação será concluída no Capítulo 4, com as considerações finais. 


\section{Fundamentação Teórica}

\section{$2.1 \quad$ Raios-X}

Nesta dissertação, utilizaremos estruturas cristalinas de Ftcs como ponto de partida do estudo. Neste contexto, apresentaremos aqui uma visão geral de como estas estruturas são obtidas experimentalmente, pois as análises iniciais foram feitas partindo das estruturas presentes no banco de dados cristalográficos CCDC (Cambridge Crystallographic Data Centre)[27] que foram sintetizadas e caracterizadas via difração de Raios-X.

Os Raios-X (que são ondas eletromagnéticas) foram descobertos em 8 de novembro de 1895, pelo físico alemão Wilhelm Conrad Röntgen. Por se tratar de algo tão desconhecido na época recebeu esse nome. Röntgen foi laureado com o primeiro prêmio Nobel de Física em 1901 por esta descoberta [28]. No espectro eletromagnético, os Raios$\mathrm{X}$ estão entre os raios gama e o ultravioleta, com comprimentos de onda medidos entre $0.01 \mathrm{~nm}$ e 10nm [29] (ver Figura 2.1).

Uma das formas de se obter Raios-X é a partir de uma diferença de potencial aplicada entre um cátodo e um alvo metálico (ânodo). Assim, um feixe de elétrons é acelerado em direção ao alvo. Estas partículas, com alta energia cinética, são desaceleradas abruptamente gerando os Raios-X desejados. Porém, a maior parte da energia cinética é convertida em calor, fazendo necessário o resfriamento do alvo metálico através de resfriamento externo [29].

Quando o elétron altamente energético, acelerado por diferença de potencial crítica $\left(V_{c}\right)$ atinge o alvo, este pode colidir com elétrons das camadas mais internas do átomo. Um elétron da camada K é liberado na forma de fotoelétron, com isso, surge nessa camada uma vacância que será ocupada por um elétron de outra camada. Para o elétron saltar de uma camada para outra é preciso liberar energia, um fóton de Raios-X. Sendo 


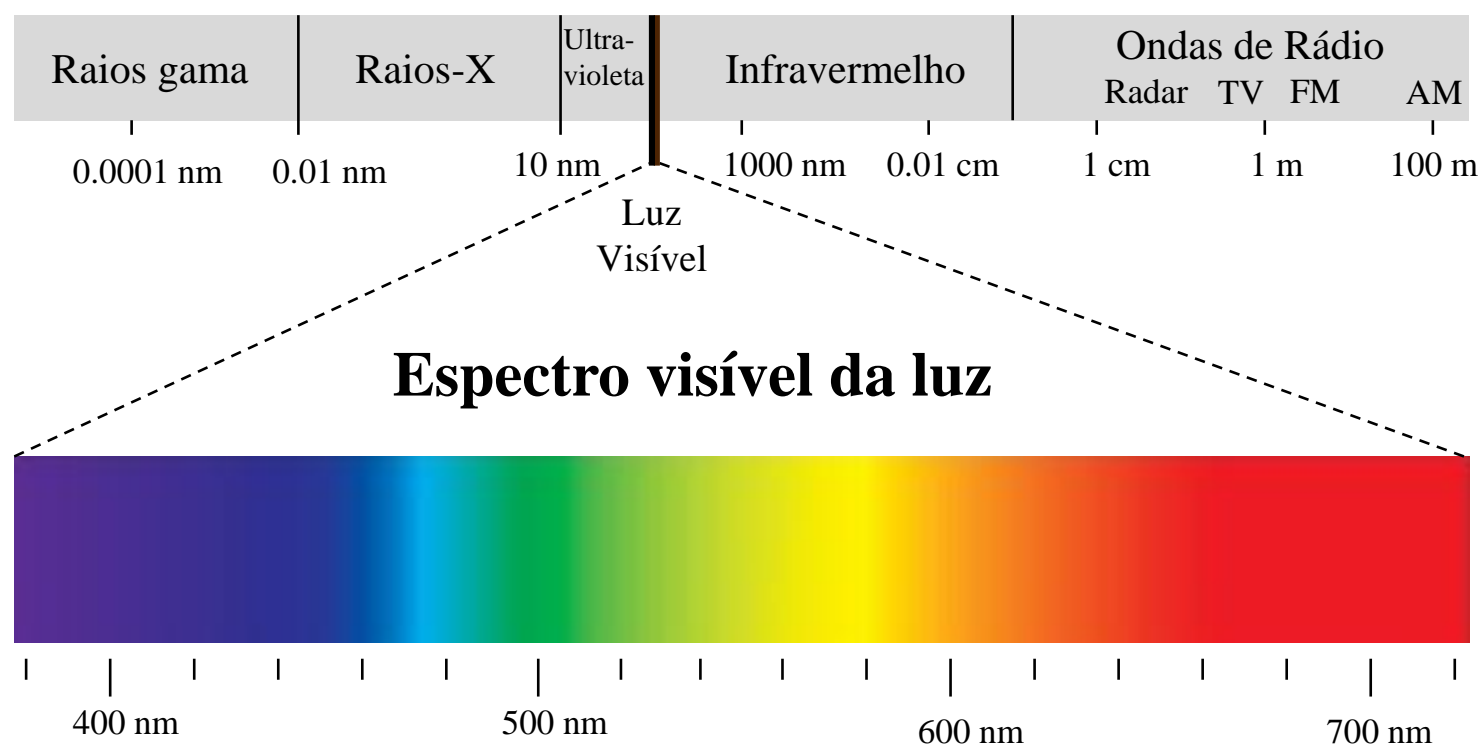

Figura 2.1: Espectro eletromagnético de radiação.

assim, a camada $\mathrm{K}$ volta a ter a mesma quantidade de elétrons que possuía antes.

A energia gerada para esse fóton é justamente a diferença de energia entre as duas camadas. A depender do estado inicial e final do elétron que realiza a transição, obtem-se radiação de Raios-X com diferentes comprimentos de onda. Na Figura 2.2, mostramos duas dessas radiações: a radiação $K_{\alpha}$, quando o elétron da camada M ocupa a vacância e a radiação $K_{\beta}$, de grande importância para o estudo de Raios-X, ocupando essa vacância um elétron da camada L [29].

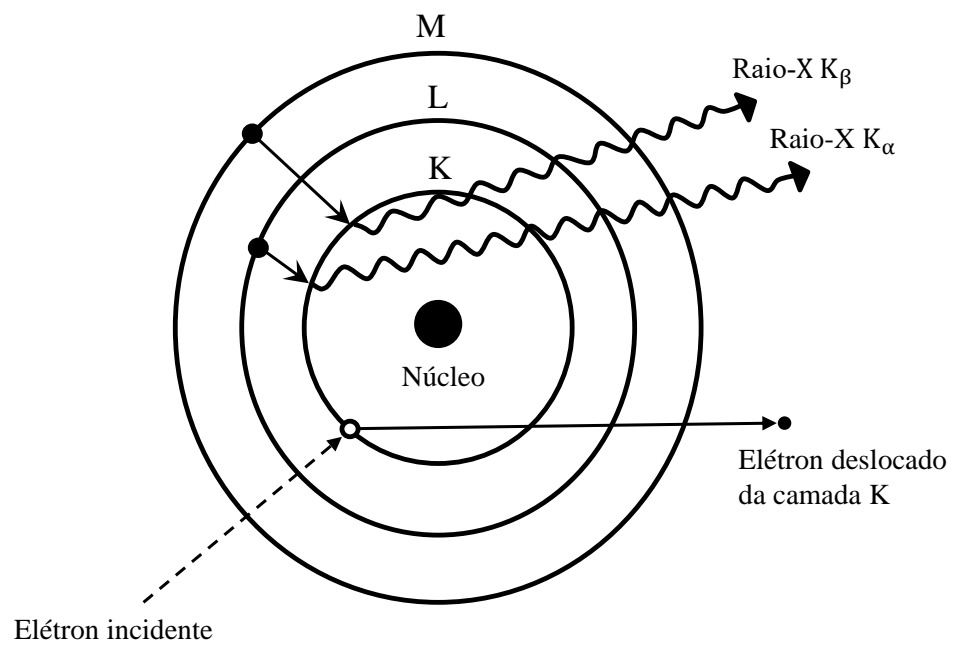

Figura 2.2: Obtenção de radiação $K_{\alpha}$ e $K_{\beta}$. 
Há uma correlação entre a voltagem e o comprimento de onda. Para voltagens mais altas, existe comprimento de onda com intensidade bem mais alta que os demais, denominada radiação característica do alvo. Os outros comprimentos de onda são chamados de radiação branca. Na Figura 2.3 é mostrado para várias diferenças de potencial as curvas do espectro, onde a radiação característica se destaca da radiação contínua [30].

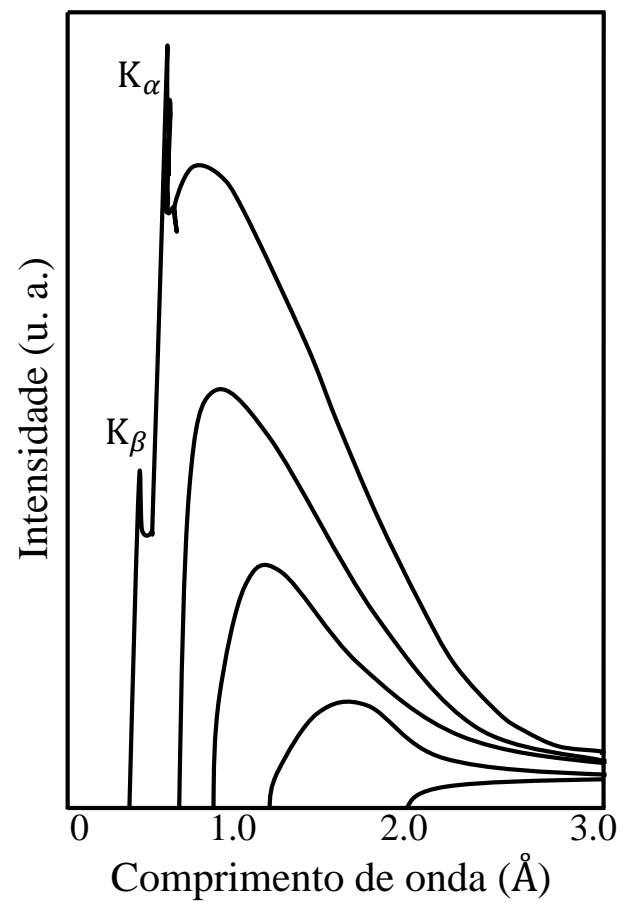

Figura 2.3: Relação entre as intensidades por cada comprimento de onda produzido.

Sendo a energia do fóton a diferença entre as energias das duas camadas envolvidas, é possível calcular o comprimento de onda da energia característica de cada elemento diferente. Pela Teoria Quântica temos que [30]:

$$
E=h \nu=\frac{h c}{\lambda}
$$

onde, $h=6,62 X 10^{-34} \mathrm{~J} . \mathrm{s}$ é a constante de Planck, $c$ é a velocidade da luz no vácuo, $\nu$ é a frequência e $\lambda$ é o comprimento de onda da radiação. Na Tabela 2.1, é mostrado o comprimento de onda das radiações características de alguns dos elementos mais usados para a obtenção de Raios-X [30]. 


\begin{tabular}{|c||c|c|}
\hline Elemento & $K_{\alpha}(\AA)$ & $K_{\beta}(\AA)$ \\
\hline \hline $\mathrm{Cu}$ & 1.54056 & 1.39221 \\
\hline $\mathrm{Mo}$ & 0.70930 & 0.63228 \\
\hline $\mathrm{Cr}$ & 2.28970 & 2.08487 \\
\hline $\mathrm{Co}$ & 1.78896 & 1.62079 \\
\hline $\mathrm{W}$ & 0.20901 & 0.18437 \\
\hline $\mathrm{Ni}$ & 1.65791 & 1.50013 \\
\hline $\mathrm{Fe}$ & 1.93604 & 1.75661 \\
\hline
\end{tabular}

Tabela 2.1: Radiações características dos principais materiais utilizados em tubos de Raios-X.

\subsection{Difração de Raios-X}

O método de difração de Raios-X é de grande importância para o estudo de estruturas cristalinas e para entender as propriedades de determinados materiais. Este método foi descoberto pelo alemão Max Von Laue em 1912, quando conseguiu o primeiro diagrama de difração, utilizando o sulfato de cobre. Neste mesmo ano, foi agraciado com o prêmio Nobel de Física quando formulou uma teoria de Raios-X para estruturas tridimensionais (cristais).

Uma característica que define bem um sólido cristalino é o arranjo ordenado e periódico de átomos. A repetição periódica é decorrente da coordenação atômica no interior do cristal, com o intuito de minimizar sua energia volumétrica [30]. Este método possui algumas limitações. Embora seja muito comum utilizá-lo na análise de cristais, não é possível fazer o mesmo para sólidos amorfos, líquidos ou gases, uma vez que é necessário a existência de uma rede cristalina ou periodicidade do arranjo atômico, para que haja difração de Raios-X [30]. Também, para que a difração ocorra é preciso que o feixe incidente seja monocromático (com um único comprimento de onda). Um outro fator preponderante é que haja uma interferência construtiva dependente da diferença de caminho percorrida pelos Raios-X e do comprimento de onda da radiação incidente, obedecendo a lei de Bragg definida pela equação abaixo [30, 31]: 


$$
n \lambda=2 d \sin \theta
$$

onde $n$ é um número inteiro, $\lambda$ é o comprimento de onda da radiação incidente, $d$ a distância entre os planos da rede cristalina e $\theta$ o ângulo de incidência dos Raios-X entre o plano cristalino e o feixe incidente [31], como mostrado na Figura 2.4.

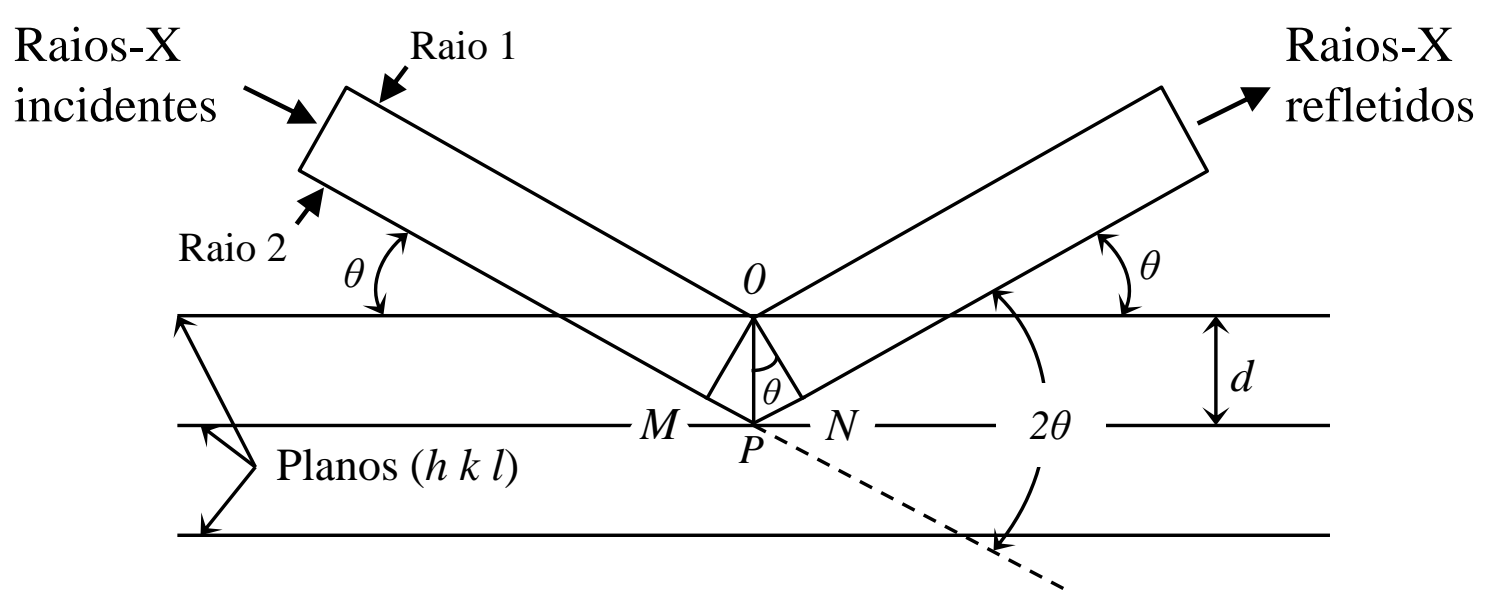

Figura 2.4: Reflexão de um feixe de Raios-X pelos planos (h k l) de um cristal.

Além disso, o ângulo $\theta$ tem que ter uma medida específica, pois é necessário que a diferença de caminho percorrida pelos raios seja igual a um número inteiro do comprimento de onda do raio incidente. Sendo assim, haverá uma superposição da onda, gerando uma interferência construtiva, aparecendo os picos de energia. Caso esse ângulo seja arbitrário, a interferência será destrutiva e não será possível observar a difração do raio $[30,31]$.

Os Raios-X e a difração de Raios-X podem ser utilizados na caracterização de cristais orgânicos. Neste trabalho, a estrutura cristalina das Ftcs será utilizada como ponto de partida de nosso estudo, nos provendo com as coordenadas geométricas dos átomos que compõe a molécula no estado sólido.

A seguir, iremos falar sobre métodos aproximativos para a solução da equação de Schrödinger, baseados na Química Quântica. Faremos uma breve discussão sobre o 
método Hartree-Fock e a Teoria do Funcional da Densidade, sendo esta última a teoria utilizada na maioria dos cálculos deste trabalho.

\subsection{Métodos aproximativos da Química Quântica}

São vários os métodos aproximativos que surgiram para resolver o problema de muitos corpos. Dentre eles o método de Hartree-Fock é um dos pioneiros para encontrar soluções aproximadas da equação de Schrödinger não-relativística e independente do tempo:

$$
\hat{H} \Psi=E \Psi
$$

onde $\hat{H}$ é um operador Hamiltoniano para um sistema molecular e $E$ a energia total do sistema.

O operador Hamiltoniano, para um sistema molecular composto de M núcleos e N elétrons descritos pelos vetores posição $\vec{R}_{A}$ e $\vec{r}_{i}$, respectivamente (ver Figura 2.5), em unidades atômicas é dado por [32]:

$$
\hat{H}=-\frac{1}{2} \sum_{i=1}^{N} \nabla_{i}^{2}-\sum_{A=1}^{M} \frac{1}{2 M_{A}} \nabla_{A}^{2}-\sum_{i=1}^{N} \sum_{A=1}^{M} \frac{Z_{A}}{r_{i A}}+\sum_{i=1}^{N} \sum_{j>i}^{N} \frac{1}{r_{i j}}+\sum_{A=1}^{M} \sum_{B>A}^{M} \frac{Z_{A} Z_{B}}{R_{A B}}
$$

sendo $\nabla_{i}^{2}$ e $\nabla_{A}^{2}$ os operadores Laplacianos que envolvem derivadas em relação as coordenadas do i-ésimo elétron e o núcleo $\mathrm{A}$, respectivamente; $M_{A}$ é a razão entre a massa do núcleo $\mathrm{A}$ e a massa do elétron; $Z_{A}$ e $Z_{B}$ são os números atômicos dos núcleos $\mathrm{A}$ e $\mathrm{B}$; $R_{A B}$ é a distância entre os núcleos $\mathrm{A}$ e $\mathrm{B} ; r_{i A}$ é a distância entre o elétron i e o núcleo A: $r_{i j}$ é a distância entre os elétrons i e j. Na Equação (2.4), o primeiro termo é o operador energia cinética dos elétrons; o segundo termo é o operador energia cinética dos núcleos; o terceiro termo representa a atração Coulombiana entre elétrons e núcleos; e o quarto e quinto termos representam a repulsão entre elétrons e núcleos, respectivamente. 


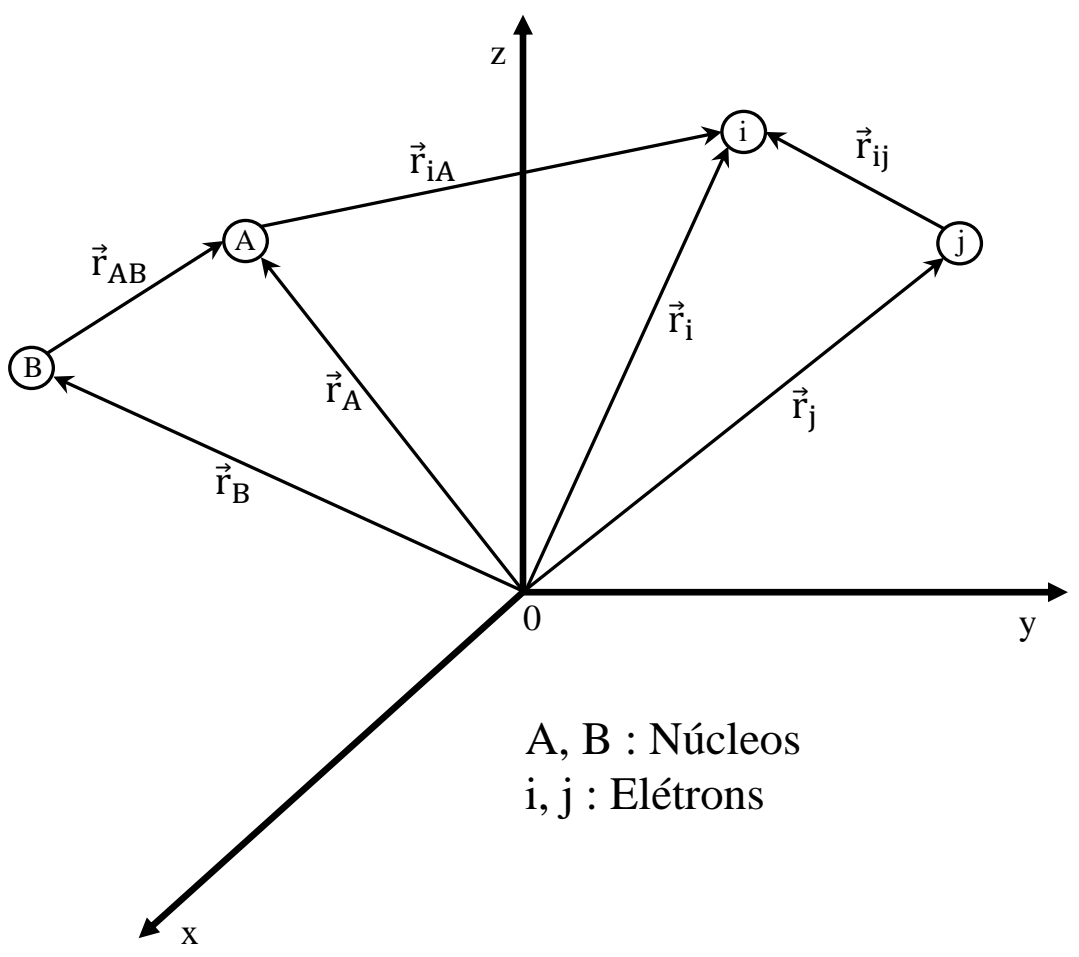

Figura 2.5: Sistema de coordenadas molecular.

Resolver a equação 2.4 não é uma tarefa muito fácil, principalmente quando se refere a sistemas com muitas partículas. Então é necessário recorrer a aproximações teóricas para chegar a uma solução do problema. A seguir apresentaremos uma destas aproximações conhecida como aproximação de Born-Oppenheimer.

\subsubsection{Aproximação de Born-Oppenheimer}

Sabendo que os elétrons em átomos e moléculas tem velocidades muito maiores que os núcleos, pode-se considerar que, em relação aos elétrons, os núcleos estão praticamente parados. Isso significa que os elétrons podem se ajustar rapidamente aos movimentos dos núcleos. Portanto é possível separar o movimento nuclear da parte eletrônica do sistema. Essa é a ideia que baseia a aproximação Born-Oppenheimer ou aproximação adiabática [33].

Com essa aproximação, o segundo termo da equação 2.4 que se refere a energia cinética dos núcleos pode ser desprezado, por ser muito menor que os outros termos e o 
último termo (que descreve a repulsão entre os núcleos) pode ser considerado como uma constante, pois qualquer constante somada a um operador não interfere nas auto funções, apenas em seus auto valores.

Os termos que restaram na equação são os que formam o Hamiltoniano eletrônico $\left(\hat{H}_{e l}\right)$

$$
\hat{H}_{e l}=-\frac{1}{2} \sum_{i=1}^{N} \nabla_{i}^{2}-\sum_{i=1}^{N} \sum_{A=1}^{M} \frac{Z_{A}}{r_{i A}}+\sum_{i=1}^{N} \sum_{j>i}^{N} \frac{1}{r_{i j}} .
$$

Para o Hamiltoniano eletrônico, a solução da equação de Schrödinger fica da seguinte forma:

$$
\hat{H}_{e l} \Psi_{e l}=\hat{E}_{e l} \Psi_{e l},
$$

e a função de onda eletrônica toma a seguinte forma:

$$
\Psi_{e l}=\Psi_{e l}\left(\left\{\vec{r}_{i}\right\} ;\left\{\vec{R}_{A}\right\}\right) .
$$

que descreve o movimento dos elétrons e depende explicitamente das coordenadas eletrônicas e parametricamente das coordenadas nucleares. O mesmo vale para e energia eletrônica,

$$
E_{e l}=E_{e l}\left(\left\{\vec{R}_{A}\right\}\right)
$$

Como os núcleos são considerados fixos, e devido à repulsão nuclear, o seguinte termo constante deve ser incluído à energia total:

$$
E_{\text {total }}=E_{e l}+\sum_{A=1}^{M} \sum_{B>A}^{M} \frac{Z_{A} Z_{B}}{R_{A B}} .
$$

Essas são as equações que constituem o problema eletrônico para a solução da equação de Schrödinger. Para resolver o problema nuclear, podemos lançar mão da mesma ideia usada para resolver o problema eletrônico, uma vez que os elétrons se movimentam 
muito mais rapidamente que os núcleos, podemos supor que o potencial sentido pelos núcleos é apenas o potencial médio dos elétrons.

Com isso, o Hamiltoniano nuclear para o movimento dos núcleos no campo médio dos elétrons pode ser escrito da seguinte forma:

$$
\begin{aligned}
H_{\text {nuclear }}= & -\sum_{A=1}^{M} \frac{1}{2 M_{A}} \nabla_{A}^{2}+\left\langle-\sum_{i=1}^{N} \frac{1}{2} \nabla_{i}^{2}-\sum_{i=1}^{N} \sum_{A=1}^{M} \frac{Z_{A}}{r_{i A}}+\sum_{i=1}^{N} \sum_{j>i}^{N} \frac{1}{r_{i j}}\right\rangle \\
& +\sum_{A=1}^{M} \sum_{B>A}^{M} \frac{Z_{A} Z_{B}}{R_{A B}} \\
= & -\sum_{A=1}^{M} \frac{1}{2 M_{A}} \nabla_{A}^{2}+E_{\text {el. }}\left(\left\{\vec{R}_{A}\right\}\right)+\sum_{A=1}^{M} \sum_{B>A}^{M} \frac{Z_{A} Z_{B}}{R_{A B}} \\
= & -\sum_{A=1}^{M} \frac{1}{2 M_{A}} \nabla_{A}^{2}+E_{\text {total }}\left(\left\{\vec{R}_{A}\right\}\right) .
\end{aligned}
$$

A energia total, $E_{\text {total }}\left(\left\{\vec{R}_{A}\right\}\right)$, fornece um potencial para o movimento nuclear. Os núcleos, na aproximação de Born-Oppenheimer, movem-se sobre uma superfície de potencial obtida ao resolvermos o problema eletrônico. As soluções da equação de Schrödinger nuclear,

$$
\hat{H}_{\text {nuclear }} \Psi_{\text {nuclear }}=\hat{E}_{\text {nuclear }} \Psi_{\text {nuclear }}
$$

descrevem as vibrações, rotações e translações de uma molécula. A energia total $E$, na aproximação de Born-Oppenheimer, inclui a energia eletrônica, vibracional, rotacional e translacional. A aproximação correspondente para a função de onda é:

$$
\Psi\left(\left\{\vec{r}_{i}\right\} ;\left\{\vec{R}_{A}\right\}\right)=\Psi_{\text {el. }}\left(\left\{\vec{r}_{i}\right\}\right) \Psi_{\text {nuclear }}\left(\left\{\vec{R}_{A}\right\}\right) .
$$

Esta é a aproximação Born-Oppenheimer, que leva em consideração os núcleos fixos, e simplifica a solução da equação de Schrödinger para o movimento eletrônico. 


\subsubsection{Determinante de Slater}

Para uma função de onda descrever um sistema de muitos elétrons é preciso que haja antissimetria diante uma troca das coordenadas de dois desses elétrons, respeitando assim o princípio de indistinguibilidade para sistemas de férmios [33], como visto abaixo:

$$
\Psi\left(\mathbf{x}_{1}, \ldots, \mathbf{x}_{i}, \ldots, \mathbf{x}_{j}, \ldots, \mathbf{x}_{n}\right)=-\Psi\left(\mathbf{x}_{1}, \ldots, \mathbf{x}_{j}, \ldots, \mathbf{x}_{i}, \ldots, \mathbf{x}_{n}\right)
$$

Esse é o chamado princípio de antissimetria e está de acordo com o princípio de exclusão de Pauli, que diz que dois elétrons não podem ocupar o mesmo estado quântico (mesmo spin-orbital).

A dependência com relação a parte espacial é vista no Hamiltoniano da equação 2.5. Porém, para descrever completamente um elétron, é preciso também identificar seu spin. Para isso são introduzidas duas funções de spin, $\alpha(\omega)$ e $\beta(\omega)$, que correspondem ao "spin para cima" e "spin para baixo" respectivamente. Essas funções, de variáveis de spin não especificadas $\omega$, formam um conjunto completo e ortonormal, como visto abaixo:

$$
\begin{aligned}
\int d \omega \alpha^{*}(\omega) \alpha(\omega) & =\int d \omega \beta^{*}(\omega) \beta(\omega)=1 \\
\int d \omega \alpha^{*}(\omega) \beta(\omega) & =\int d \omega \beta^{*}(\omega) \alpha(\omega)=0 .
\end{aligned}
$$

Assim, um elétron é descrito pelas suas três coordenada espaciais, $\vec{r}$, e também por uma coordenada de spin, $\omega$. Esses quatro conjuntos de coordenadas serão agora representadas por $\vec{x}$.

Para formalizar a função de onda é preciso inserir o termo de spin, uma vez que já foram atendidas as exigências necessárias para a função de onda. Isto pode ser feito através da multiplicação da função de onda espacial pela função de spin $\alpha(\omega)$ e $\beta(\omega)$, como definido no início da seção. Agora, a função de onda do elétron relacionada a parte espacial e de spin é escrita como spin-orbital, $\chi(\vec{x})$ : 


$$
\chi(\vec{x})=\Psi(\vec{r}) \alpha(\omega) \quad \text { ou } \quad \chi(\vec{x})=\Psi(\vec{r}) \beta(\omega) .
$$

Esta é a função de onda de um único elétron em um sistema molecular.

Os $\Psi^{\prime}$ s são funções apenas das coordenadas espaciais de um elétron, chamadas orbitais moleculares. Caso não tenha restrição aos orbitais moleculares, o método é chamado Hartree-Fock não Restrito (UHF); normalmente utilizado para sistemas de camada aberta ou de elétrons desemparelhados.

Para um sistema com número par de elétrons, o estado eletrônico usualmente é chamado de camada fechada e é preciso fazer uma restrição onde os orbitais são associados a dois elétrons, um com spin $\alpha$ e o outro com spin $\beta$; esse método é conhecido como Hartree-Fock Restrito (RHF). Há também o método Hartree-Fock Restrito para Camada Aberta (ROHF), onde sistemas de camada aberta também podem ser descritos por uma função de onda do tipo restrita, onde as partes espaciais dos spin-orbitais duplamente ocupados são forçados a serem as mesmas [32, 34, 35].

O próximo passo é generalizar a função de onda para um conjunto de $\mathrm{N}$ elétrons. Analisando o $\hat{H}_{e l}$ (Equação 2.5) pode-se concluir que o terceiro termo do lado direito da igualdade é o único que envolve as coordenadas de dois elétrons. Com isso o $\hat{H}_{e l}$ pode ser reescrito da seguinte forma:

$$
\hat{H}=\hat{O}_{1}+\hat{O}_{2},
$$

onde

$$
\hat{O}_{1}=\sum_{i=1}^{N} h(i)
$$

com

$$
\hat{h}(i)=-\frac{1}{2} \nabla_{i}^{2}-\sum_{A=1}^{M} \frac{1}{r_{i A}}
$$


$\mathrm{e}$

$$
\hat{O}_{2}=\sum_{i=1}^{N} \sum_{j>i}^{N} \frac{1}{r_{i j}}
$$

Se o termo $\hat{O}_{2}$ (que envolve as coordenadas de dois elétrons) não existisse, o problema se restringiria a resolver $\mathrm{N}$ equações de um único elétron. Poderíamos escrever a equação (2.5) como:

$$
\hat{H}=\sum_{i=1}^{N} \hat{h}(i),
$$

onde $\hat{h}(i)$ é um operador de um elétron que envolve os termos relativos ao elétron $i$ nos dois primeiros somatórios da Equação (2.5). Para cada elétron, haveria uma equação de autovalores do tipo

$$
\hat{h}(i) \chi_{j}\left(\vec{x}_{i}\right)=\epsilon_{j} \chi_{j}\left(\vec{x}_{i}\right)
$$

e a equação de Schrödinger para o sistema molecular seria dada por:

$$
\hat{H} \Psi^{\mathrm{PH}}=\sum_{i} h(i) \Psi^{\mathrm{PH}}=\sum_{i} \epsilon_{i} \Psi^{\mathrm{PH}}
$$

Sendo esta última uma equação separável, é permitido escrever $\Psi^{\mathrm{PH}}$ como

$$
\Psi^{\mathrm{PH}}=\chi_{i}\left(\vec{x}_{1}\right) \chi_{j}\left(\vec{x}_{2}\right) \ldots \chi_{k}\left(\vec{x}_{N}\right)
$$

Já que a antissimetria é uma característica dos determinantes, a função de onda eletrônica pode ser convenientemente expandida em um conjunto completo de funções determinantais. A função de onda escrita como um determinante é chamada de determinante de Slater: 


$$
\Psi=\frac{1}{(N !)^{1 / 2}}\left|\begin{array}{cccc}
\chi_{1}\left(\vec{x}_{1}\right) & \chi_{2}\left(\vec{x}_{1}\right) & \ldots & \chi_{2 K}\left(\vec{x}_{1}\right) \\
\chi_{1}\left(\vec{x}_{2}\right) & \chi_{2}\left(\vec{x}_{2}\right) & \ldots & \chi_{2 K}\left(\vec{x}_{2}\right) \\
\vdots & \vdots & \ddots & \vdots \\
\chi_{1}\left(\vec{x}_{2 K}\right) & \chi_{2}\left(\vec{x}_{2 K}\right) & \ldots & \chi_{2 K}\left(\vec{x}_{2 K}\right)
\end{array}\right|
$$

Note que a troca das coordenadas de dois elétrons implica em trocar duas linhas do determinante, o que implica na inversão do sinal de $\Psi$. Nota-se também que a antissimetria imposta não altera a "energia de Hartree".

Para retratar de maneira mais verdadeira a solução do problema, é preciso incluir o termo de repulsão Coulombiana entre os elétrons. Contudo, a equação diferencial resultante não tem uma solução analítica na maioria dos casos. Em 1930 foi proposto por Hartree, Fock e Slater [36] uma solução aproximada que consiste em usar o princípio variacional, em que os spin-orbitais figuram como funções (parâmetros) variacionais no processo de mínima energia, como será apresentada na próxima seção.

\subsubsection{A Equação de Hartree-Fock}

Para simplificar a solução da equação de Schrödinger eletrônica para sistemas de muitos corpos é preciso lançar mão de métodos aproximativos. A aproximação HartreeFock (HF) é um método cuja ideia é utilizar o princípio variacional em que a função de onda que descreve o sistema molecular é um determinante de Slater,

$$
\left|\Phi_{0}\right\rangle=\left|\chi_{1}, \chi_{2}, \ldots, \chi_{a}, \chi_{b}, \ldots, \chi_{N}\right\rangle
$$

onde os X são os spin-orbitais moleculares e a energia do estado fundamental é dado por:

$$
E_{0}=\left\langle\Phi_{0}|H| \Phi_{0}\right\rangle=\sum_{i=1}^{N} h_{i i}+\frac{1}{2} \sum_{i=1}^{N} \sum_{j=1}^{N}\left(J_{i j}-K_{i j}\right)
$$

onde,

$$
h_{i i}=\left\langle\chi_{i}(1)|\hat{h}| \chi_{i}(1)\right\rangle=\int \chi_{i}^{*}(1) \hat{h} \chi_{i}(1) d \vec{x}_{1}
$$


sendo,

$$
\begin{gathered}
\hat{h}=-\frac{1}{2} \nabla_{1}^{2}-\sum_{A} \frac{Z_{A}}{r_{1 A}}, \\
J_{i j}=\int \chi_{i}^{*}\left(\vec{x}_{1}\right) \chi_{i}\left(\vec{x}_{1}\right) \frac{1}{r_{12}} \chi_{j}^{*}\left(\vec{x}_{2}\right) \chi_{j}\left(\vec{x}_{2}\right) d \vec{x}_{1} d \vec{x}_{2}
\end{gathered}
$$

e

$$
K_{i j}=\int \chi_{i}^{*}\left(\vec{x}_{1}\right) \chi_{j}\left(\vec{x}_{1}\right) \frac{1}{r_{12}} \chi_{j}^{*}\left(\vec{x}_{2}\right) \chi_{i}\left(\vec{x}_{2}\right) d \vec{x}_{1} d \vec{x}_{2}
$$

Onde, $\vec{x}_{1}$ representa as coordenadas espaciais $(\vec{r})$ e de $\operatorname{spin}(\omega)$ do elétron 1 e $r_{12}$ é a distância entre os elétrons 1 e 2. Com base nas equações anteriores, concluímos que a energia eletrônica é um funcional dos spin-orbitais moleculares $\left\{\chi_{a}\right\}$. Assim, a energia no estado fundamental fica

$$
E_{0}=E_{0}\left[\left\{\chi_{a}\right\}\right]
$$

Para encontrar as equações de HF é preciso agora resolver a equação (2.31), que quando é minimizada com relação aos spin-orbitais precisa respeitar a condição de ortonormalidade, isto é:

$$
\int d \vec{x}_{1} \chi_{a}^{*}(1) \chi_{b}(1)=\langle a \mid b\rangle=\delta_{a b}
$$

Ou seja, os vínculos tem a forma:

$$
\left\langle\chi_{a} \mid \chi_{b}\right\rangle=\delta_{a b}
$$

Utilizando o método de multiplicadores de Lagrange, temos a seguinte equação: 


$$
f\left|\chi_{a}\right\rangle=\sum_{b=1}^{N} \epsilon_{b a}\left|\chi_{b}\right\rangle
$$

onde $\epsilon_{b a}$ são os multiplicadores de Lagrange, e $f$ é o operador de Fock.

Para escrever as equações na forma canônica, é preciso que uma transformação unitária da forma

$$
\chi^{\prime}{ }_{a}=\sum_{b} \chi_{b} U_{b a}
$$

que satisfaça a relação:

$$
\mathbf{U}^{\dagger}=\mathbf{U}^{-1}
$$

seja realizada sobre os spin-orbitais $\left\{\chi_{a}\right\}$, de forma que a matriz que representa os multiplicadores de Lagrange torne-se diagonal

$$
\epsilon^{\prime}=\mathbf{U}^{\dagger} \epsilon \mathbf{U}
$$

onde $\epsilon$ é uma matriz hermitiana. Este novo conjunto de spin-orbitais que diagonalizam a matriz $\epsilon$ são chamados de spin-orbitais canônicos. Assim, a equação de HF passa a ter a forma

$$
f\left|\chi_{a}\right\rangle=\epsilon_{a}\left|\chi_{a}\right\rangle
$$

\subsubsection{Teorema de Koopmans}

Em um sistema de N elétrons, a minimização da energia da função de onda de Slater, $\left|\Psi_{0}\right\rangle=\left|\chi_{1}, \chi_{2}, \ldots, \chi_{N}\right\rangle$, conduz a uma equação de autovalores $f\left|\chi_{a}\right\rangle=\epsilon_{a}\left|\chi_{a}\right\rangle$ para os N spin-orbitais ocupados $\left\{\chi_{a}\right\}$. O operador de Fock tem uma dependência funcional nestes spin-orbitais ocupados. Uma vez que os spin-orbitais são conhecidos, o operador de Fock torna-se um operador Hermitiano bem definido que terá um número infinito de autofunções, isto é,

$$
f\left|\chi_{j}\right\rangle=\epsilon_{j}\left|\chi_{j}\right\rangle
$$


Para $j=1,2, \ldots, \infty$ cada valor de $j$ tem a solução de $f\left|\chi_{j}\right\rangle$ uma energia associada $\epsilon_{j}$. Os spin-orbitais ocupados, que formam a $\left|\Psi_{0}\right\rangle$, são aqueles de mais baixa energia e que normalmente são identificados pelos índices $a, b, \ldots$, enquanto que os infinitos spin-orbitais remanescentes com alta energia, são identificados pelos índices $r, s, \ldots$ Esses são os spin-orbitais virtuais ou desocupados.

Para encontrar as expressões para as energias orbitais $\epsilon_{a}$ e $\epsilon_{r}$ é preciso primeiramente mostrar que a representação matricial do operador de Fock na base das funções de onda dos spin-orbitais é diagonal, sendo seus elementos diagonais iguais às energias orbitais. Para isso, a equação (2.39) deve ser multiplicada por $\left\langle\chi_{i}\right|$, levando a seguinte equação:

$$
\left\langle\chi_{i}|f| \chi_{j}\right\rangle=\epsilon_{j}\left\langle\chi_{i} \mid \chi_{j}\right\rangle=\epsilon_{j} \delta_{i j}
$$

As energias orbitais podem ser escritas como

$$
\varepsilon_{i}=\left\langle\chi_{i}|f| \chi_{i}\right\rangle=\left\langle\chi_{i}|h| \chi_{i}\right\rangle+\sum_{b}\langle i b|| i b\rangle
$$

Assim, temos que

$$
\varepsilon_{a}=\langle a|h| a\rangle+\sum_{b=1}^{N}\langle a b|| a b\rangle
$$

e

$$
\varepsilon_{r}=\langle r|h| r\rangle+\sum_{b=1}^{N}\langle r b|| r b\rangle .
$$

Como

$$
\langle a a|| a a\rangle=0
$$

estes resultados ficam

$$
\epsilon_{a}=\langle a|h| a\rangle+\sum_{b \neq a}\langle a b \mid a b\rangle-\langle a b \mid b a\rangle
$$

e

$$
\epsilon_{r}=\langle r|h| r\rangle+\sum_{b}\langle r b \mid r b\rangle-\langle r b \mid b r\rangle .
$$


Fazendo uma análise do significado físico das energias orbitais, partimos do fato de que a energia orbital $\varepsilon_{a}$ representa a energia de um elétron no spin-orbital $\left|\chi_{a}\right\rangle$. Esta energia é igual a energia cinética e a atração do núcleo $(\langle a|h| a\rangle)$ adicionada à energia de Coulomb $(\langle a b \mid a b\rangle)$ e troca $(-\langle a b \mid b a\rangle)$ com cada um dos $(N-1)$ elétrons restantes nos $(N-1)$ spin-orbitais remanescentes $\left|\chi_{b}\right\rangle$, onde $b \neq a$.

A integral $\langle a b \mid b a\rangle$ é não nula apenas se os spin dos elétrons em $\left|\chi_{a}\right\rangle$ e $\left|\chi_{b}\right\rangle$ forem paralelos. Já a energia do spin-orbital virtual $\left(\varepsilon_{r}\right)$ tem um caráter distinto. Ela inclui a energia cinética e a atração nuclear de um elétron em $\left|\chi_{r}\right\rangle$, isto é $\langle r|h| r\rangle$, mas inclui as interações de Coulomb $(\langle r b \mid r b\rangle)$ e de troca $(-\langle r b \mid b r\rangle)$ com todos os $N$ elétrons do estado fundamental HF $\left|\Psi_{0}\right\rangle$, isto é, interações com todos os $N$ spin-orbitais. Como se adicionasse a $\left|\Psi_{0}\right\rangle$ um elétron para produzir um estado com $(N+1)$ elétrons e $\varepsilon_{r}$ representa a energia deste elétron extra.

Dado um determinante de Slater, solução da equação de HF para um sistema de $N$ elétrons $\left(\left|\Phi_{0}^{N}\right\rangle\right)$, com energias dos orbitais ocupados e virtuais iguais a $\epsilon_{a}$ e $\epsilon_{r}$, respectivamente, o potencial de ionização para produzir um determinante de $(N-1)$ elétrons $\left(\left|\Phi_{a}^{N-1}\right\rangle\right)$ obtido ao se remover um elétron do spin-orbital $\chi_{a}$, e a afinidade eletrônica, para produzir um determinante de $(N+1)$ elétrons, obtido ao se adicionar um elétron ao spin-orbital $\chi_{r}$, são iguais a $-\epsilon_{a}$ e $-\epsilon_{r}$, respectivamente.

Uma forma de se calcular potenciais de ionização e afinidades eletrônica é através do teorema de Koopmans. A aproximação de "orbitais congelados" diz que, tanto para os spin-orbitais dos $(N+1)$ estados eletrônicos, como para os estados eletrônicos $(N-$ 1) elétrons, não há nenhuma alteração em seu estado, em relação ao estado N, ou seja, são idênticos. Esta é uma aproximação que despreza a relaxação dos spin-orbitais de $\left|\Phi_{a}^{N-1}\right\rangle$ ou $\left|\Phi_{r}^{N+1}\right\rangle$. Desprezar esta relaxação no teorema de Koopmans implica dizer que está sendo desprezada a diminuição das energias $E_{a}^{N-1}$ e $E_{r}^{N+1}$, decorrente da otimização dos spin-orbitais dos determinantes de $(N \pm 1)$ elétrons. A consequência disto são potenciais de ionização mais positivos e afinidades eletrônicas mais negativas.

Outro fato resultante desta aproximação é o erro decorrente na aproximação de representar uma função de onda por um único determinante. O efeitos de correlação que podem ser levados em conta apenas usando aproximações que vão além da teoria de Hartree-Fock, produzirão correções adicionais aos resultados obtidos pelo teorema de 
Koopmans. Quanto maior for o número de elétrons em um sistema, maior será a energia de correlação. Com isto, os efeitos de correlação tendem a corrigir o erro gerado pelo fato de desprezar a relaxação dos orbitais no cálculo do potencial de ionização, porém aumenta o erro associado à relaxação, no caso da afinidade eletrônica. Dessa forma, os potenciais de ionização obtidos usando o teorema de Koopmans são comparáveis com os valores experimentais, enquanto que as afinidades eletrônicas são razoavelmente diferentes dos valores experimentalmente obtidos.

Com a discursão do modelo de HF bem definido, podemos passar agora para a DFT, uma teoria alternativa que usa a densidade eletrônica ao invés da função de onda como objeto matemático central da representação de um sistema molecular ou atômico.

\subsubsection{Teoria do Funcional da Densidade}

A maior parte dos cálculos que apresentaremos nesta dissertação serão realizados utilizando a Teoria do Funcional da Densidade (DFT - do inglês, Density Functional Theory). Neste sentido, apresentaremos aqui um breve histórico desta teoria.

No início da Mecânica Quântica Moderna, no ano de 1925, foi proposta a famosa equação de Schrödinger, pelo físico austríaco Erwin Schrödinger, para se determinar o estado de um sistema seja este um átomo, uma molécula ou um sólido. Com a solução dessa equação é possível determinar através da função de onda quântica todas as informações do estado do sistema, mas resolvê-la não é uma tarefa simples [37].

Para sistemas muito pequenos (da ordem de dezenas de átomos) ainda é possível chegar a um resultado preciso mas, de acordo o aumento do sistema, tornase praticamente impossível uma solução $\operatorname{exata}^{27}$. Devido a essa dificuldade na solução dessa equação, foi necessário a busca de aproximações para se chegar a um resultado com precisão aceitável [37].

Assim, surgiram vários métodos aproximados para a solução da equação de Schödinger. Dentre estes podemos citar os métodos ab initio (o método de HartreeFock, a teoria de Moller Plesset, a teoria de Coupled Cluster, entre outros), os métodos semi-empíricos (AM1, PM6, RM1, entre outros) e como alternativa aos métodos até aqui 
citados, baseados na função de onda, surgiu a DFT. Neste trabalho, utilizaremos a DFT por se tratar de um método com alta precisão e eficiência computacional considerando-se o tamanho dos sistemas que iremos estudar ( $\sim$ de 40 átomos pesados).

Em 1964 o norte-americano Walter Kohn e o francês Pierre Hohenberg desenvolveram uma teoria onde apresentavam a Mecânica Quântica baseada na densidade eletrônica, geralmente representada por $\rho(\vec{r})$. Até então, o método utilizado para representar um sistema quântico era descrito em termos da função de onda. Embora essa teoria fosse adequada para descrever sistemas maiores, era necessário torná-la eficiente na prática com um sistema real. Foi então que no ano seguinte, Walter Kohn e Lu Sham apresentaram as equações apropriadas para encontrar a densidade eletrônica $\rho(\vec{r})$ de um sistema real [37].

No começo, essa teoria era válida para os estados não-degenerados, mas passou a ser usada no desenvolvimento de equações auto consistentes, incluindo também efeitos de troca e correlação, que depois vieram a ser generalizados por Levy (1979) e Lieb (1983) para sistemas contendo estados degenerados. Muitos foram os que contribuíram para o desenvolvimento da DFT: Thomas-Fermi (1927), Dirac (1930) e Slater (1037 e 1951), entre outros [38].

São dois os postulados básicos que definem a Teoria do Funcional da Densidade:

(1) A função de onda do estado fundamental e daí todas as propriedades deste estado são funcionais da densidade eletrônica $\rho(\vec{r})$;

(2)A energia do estado fundamental de um sistema multieletrônico sob um dado potencial externo $V(r)$, pode ser escrita como:

$$
E_{v}[\rho(\vec{r})]=\int v(\vec{r}) \rho(\vec{r}) d \vec{r}+F[\rho]
$$

onde $F[\rho]$ é chamado de funcional universal da densidade, que não depende do potencial externo $v(\vec{r})$. Substituindo a função densidade exata deste estado por uma outra função aproximada $\tilde{\rho}$ contendo a energia de repulsão e energia cinética, chegamos a seguinte expressão para a energia:

$$
\tilde{E}[\tilde{\rho}]=\int v(\vec{r}) \rho(\vec{r}) d \vec{r}+F[\tilde{\rho}] \geq E[\rho]=E_{0} .
$$

Com esse novo método, já era possível investigar problemas com muitos corpos. 
Uma vez que se conhece a densidade eletrônica, pode-se determinar todas as propriedades de um sistema, inclusive seu estado fundamental. Para obtê-lo, basta minimizar a sua energia total em função desta densidade eletrônica [38].

Apesar da aparente simplicidade deste método, existe um ponto crucial: a forma analítica do funcional que descreve a energia em função da densidade, $E[\rho]$. Para tentar resolver esse problema, é preciso recorrer a aproximações de $E[\rho]$, a fim de chegar a resultados aceitáveis [37].

Kohn e Sham tiveram a ideia de utilizar a densidade de um segundo sistema, chamado de sistema de interação. A ideia era a de trocar o sistema interagente em análise por um sistema não interagente. Para isso, ambos precisavam ter a mesma densidade. Assim, eles criaram um sistema onde elétrons "fictícios" são colocados em um potencial efetivo, chamado de potencial de Kohn-Sham, de forma que a condição citada (de equivalência entre os sistemas interagentes e não interagentes) seja satisfeita. Portanto, a equação de Kohn-Sham tornou-se similar a equação de Schrödinger para o átomo de hidrogênio, uma vez que ela é não interagente [37]. Essas duas equações diferem apenas na parte do potencial elétrico criado pelo núcleo de hidrogênio na equação de Schrödinger,

$$
\left[-\frac{h^{2}}{2 m_{e}} \nabla^{2}-\frac{k e^{2}}{|\vec{r}|}\right] \Psi(\vec{r})=E \Psi(\vec{r})
$$

onde o termo $-k e^{2} /|\vec{r}|$ é substituído pelo potencial de Kohn-Sham $v_{K S}(\vec{r})$, um funcional da densidade, pode ser reescrito como $v_{K S}[\rho](\vec{r})$, sendo formado pela soma de três partes $[37]$ :

$$
v_{K S}[\rho](\vec{r})=v_{\text {ext }}(\vec{r})+v_{\text {Hartree }}[\rho](\vec{r})+v_{x c}[\rho](\vec{r}) .
$$

O primeiro termo do lado direito da igualdade é o potencial externo, o segundo termo o potencial de Hartree (que considera a interação eletrostática clássica entre os elétrons) e o terceiro termo representa o potencial de troca e correlação (nele inclui todos os termos não triviais da interação). Sendo assim, o que falta é determinar este último termo [37]. Para isso, novas aproximações são feitas.

Kohn e Sham propuseram a aproximação da densidade local (LDA - do inglês, Local Density Approximation) que apesar de simples, fornece resultados já razoavelmente 
bons. A LDA se baseia no gás homogêneo de elétrons, que é um sistema idealizado, em que os núcleos atômicos são considerados como uma carga positiva contínua e constante. As equações de Kohn-Sham são facilmente resolvidas com essa aproximação e com baixo custo computacional [37]. Um problema da LDA é que apesar de ser muito eficaz em sistemas que se comportam como gás homogêneo, ela falha em sistemas reais que não tenham esse comportamento. Mas, muito se tem feito para melhorar a aproximação LDA, e uma forma é introduzindo as chamadas correções não-locais [38].

A medida da densidade eletrônica não homogênea em um sistema finito pode ser feita a partir de seu gradiente, e a representação dos funcionais energia de troca, correlação e/ou troca-correlação do sistema pode ser apresentada de uma maneira mais realística pela seguinte expressão:

$$
E_{X}^{N L-L D A}[\rho]=E_{X}^{L D A}[\rho]+F_{X}\left[\rho^{\alpha}, \rho^{\beta}, \nabla \rho^{\alpha}, \nabla \rho^{\beta}, \ldots\right]
$$

onde $F_{X}\left[\rho^{\alpha}, \rho^{\beta}, \nabla \rho^{\alpha}, \nabla \rho^{\beta}, \ldots\right]$ é um funcional adequado, chamado de componente nãohomogênea da energia de troca. Para os casos em que o sistema se comporta de maneira homogênea, a correção não-local é nula, ou seja $F_{X}=0$ [38].

O método DFT desenvolvido por Kohn, Hohenberg e Sham para estudar sistemas moleculares médios e grandes com eficiência não conseguiu solucionar todos os problemas existentes, pois esse método tinha limitação para sistemas em estado fundamental e estático. Devido às limitações e necessidades de resolver sistemas dependentes do tempo, surgiu a Teoria do Funcional da Densidade Dependente do Tempo (TD-DFT do inglês, Time Dependent Density Functional Theory). Esse novo método, desenvolvido por Runge e Gross, é capaz de tratar fenômenos dependentes do tempo e estado excitado. Este método é semelhante aos teoremas de Kohn-Hohenberg e Kohn-Sham, com o acréscimo de uma formulação de resposta linear para calcular espectros de excitação [39].

Neste trabalho estamos interessados em analisar os efeitos dos metais nas propriedades das Ftcs e utilizaremos a TD-DFT para realizar os cálculos das energias da primeira transição vertical (primeira energia de excitação) e os respectivos comprimentos de onda e força de oscilador neste estudo.

Utilizaremos a Teoria do Funcional da Densidade, juntamente com o funcional 
B3LYP nestes cálculos. Este funcional híbrido, formulado por Becke [40], é um dos mais utilizados atualmente. Este funcional é caracterizado por três parâmetros: dois deles servem para misturar termos de troca de Hartree Fock (HF) e de LDA e termos de troca de Becke e o outro parâmetro mistura termos de correlação de Lee-Yang-Parr (LYP) com aqueles desenvolvidos por Vosko, Wilk e Nusair (VWN) [41].

Tendo visto os métodos que utilizaremos nas simulações, podemos passar para o próximo capítulo, onde apresentaremos os resultados e conclusões deste trabalho utilizando as moléculas de Ftcs retiradas do banco de dados CCDC que estão apresentadas no apêndice $\mathrm{A}$. 


\section{Resultados e Discussões}

Neste capítulo, apresentaremos os resultados teóricos obtidos na análise das MFtcs em estudo. Iniciaremos nossa discussão avaliando o impacto que diferentes átomos centrais provocam na estrutura geométrica dessas moléculas. Nos casos em que o átomo central é um metal de transição, mostraremos a contribuição dos orbitais $d$ na estrutura eletrônica de valência das MFtcs. Por fim, discutiremos as propriedades eletrônicas das Ftcs, como a energia dos orbitais de fronteira e finalizaremos com uma análise da energia das primeiras excitações eletrônicas, ou seja, das transições entre o estado fundamental e os primeiros estados excitados, mais particularmente da primeira transição que define o limiar da absorção, isto é, a transição $\mathrm{S}_{0} \rightarrow S_{1}$ que define o comprimento de onda máximo de absorção $\left(\lambda_{m a ́ x}\right)$.

Nos cálculos teóricos aqui apresentados, utilizamos a DFT juntamente com o funcional B3LYP e a base 6-31G** . Na análise das propriedades ópticas e eletrônicas das Ftcs, utilizamos a TD-DFT. Em todos os cálculos aqui apresentados utilizamos o pacote computacional Gaussian 09 [25].

\subsection{Propriedades Geométricas}

Primeiramente utilizamos a geometria de Raios-X das nove metaloftalocianinas retiradas do banco de dados CCDC, como discutido anteriormente e, em seguida, essas geometrias foram adaptadas para serem posteriormente submetidas aos cálculos de otimização da geometria.

Para os cálculos, o funcional e a base usados foram escolhidos por serem eficientes em outros estudos já realizados a respeito desta classe de moléculas [16]. Calcu- 
lamos o centro médio (CM) entre os quatro nitrogênios e a distância do metal até esse CM. Para essa análise, foram utilizadas as Ftcs de titânio $(\mathrm{Ti})$, vanádio $(\mathrm{V})$, lítio $(\mathrm{Li})$, cobalto $(\mathrm{Co})$, ferro $(\mathrm{Fe})$, níquel $(\mathrm{Ni})$, cobre $(\mathrm{Cu})$, zinco $(\mathrm{Zn})$ e silício $(\mathrm{Si})$, embora o Si não seja um metal e sim um semicondutor foi incluído em nosso estudo devido a importância na eletrônica convencional.

Na análise das propriedades geométricas das Ftcs em estudo, uma pergunta que aparece repetidas vezes na literatura é se o átomo central se encontra no plano da molécula da ftalocinanina ou fora deste plano. Para respondermos esta pergunta, parece óbvio que uma comparação entre o raio atômico do átomo que estará no centro da molécula de ftalocianina e uma comparação entre este raio e o tamanho da circunferência formada pelos quatro átomos de nitrogênio mais internos da molécula é o suficiente para respondermos esta pergunta.

Seguindo este pensamento, fizemos uma comparação entre o tamanho dos átomos utilizados com relação a gaiola central das Ftcs, para investigar se os átomos cabem ou não nesta gaiola. Como veremos a seguir, observamos que dependendo do tamanho do átomo central, a estrutura da ftalocianina pode sofrer dilatação, contração ou, até mesmo, se manter com o tamanho original da Ftc- $\mathrm{H}_{2}$. Utilizaremos o tamanho da gaiola da ftalocianina não substituída como referência de "tamanho da gaiola" em todas nossas análises.

Todas as ftalocianinas analisadas tem carga nula. Inicialmente, consideramos os casos de Raios-X do CCDC e, em seguida, fizemos os cálculos de otimização das Ftcs e comparamos os dois resultados. É importante notar aqui que as geometrias provenientes da CCDC são obtidas a partir de cristais de Ftcs. Ou seja, as moléculas encontram-se em seu estado sólido. Já em nossos cálculos, as moléculas estão isoladas. Sendo assim, esperamos pequenos desvios, principalmente no que diz respeito à planaridade, entre as geometrias experimentais (CCDC) e os cálculos teóricos, uma vez que esperamos que o empacotamento cristalino tenha um impacto direto no desvio da planaridade destas moléculas.

Em uma primeira aproximação, tentamos utilizar o raio de van der Walls $\left(\mathrm{r}_{\mathrm{vdw}}\right.$ - considerando como o raio de uma esfera rígida) de cada átomo central analisado a fim de investigar porque algumas MFtcs tem seu átomo de metal para fora do plano e outros 
se encaixam a seu centro. $\mathrm{O} \mathrm{r}_{\mathrm{vdw}}$ é de grande importância na Mecânica Molecular [42]. Algumas propriedades físicas de cristais moleculares podem ser compreendidas através de estudos utilizando o $\mathrm{r}_{\mathrm{vdw}}$, por exemplo: o ponto de fusão, o comportamento magnético e a condutividade elétrica [43].

Na Figura 3.1 é mostrada a distância (Z) entre o CM e o átomo de metal (M) para os casos de Raios-X e geometria otimizada (GO).

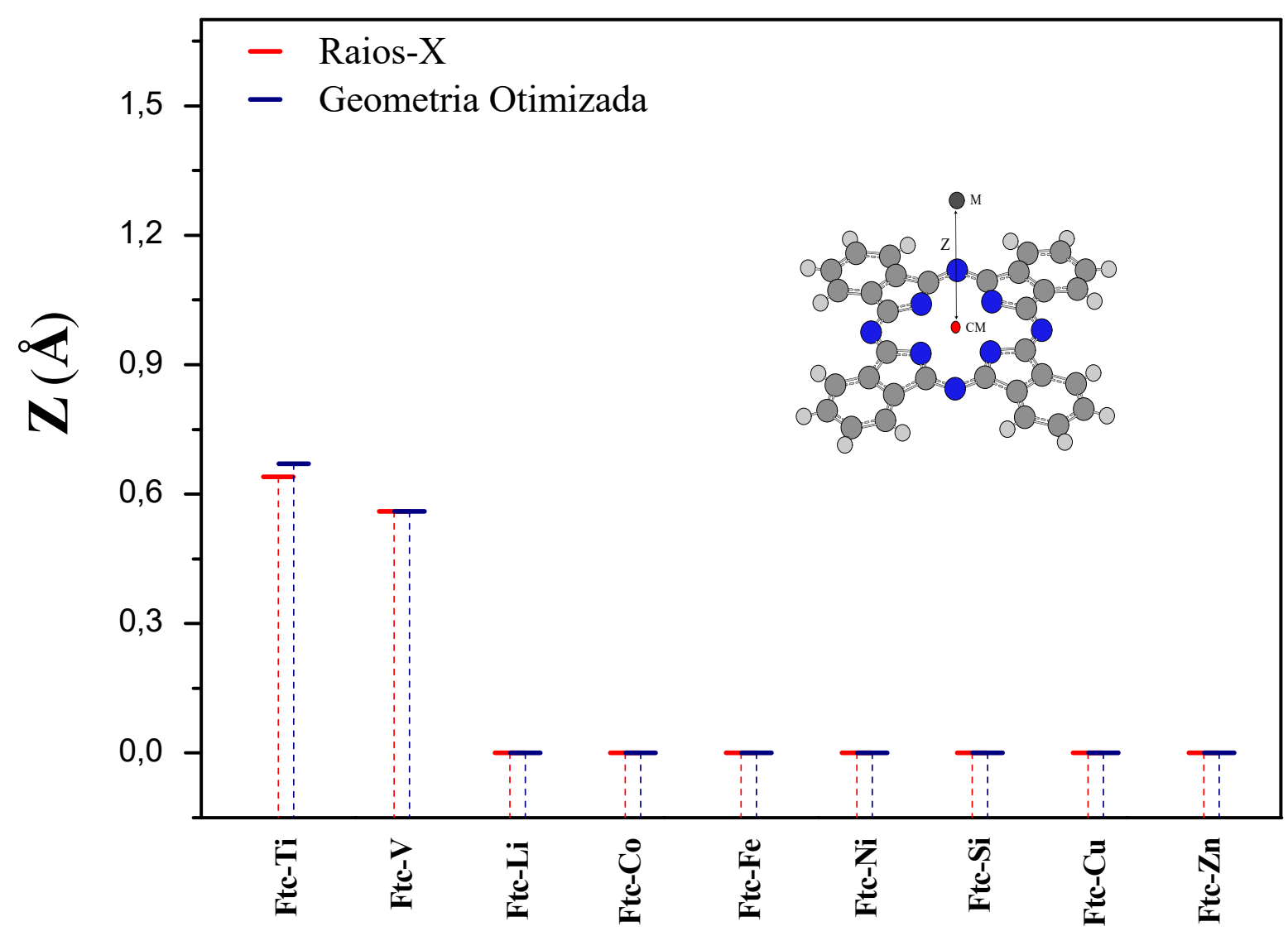

Figura 3.1: Distância do centro médio da molécula ao metal para os casos Raios-X e geometria otimizada.

$\mathrm{Na}$ análise da geometria da CCDC, vimos que os átomos de Li, Co, Fe, Ni, Si, $\mathrm{Zn}$ e Cu cabem completamente no centro da molécula. Já os metais $\mathrm{V}$ e Ti ficam fora do plano com uma distância de $0,56 \AA$ e $0,64 \AA$, respectivamente.

Na Tabela 3.1 observamos que a presença dos átomos de $\mathrm{V}$ e Zn provocaram uma dilatação da gaiola central da Ftc de 1,97 $\AA$ para 1,98 A. Já para os demais átomos foi visto que houve uma contração da gaiola, sendo que a maior diferença foi observada 
na Ftc-Ni com uma contração de 0,14 A.

\begin{tabular}{|c|c|c|c|}
\hline Molécula & $\begin{array}{c}\text { Raio médio da gaiola } \\
\text { central da Ftc com } \\
\text { Raios-X }(\AA)\end{array}$ & $\begin{array}{c}\text { Raio médio da gaiola } \\
\text { central da Ftc com } \\
\text { GO }(\AA)\end{array}$ & $\begin{array}{c}\text { Raio de van der Walls } \\
(\AA)\end{array}$ \\
\hline \hline Ftc- $H_{2}$ & 1,97 & 1,99 & 2,46 \\
\hline Ftc-Ti & 1,98 & 1,99 & 2,42 \\
\hline Ftc-V & 1,95 & 1,96 & 2,12 \\
\hline Ftc-Li & 1,94 & 1,97 & 2,40 \\
\hline Ftc-Co & 1,93 & 1,94 & 2,44 \\
\hline Ftc-Fe & 1,94 & 1,96 & 2,40 \\
\hline Ftc-Ni & 1,83 & 1,91 & 2,19 \\
\hline Ftc-Si & 1,96 & 1,85 & 2,38 \\
\hline Ftc-Cu & 1,95 & 1,96 & 2,39 \\
\hline Ftc-Zn & 1,98 & 1,99 & \\
\hline
\end{tabular}

Tabela 3.1: Raio médio da gaiola central das Ftcs e raio de van der Walls.

Vimos também que os átomos de $\mathrm{V}$ e Ti ficam fora do plano da molécula, com o $\mathrm{r}_{\mathrm{vdw}}$ de 2,42 $\AA$ e 2,46 $\AA$, respectivamente (ver Tabela 3.1). Estes são considerados átomos grandes se comparados com o raio médio da gaiola da molécula. Mesmo que a Ftc sofra uma dilatação, ainda assim, não seria suficiente para caber nenhum desses metais.

Em nossa análise, observamos que a Ftc- $\mathrm{H}_{2}$ é uma molécula plana, mas quando substituídos seus dois hidrogênios centrais pelos metais $\mathrm{V}$ ou Ti, sua estrutura é deformada. Foi observado no entanto, que para os demais casos estudados a molécula continua com sua caraterística planar.

Podemos partir da hipótese de que o $\mathrm{r}_{\mathrm{vdw}}$ do átomo central, quando comparado com o tamanho da gaiola da Ftc, pode nos indicar imediatamente se este átomo cabe ou não na "gaiola". No entanto, analisando os gráficos da Figura 3.2, podemos observar que esta correlação não é direta. Da Figura 3.2 podemos observar que átomos com $\mathrm{r}_{\mathrm{vdw}}$ de até $2,40 \AA$ (quase $22 \%$ maior que o raio médio da gaiola central da Ftc- $\mathrm{H}_{2}$ ) couberam na gaiola. 


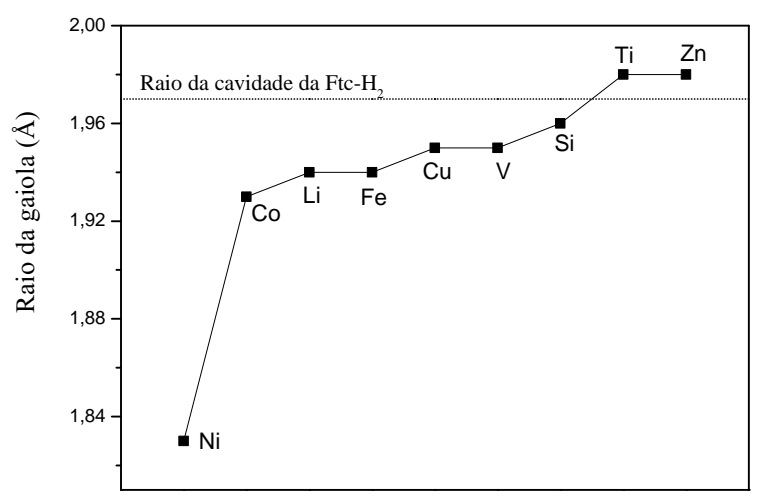

(a)

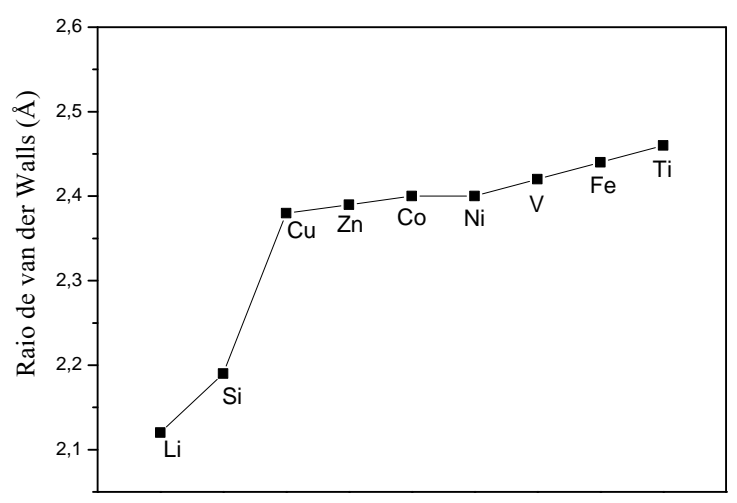

(b)

Figura 3.2: (a) raio da gaiola e (b) raio de van der Walls.

A próxima pergunta que poderíamos fazer aqui é se existe um raio de van der Walls para o qual acima deste os átomos com tais raios não cabem mais na "gaiola". Com relação a esta questão, utilizamos o $\mathrm{r}_{\mathrm{vdw}}$ de 2,40 $\AA$ para ser nossa referência, já que este seria o valor de fronteira entre os átomos que couberam ou não na gaiola.

Já os átomos com $\mathrm{r}_{\mathrm{vdw}}$ acima de 2,40 $\AA$, foi observado que ficaram fora do plano da gaiola central. Mesmo que a molécula possa se dilatar, não foi suficiente para acomodar esses átomos. Uma exceção, foi o átomo de $\mathrm{Fe}$, com $\mathrm{r}_{\mathrm{vdw}}$ de $2,44 \AA$. Isso pode ser atribuído, ao fato desta molécula conter em sua estrutura, duas moléculas de piridina ligadas ao átomo central, que pode estar removendo carga deste metal. Sabemos de outros estudos [15] que o efeito desta transferência de carga é deslocar o átomo central mais para o interior da gaiola.

Analisando os cálculos obtidos das moléculas otimizadas, podemos observar que existe uma dilatação da gaiola central das moléculas após a otimização, que varia de $0,01 \AA$ a $0,03 \AA$ para a maioria das MFtcs, o que favorece os átomos metálicos se acomodarem em seu centro. Uma maior dilatação é observada na Ftc-Ni com 0,08 A, que pode ser justificada pelo tamanho do seu metal com $\mathrm{r}_{\mathrm{vdw}}$ medindo $2,40 \AA$, considerado grande em relação a gaiola central, mas ainda é capaz de acomodar-se totalmente no centro da Ftc. Já na Ftc-Si com $\mathrm{r}_{\mathrm{vdw}}$ do Si medindo 2,19 А, um dos menores átomos usados neste trabalho, a gaiola da Ftc sofre uma contração para acomoda-lo em seu centro.

Uma outra comparação foi feita com a Ftc- $\mathrm{H}_{2}$ e observamos que apesar da Ftc-Ti ter o seu metal um $\mathrm{r}_{\mathrm{vdw}}$ de $2,46 \AA$, sendo maior que o nosso raio de referência 
$(2,40 \AA)$ para caber no centro da molécula, ficando 0,67 A para fora do plano da Ftc, não provocou nenhuma mudança no tamanho da gaiola central. Porém o $\mathrm{V}$ com $\mathrm{r}_{\mathrm{vdw}}$ de 2,42 $\AA$, que também fica para fora do plano, com $0,56 \AA$, causou uma contração do centro da molécula.

Vimos também, que o átomo de Zn não provocou nenhuma alteração no tamanho da gaiola. Porém, com um $\mathrm{r}_{\mathrm{vdw}}$ de 2,39 $\AA$ fica completamente no plano da molécula. Já as demais moléculas sofreram uma contração da gaiola central, tendo a Ftc-Si o menor raio médio da gaiola de todas as moléculas, com 1,85 A.

Novamente, observamos que os átomos com $\mathrm{r}_{\mathrm{vdw}}$ até 2,40 Å ficaram para dentro da gaiola da Ftc e os átomos com $\mathrm{r}_{\mathrm{vdw}}$ maior que 2,40 $\AA$ ficaram para fora do plano da molécula, com exceção do Fe que tendo $\mathrm{r}_{\mathrm{vdw}}$ de $2,44 \AA$ ainda consegue se acomodar no plano da Ftc.

Observamos que mesmo após a otimização das Ftcs, sua planaridade é preservada tanto para a Ftc- $\mathrm{H}_{2}$ como as MFtcs. Porém, duas exceções aconteceram para os metais de $\mathrm{V}$ e Ti que provocaram um arqueamento na molécula.

A comparação da distância Z entre o CM e o átomo central para os casos de Raios-X e GO, mostra que não há ou é pequena a variação da distância do metal na maioria dos casos após a otimização, indicando que o método escolhido (B3LYP/6-31G**) é apropriado para descrever os parâmetros geométricos desta classe de moléculas.

Uma característica importante da classe das Ftcs é a possibilidade de funcionalizá-las com diferentes metais. Estes metais podem provocar desde pequenas distorções na estrutura das Ftcs quanto distorções mais profundas, por exemplo modificando a estrutura plana da molécula, tornando-a arqueada como visto na Figura 3.3.

Apesar da Ftc- $\mathrm{H}_{2}$ ter simetria $\mathrm{D}_{2 h}$, a presença do metal na sua estrutura, pode alterar sua planaridade e consequentemente sua simetria. As MFtcs, onde os íons metálicos (por exemplo, $\mathrm{Ni}^{2+}, \mathrm{Cu}^{2+}, \mathrm{Co}^{2+}$ e $\mathrm{Fe}^{2+}$ ) se encaixam completamente em seu centro, melhoram sua planaridade e sua simetria aumenta para $\mathrm{D}_{4 h}$. Já no caso do íon metálico $\mathrm{Zn}^{2+}$ que fica para fora do plano, distorce a molécula e pode diminuir sua simetria para $\mathrm{C}_{4 v}[15]$. 


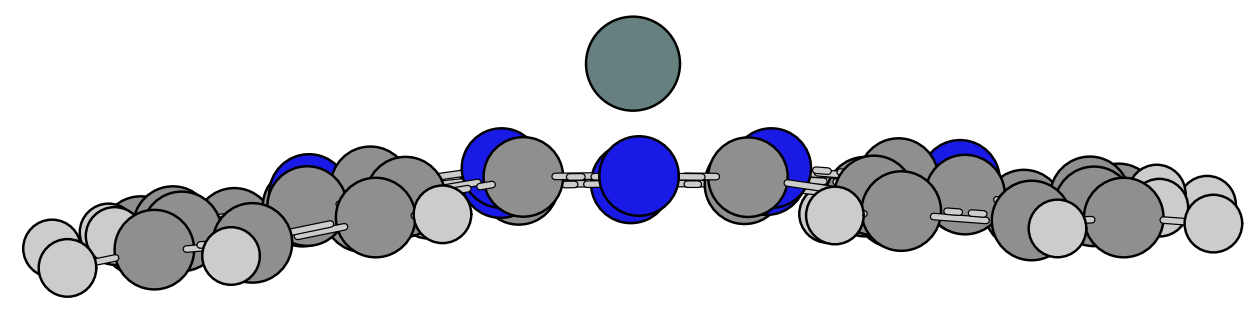

Figura 3.3: Representação do arqueamento da MFtc decorrente da presença do metal na gaiola central.

Considerando o $\mathrm{r}_{\mathrm{vdw}}$ o raio de uma esfera rígida, como dito anteriormente, para o caso das Ftcs, muitos desses átomos não poderiam caber na gaiola da Ftc, porém, muitos se acomodam completamente no centro da molécula. Na prática, o $\mathrm{r}_{\mathrm{vdw}}$ trata-se de nuvens eletrônicas de átomos que podem interagir, e com isso justifica o fato de átomos considerados como grandes, caberem na gaiola central da molécula.

Concluímos que o $\mathrm{r}_{\mathrm{vdw}}$ não é apropriado para indicar se o átomo substituinte cabe na gaiola central das MFtcs, apesar de ser de grande importância na mecânica molecular na descrição de algumas propriedades físicas de cristais moleculares. Sendo o $\mathrm{r}_{\mathrm{vdw}}$ uma análise clássica é necessário uma abordagem quântica para avaliar as propriedades geométricas desta classe de molécula, onde pode ser a justificativa pelo fato do $\mathrm{r}_{\mathrm{vdw}}$ não ter sido eficiente na avaliação do tamanho do átomo central em relação a gaiola das Ftcs. 


\subsection{Contribuições dos Orbitais $d$}

Nesta seção, iremos discutir sobre a contribuição do orbital $d$ dos metais de transição na estrutura eletrônica das MFtcs ( $\mathrm{M}=\mathrm{Ti}, \mathrm{V}, \mathrm{Co}, \mathrm{Fe}, \mathrm{Ni}, \mathrm{Cu}$ e Zn). Ou seja, na formação dos orbitais moleculares de fronteira.

Os metais de transição são conhecidos por terem sua camada $d$ incompleta, na maioria dos casos, o que favorece uma maior transição de elétrons. Devido a absorção da luz visível de um determinado comprimento de onda é possível observar as cores destes compostos, pois, esta absorção corresponde a energia capaz de promover um elétron do estado fundamental para o estado excitado. Nos metais de transição, esta promoção geralmente acontece nesses orbitais.

Os orbitais $d$, diferente dos orbitais do tipo $s$ (sem plano nodal) e do tipo $p$ (um plano nodal), possuem dois planos nodais, onde a probabilidade de encontrar um elétron é nula. Os orbitais $d$ possuem cinco representações, sendo elas: $d_{x y}, d_{y z}, d_{x z}$, $d_{x^{2}-y^{2}}$ e $d_{z^{2}}$, ilustradas na Figura 3.4.

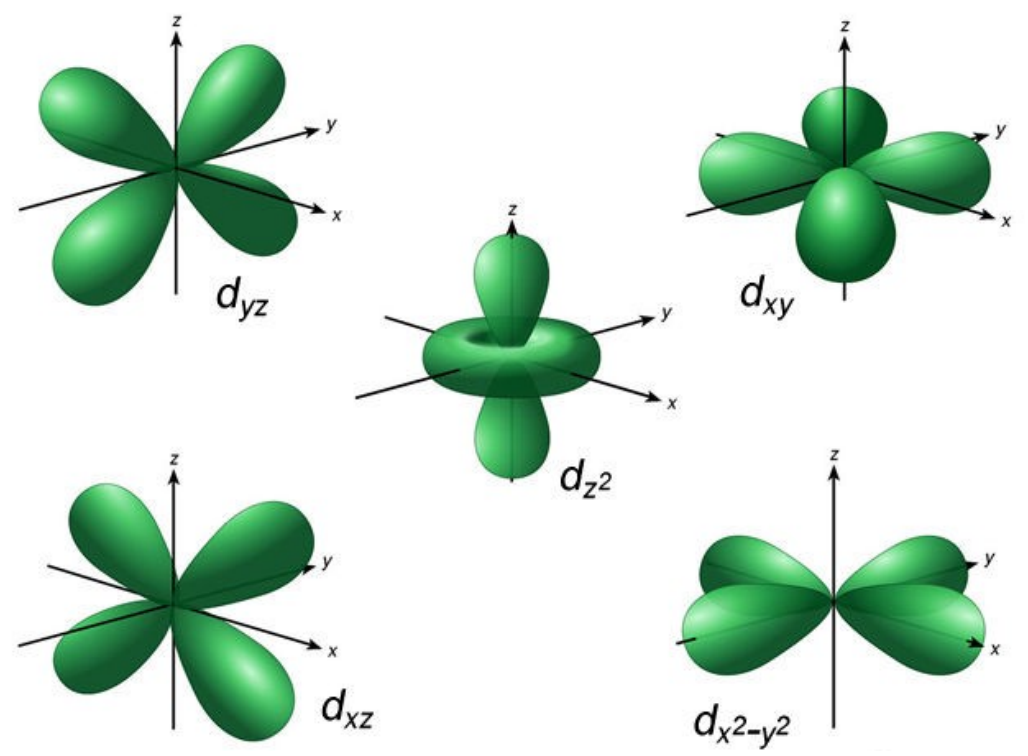

Figura 3.4: Representação dos orbitais $d$. 
Neste trabalho, avaliamos a contribuição percentual de cada orbital atômico na constituição dos orbitais moleculares, utilizando o coeficiente que representa a contribuição deste orbital atômico para o orbital molecular em questão, segundo a expressão:

$$
\text { Contribuição } \%=\frac{c_{i}^{2}}{\sum \sqrt{c_{j}^{2}}} 100
$$

onde $c_{i}^{2}$ é a amplitude dos orbitais $d$ e $c_{j}^{2}$ é a amplitude de todos os orbitais que formam o orbital molecular HOMO ou LUMO, por exemplo. Na análise dos resultados, nos gráficos e nas tabelas que seguirão foram levadas em consideração apenas as contribuições dos orbitais $d$ acima de $10 \%$.

Na Figura 3.5 são mostradas as contribuições dos orbitais $d$, para cada uma das moléculas. Nas tabelas seguintes, apresentamos a maior contribuição do orbital $d$ de cada MFtc, bem como, em qual orbital molecular esta contribuição está localizada, tanto para os orbitais ocupados quanto para os orbitais desocupados. Para consultar as tabelas completas com os orbitais HOMO-N e LUMO+N com contribuições acima de $10 \%$ (sendo $\mathrm{N}$ o número do orbital correspondente), ver apêndice $\mathrm{C}$.

Embora não esperamos que exista uma correlação entre a posição relativa do metal ao plano da Ftc e a posição do orbital $d$ em relação aos orbitais $\pi$, apresentamos na Tabela 3.2 a posição do metal e a posição do orbital $d$ com relação ao HOMO da molécula.

Na Tabela 3.2, podemos observar que as maiores contribuições do orbital $d$ para os orbitais ocupados e desocupados não acontecem, na maioria das vezes, nos orbitais de fronteira HOMO ou LUMO. Estas contribuições acontecem de forma variada entre os diversos orbitais ocupados e desocupados. Podemos ver a contribuição máxima de orbitais $d$ ao orbital molecular podem ser superiores a $60 \%$ para quase todos os casos, chegando a quase $74 \%$ para o $\mathrm{Cu}$. A menor destas contribuições acontece para o Ti, com cerca de $26 \%$.

Observamos que quanto maior o número de elétrons da camada $d$ destes metais, maior será sua contribuição ao orbital molecular e mais afastado da fronteira estará este orbital. Uma exceção é vista para o caso do Ti, tendo apenas 2 elétrons na camada $d$ e contribuição de 26\%, encontra-se no orbital HOMO-15, considerado muito afastado da fronteira, se comparado com o que acontece para os outros metais aqui analisados. 


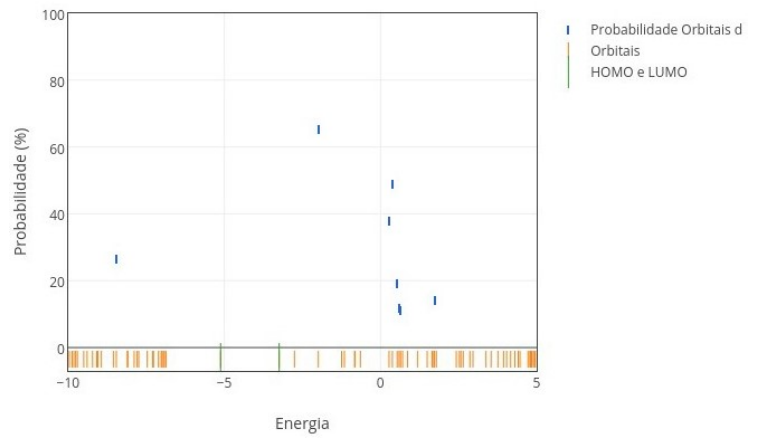

(a) Ftc-Ti

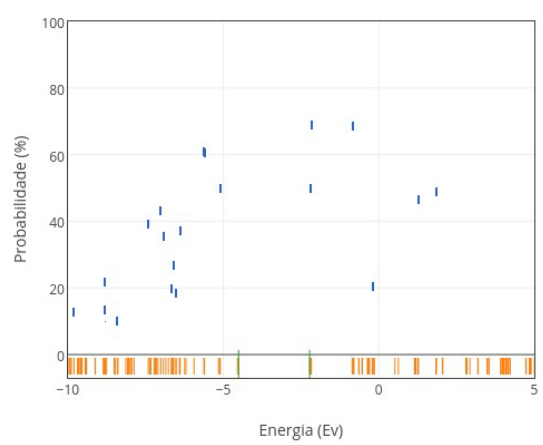

(c) Ftc-Co

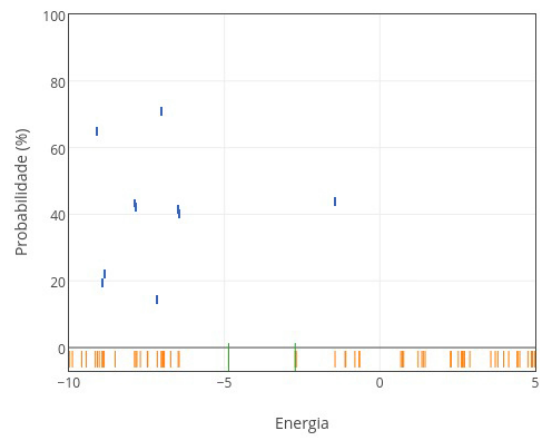

(e) Ftc-Ni

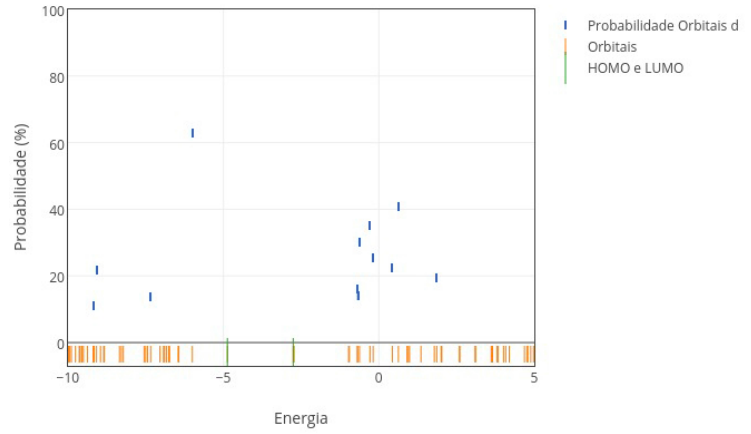

(b) Ftc-V

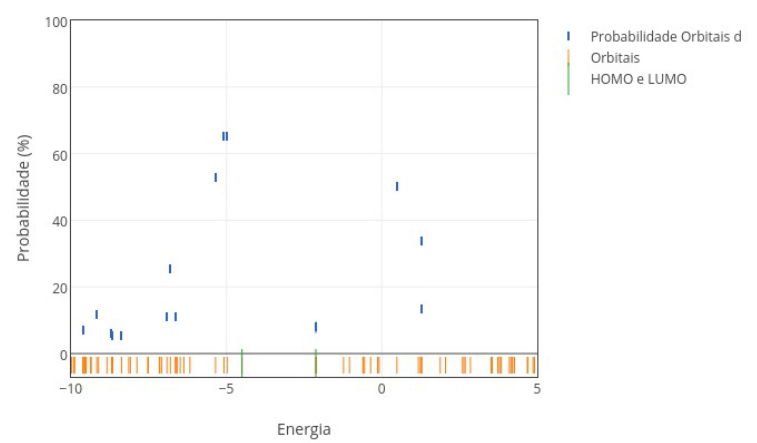

(d) Ftc-Fe

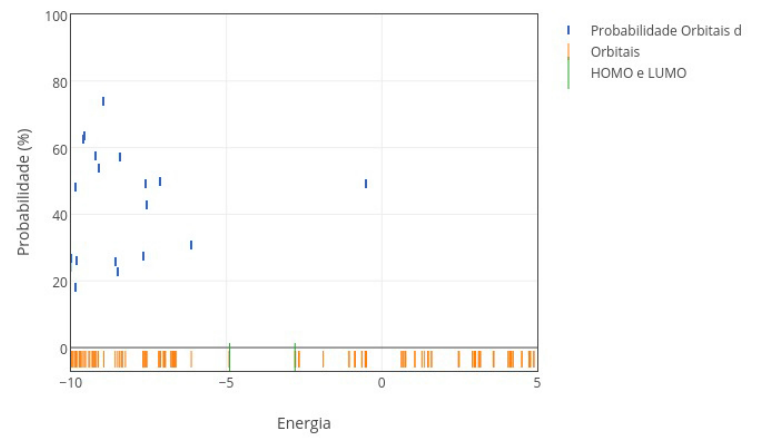

(f) Ftc-Cu

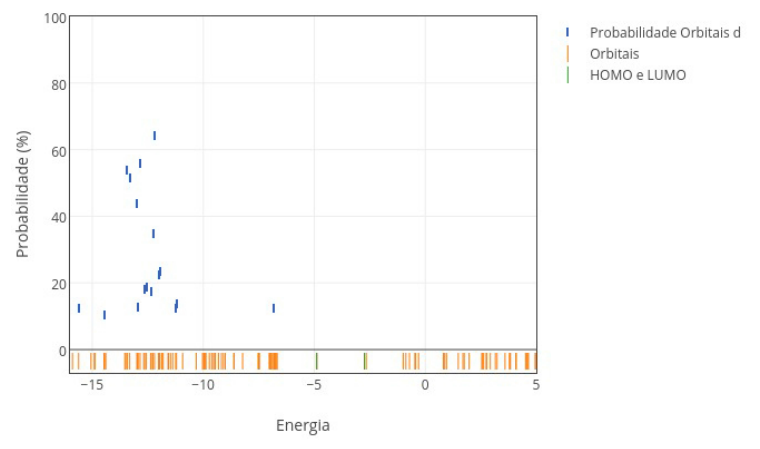

(g) Ftc-Zn

Figura 3.5: Contribuições dos orbitais d acima de 10\% para as moléculas de Ftcs. 


\begin{tabular}{|c|c|c|c|c|}
\hline Molécula & $\begin{array}{c}\text { Maior } \\
\text { contribuição do } \\
\text { orbital } d \text { em } \%\end{array}$ & $\begin{array}{c}\text { No de eletrons } \\
\text { na camada } d\end{array}$ & Posição do metal & Orbital \\
\hline \hline Ftc-Ti & 26 & 2 & Fora & HOMO-15 \\
\hline Ftc-V & 63 & 3 & Fora & HOMO-1 \\
\hline Ftc-Fe & 65 & 6 & Dentro & HOMO-2 \\
\hline Ftc-Co & 61 & 7 & Dentro & HOMO-3 \\
\hline Ftc-Ni & 71 & 8 & Dentro & HOMO-8 \\
\hline Ftc-Cu & 74 & 9 & Dentro & HOMO-17 \\
\hline Ftc-Zn & 64 & 10 & Dentro & HOMO-46 \\
\hline
\end{tabular}

Tabela 3.2: Maior contribuição do orbital $d$, número de elétrons da camada $d$, posição do metal central e orbital molecular ocupado de maior contribuição $d$.

Algo diferente também acontece com o Co, mesmo tendo uma quantidade maior de elétrons na camada $d$, sua contribuição de $61 \%$ é menor que as de $\mathrm{V}$ e Fe, tendo estes dois metais contribuições de $63 \%$ e $65 \%$, respectivamente.

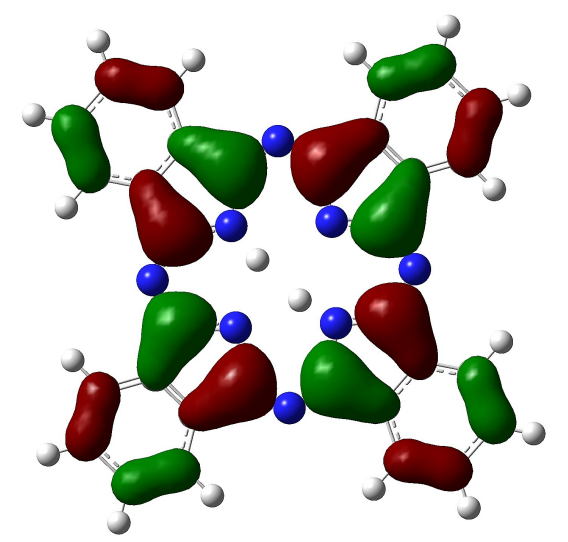

(a) $\mathrm{Ftc}-\mathrm{H}_{2}(\mathrm{H})$

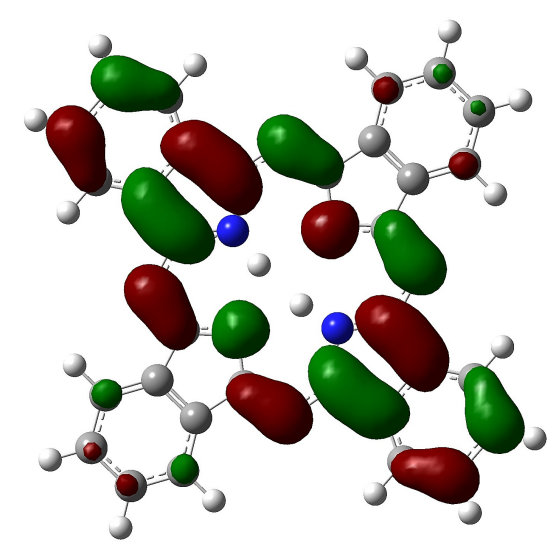

(b) Ftc- $\mathrm{H}_{2}(\mathrm{~L}+1)$

Figura 3.6: Orbitais moleculares para a Ftc- $\mathrm{H}_{2}$.

Nas Figuras 3.6 à 3.15 são apresentados os orbitais moleculares para a Ftc$\mathrm{H}_{2}$ e as MFtcs cujos átomos centrais são metais de transição. Aqui podemos ver as contribuições dos orbitais $d$ na formação dos orbitais moleculares HOMO e LUMO de cada molécula. 


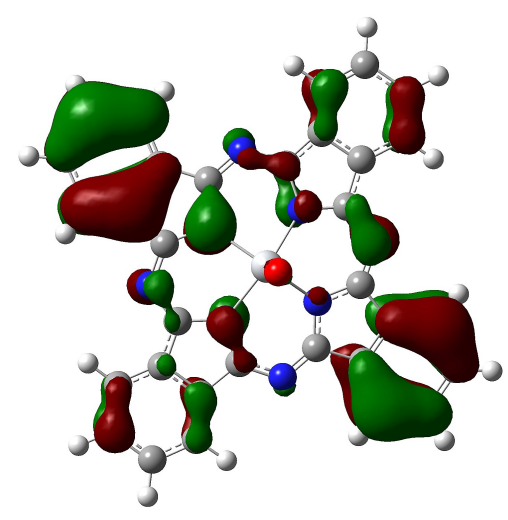

(a) Ftc-Ti (H)

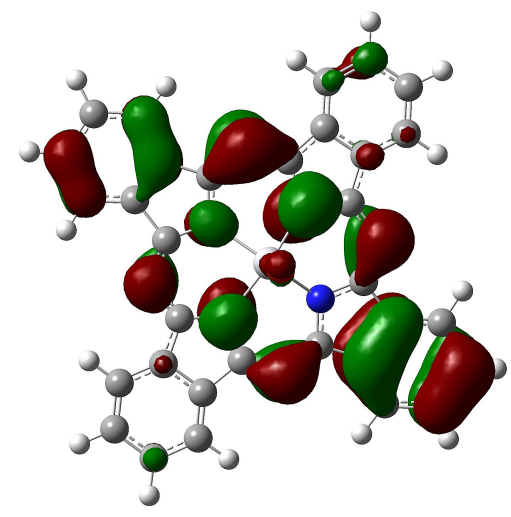

(b) Ftc-Ti (L)

Figura 3.7: Orbitais moleculares para a Ftc-Ti.

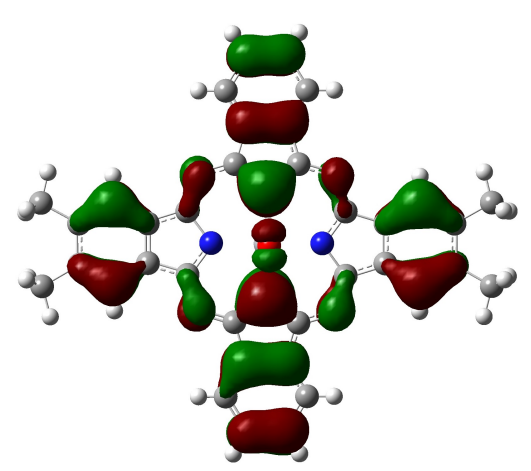

(a) Ftc-V (H)

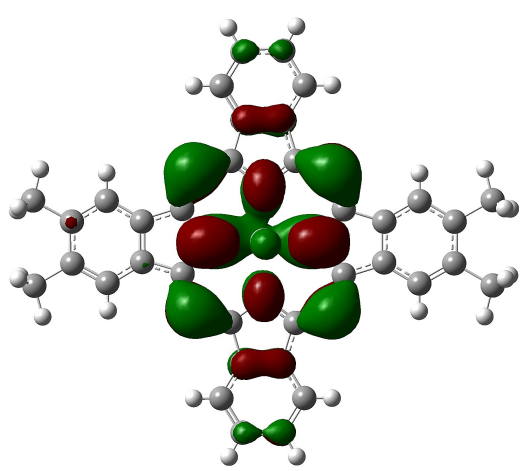

(b) Ftc-V (L)

Figura 3.8: Orbitais moleculares para a Ftc-V.

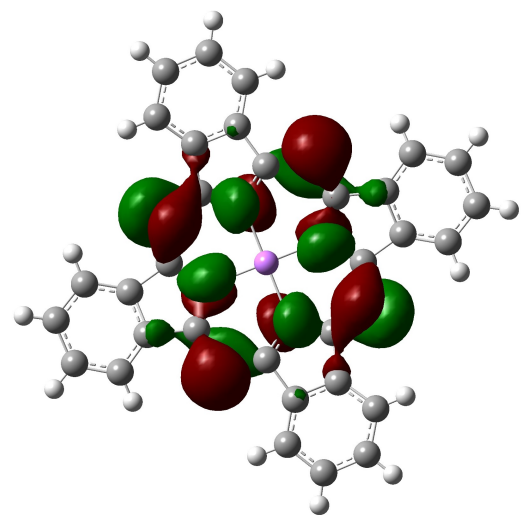

(a) Ftc-Li (H)

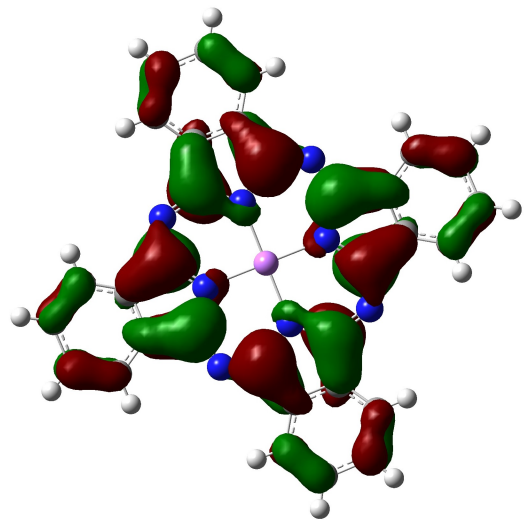

(b) Ftc-Li (L)

Figura 3.9: Orbitais moleculares para a Ftc-Li. 


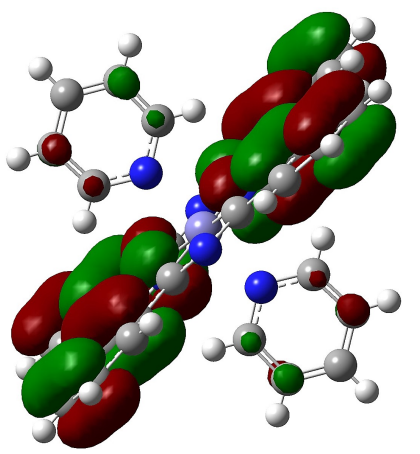

(a) Ftc-Fe (H)

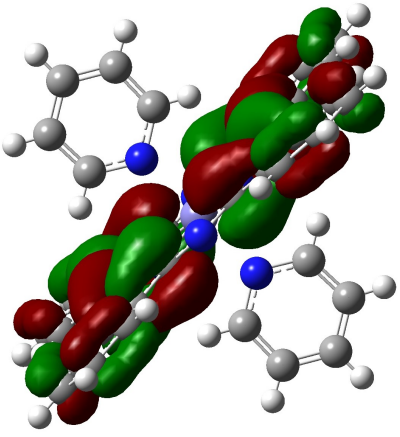

(b) Ftc-Fe $(\mathrm{L}+1)$

Figura 3.10: Orbitais moleculares para a Ftc-Fe.

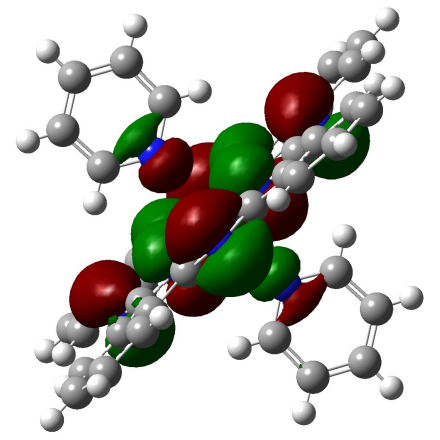

(a) Ftc-Co $(\mathrm{H})$

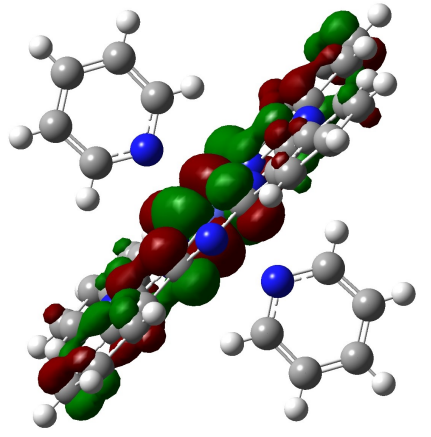

(b) Ftc-Co $(\mathrm{L}+1)$

Figura 3.11: Orbitais moleculares para a Ftc-Co.

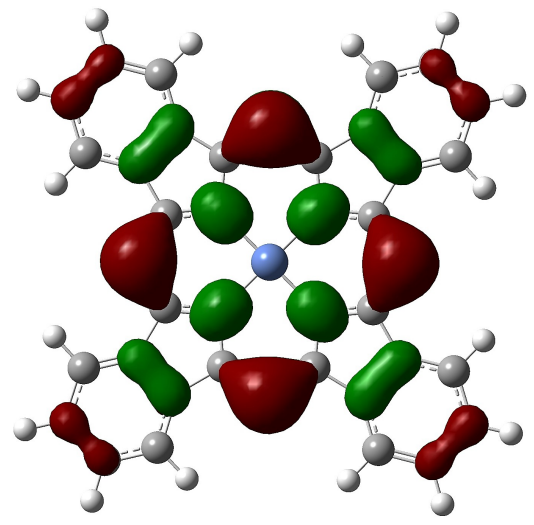

(a) Ftc-Ni (H)

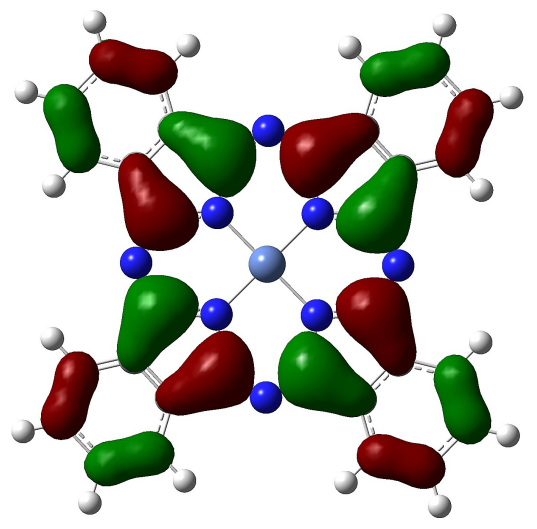

(b) Ftc-Ni (L)

Figura 3.12: Orbitais moleculares para a Ftc-Ni. 


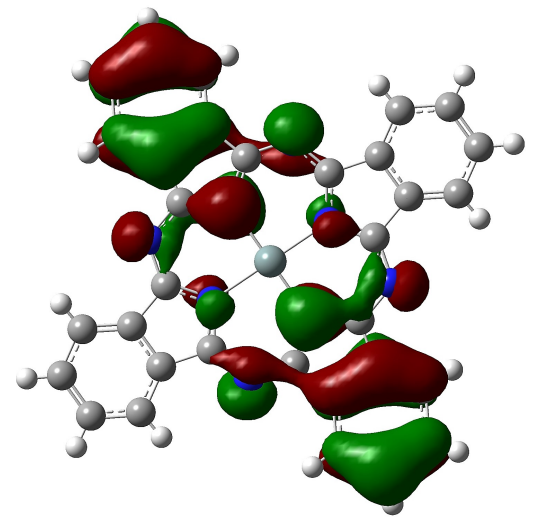

(a) Ftc-Si $(\mathrm{H})$

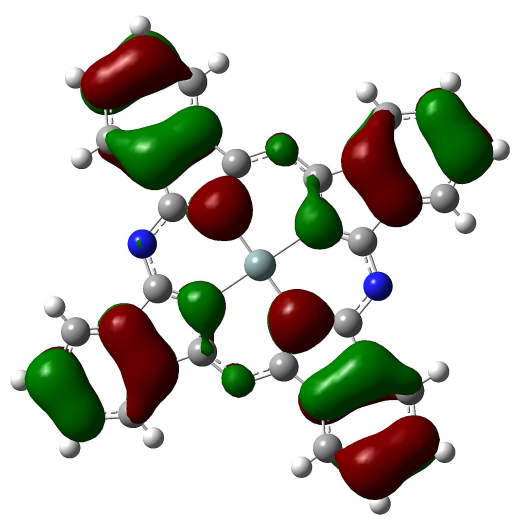

(b) Ftc-Si (L)

Figura 3.13: Orbitais moleculares para a Ftc-Si.

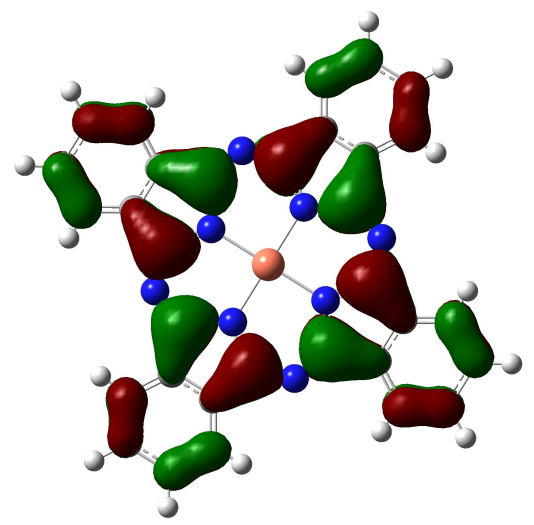

(a) Ftc-Cu (H)

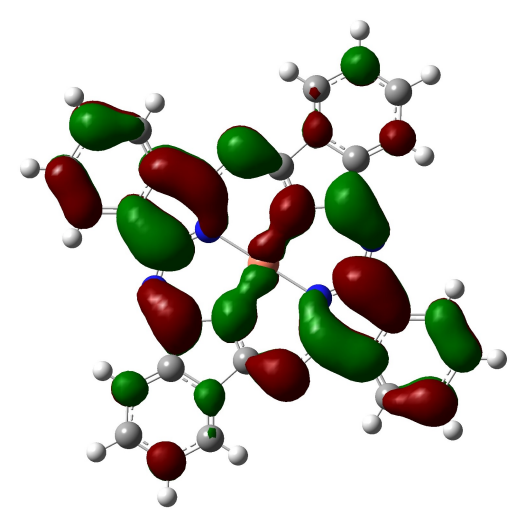

(b) Ftc-Cu (L)

Figura 3.14: Orbitais moleculares para a Ftc-Cu.

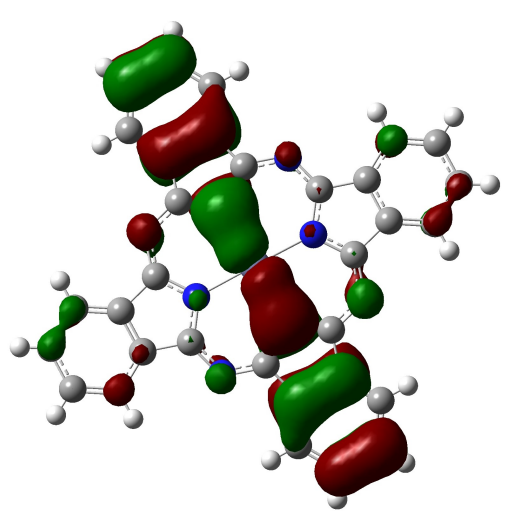

(a) Ftc-Zn (H)

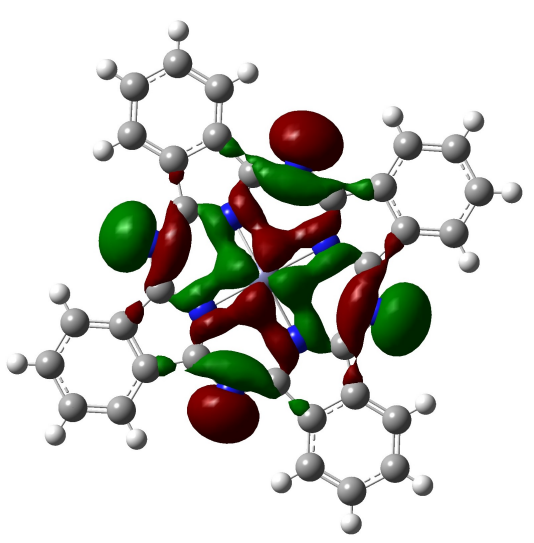

(b) Ftc-Zn (L)

Figura 3.15: Orbitais moleculares para a Ftc-Zn. 


\begin{tabular}{|c|c|c|c|c|}
\hline Molécula & $\begin{array}{c}\text { Maior } \\
\text { contribuição do } \\
\text { orbital } d \text { em } \%\end{array}$ & $\begin{array}{c}\mathrm{N}^{\circ} \text { de eletrons } \\
\text { na camada } d\end{array}$ & Posição do metal & Orbital \\
\hline \hline Ftc-Ti & 65 & 2 & Fora & LUMO+2 \\
\hline Ftc-V & 41 & 3 & Fora & LUMO+10 \\
\hline Ftc-Fe & 50 & 6 & Dentro & LUMO+11 \\
\hline Ftc-Co & 20 & 7 & Dentro & LUMO+10 \\
\hline Ftc-Ni & 44 & 8 & Dentro & LUMO+2 \\
\hline Ftc-Cu & & 9 & Dentro & \\
\hline Ftc-Zn & & 10 & Dentro & \\
\hline
\end{tabular}

Tabela 3.3: Maior contribuição do orbital $d$, número de elétrons da camada $d$, posição do metal central e orbital molecular desocupado de maior contribuição $d$.

Já a contribuição dos orbitais $d$ para os orbitais desocupados, como visto na Tabela 3.3, possuem contribuições maiores variando de $20 \%$ a $65 \%$. Porém, é visto que os orbitais $d$ do $\mathrm{Cu}$ e o do $\mathrm{Zn}$, não contribuem para o orbital molecular da Ftc-Cu e da Ftc-Zn, respectivamente, dentro do intervalo de energia avaliado (-10 eV a $5 \mathrm{eV})$ que tenha uma contribuição inferior a $10 \%$.

Já o Ti é o metal de maior contribuição $d$ para os orbitais moleculares desocupados, com apenas 2 elétrons na camada $d$, tendo uma contribuição de $65 \%$ localizado no orbital molecular LUMO+2. Essa contribuição no orbital molecular desocupado é o oposto que acontece em relação ao orbital molecular ocupado, cuja contribuição foi a menor de todas com $26 \%$.

O metal de menor contribuição do orbital $d$ para a formação do orbital molecular desocupado é o Co, sem levar em consideração o Cu e o Zn, que como dito anteriormente, está fora da faixa do intervalo da análise. A contribuição do Co é de apenas $20 \%$, localizado no orbital LUMO+10.

Observamos que as contribuições dos orbitais $d$ na formação dos orbitais moleculares desocupados, têm uma tendência em que, quanto menor a quantidade de elétrons 
da camada $d$, maior será sua contribuição na formação dos orbitais moleculares LUMO.

Porém, o Fe com 6 elétrons na camada $d$, tem uma contribuição do orbital $d$ na formação do orbital molecular LUMO+11 de 50\%, sendo maior que a contribuição de $41 \%$ do átomo de $\mathrm{V}$ cuja camada $d$ é composta por 3 elétrons. O mesmo acontece com o átomo de $\mathrm{Ni}$, com 8 elétrons e contribuição do orbital $d$ de $44 \%$ na formação do orbital molecular LUMO+2, sendo a contribuição do orbital $d$ menor que o do $\mathrm{V}$.

Algo que também merece atenção, são as energias $(\Delta)$ que separam os orbitais de fronteira dos orbitais mais próximos, com contribuições maiores que 10\%. Estas energias são apresentadas na Tabela 3.4 , onde $\Delta_{H O M O}$ é a diferença de energia entre o orbital molecular mais próximo (com contribuição do orbital $d$ acima de 10\%) e o orbital de fronteira HOMO. Já o $\Delta_{L U M O}$ é a diferença de energia entre o orbital LUMO e o orbital mais próximo dele (com contribuição do orbital $d$ acima de $10 \%$ ) e N é o número do orbital correspondente.

\begin{tabular}{|c|c|c|c|c|c|c|}
\hline Molécula & $\Delta_{\text {HOMO }}$ & $\Delta_{\text {LUMO }}$ & $\begin{array}{c}\text { Maior } \\
\text { contribuição } \\
\text { do orbital } d \\
\text { em } \%\end{array}$ & $\begin{array}{c}\text { Posição do } \\
\text { metal }\end{array}$ & $\begin{array}{c}\text { Orbital } \\
\text { HOMO }\end{array}$ & $\begin{array}{c}\text { Orbital } \\
\text { LUMO }\end{array}$ \\
\hline \hline Ftc-Ti & $-3,34$ & $-1,25$ & 26 & Fora & HOMO-15 & LUMO+2 \\
\hline Ftc-V & $-1,13$ & $-2,06$ & 63 & Fora & HOMO-1 & LUMO+4 \\
\hline Ftc-Fe & $-0,48$ & $-2,61$ & 65 & Dentro & HOMO-1 & LUMO+11 \\
\hline Ftc-Co & $-0,60$ & $-2,02$ & 50 & Dentro & HOMO-1 & LUMO+9 \\
\hline Ftc-Ni & $-1,59$ & $-1,28$ & 40 & Dentro & HOMO-1 & LUMO+2 \\
\hline Ftc-Cu & $-1,23$ & & 31 & Dentro & HOMO-1 & \\
\hline Ftc-Zn & $-1,92$ & & 12 & Dentro & HOMO-4 & \\
\hline
\end{tabular}

Tabela 3.4: Energias $\Delta_{H O M O}$ e $\Delta_{L U M O}$, contribuição do orbital $d$ na formação do orbital molecular ocupado, contribuição do orbital $d$ na formação do orbital molecular desocupado, posição do metal central, orbital molecular ocupado de maior contribuição $d$ e orbital molecular desocupado de maior contribuição $d$.

Na Ftc-Ti, o orbital HOMO-15 é o mais próximo do HOMO com contribuição 
$d$ acima de $10 \%$. Esta molécula é a que tem a maior energia $\Delta_{H O M O}$ com $3,34 \mathrm{eV}$, o que sugere ser por causa do orbital HOMO-15 (cuja contribuição do orbital $d$ é de 26\%) ser o mais afastado de todas as moléculas estudadas. Ela também, tem o metal com menor número de elétrons da camada $d$, com apenas 2 elétrons. Sua energia $\Delta_{L U M O}$ de 1,25 eV, é a menor de todas, sendo o LUMO+2 formado com $65 \%$ de contribuição do orbital $d$.

A Ftc-Zn é a segunda a ter o orbital mais próximo do HOMO com contribuições $d$ acima de $10 \%$, о HOMO-4, com $\Delta_{\text {номо }}$ de $-1,92 \mathrm{eV}$, sendo a segunda maior energia, e que também sugere ser, devido ao fato deste orbital ser mais afastado da fronteira. A energia $\Delta_{L U M O}$ da Ftc-Zn não foi mostrada aqui, por ter ficado fora do intervalo proposto para análise, como mencionado anteriormente. O mesmo acontece para $\mathrm{Ftc}-\mathrm{Cu}$, sendo que o $\mathrm{Zn}$ e o $\mathrm{Cu}$ tem 10 e 9 elétrons, respectivamente, na camada $d$ do metal. O que poderia ser o motivo pelo qual a contribuição do orbital $d$ ficasse abaixo de $10 \%$.

Observamos que nos orbitais moleculares mais próximos do HOMO, com contribuição do orbital $d$ acima de $10 \%$, aumenta sua contribuição de acordo vai aumentando o número de elétrons na camada $d$ até 6 elétrons. Porém, a partir de 7 elétrons na camada $d$, sua contribuição vai diminuindo gradativamente, como pode ser visto na Tabela 3.4.

Para o caso dos orbitais moleculares desocupados, a Ftc-Fe é a molécula que tem o orbital molecular desocupado mais afastado da fronteira. Com uma contribuição de 50\%, o LUMO+11 é o orbital mais próximo do LUMO, com contribuições $d$ acima de $10 \%$, tendo uma energia $\Delta_{L U M O}$ de $2,61 \mathrm{eV}$.

Concluímos que as maiores contribuições para os orbitais HOMO-1, aconteceram para as Ftcs de V e de Fe com $63 \%$ e 65\%, respectivamente. Porém, os menores gaps de energia entre HOMO e HOMO-1, ocorreram nas Ftcs de Fe e de Co com energias de 0,48 eV e 0,60 eV, respectivamente. Não foram vistas as contribuições para os orbitais LUMO+1, pois em nossas análises só estudamos as contribuições acima de 10\%, estes orbitais tiveram uma contribuição menor que este valor. Porém, o metal que teve uma maior contribuição do orbital $d$ acima de $10 \%$ e mais próximo ao LUMO foi o Ni com $40 \%$ localizado no orbital LUMO+2. 


\subsection{Energia de Excitação}

Nesta seção, o nosso objetivo é o de estudar as energias dos orbitais de fronteira e analisar as energias de excitação mais baixas, ou seja, na região do ultra-violeta-visível (UV-VIS). Este estudo é importante para a análise das propriedades eletrônicas e ópticas de eventuais dispositivos que utilizam-se destes compostos como materiais ativos.

O pesquisador Kenichi Fukui e colaboradores [44], mostraram que os orbitais moleculares são responsáveis na interpretação das reações químicas. Estudando a reatividade de compostos aromáticos, perceberam que analisando a densidade eletrônica em cada átomo dos orbitais de fronteira (ao invés de interpretar apenas as energias ou análise populacional), que o HOMO é de grande importância para a reatividade desses compostos $[45]$.

Em isolantes, o gap é muito grande e os elétrons não conseguem saltar da banda de valência para a banda de condução. Normalmente, a energia $E_{g}$ é maior que $3 \mathrm{eV}$. Nos semicondutores, o gap não é suficientemente grande, e alguns elétrons podem passar para a banda de condução através da ativação térmica ou sob a ação de um campo elétrico. Geralmente, a energia $E_{g}$ é menor que $3 \mathrm{eV}$. Já para os condutores, não existe este gap, e os elétrons podem transitar livremente entre as bandas de valência e condutividade.

Em moléculas orgânicas, a $E_{g}$ pode variar entre 1,5 eV e 6 eV. Quando acontece uma transição entre estes orbitais, tem seu espectro de absorção nas regiões UV-VIS. Em sistemas $\pi$-conjugados, como as Ftcs, o valor da $E_{g}$, é responsável pelas propriedades ópticas e eletrônicas das moléculas.

Com uma energia $\mathrm{E}_{g}$ de $2,15 \mathrm{eV}$, a $\mathrm{Ftc}-\mathrm{H}_{2}$ é nossa referência na análise da influência que o metal exerce sobre a $\mathrm{E}_{g}$ das MFtcs. Observamos que as $\mathrm{E}_{g}$ são muito próximas da nossa referência. No entanto, uma diferença de 0,29 eV é observada na Ftc-Li

em relação a Ftc- $\mathrm{H}_{2}$. É vista uma maior diferença na Ftc-Si, com uma $\mathrm{E}_{g}$ de 1,23 eV. Já para os demais casos, a $\mathrm{E}_{g}$ é pouco mais de $2 \mathrm{eV}$, como podemos observar pela Figura 3.16, estando esta energia de acordo com a literatura [19]. 


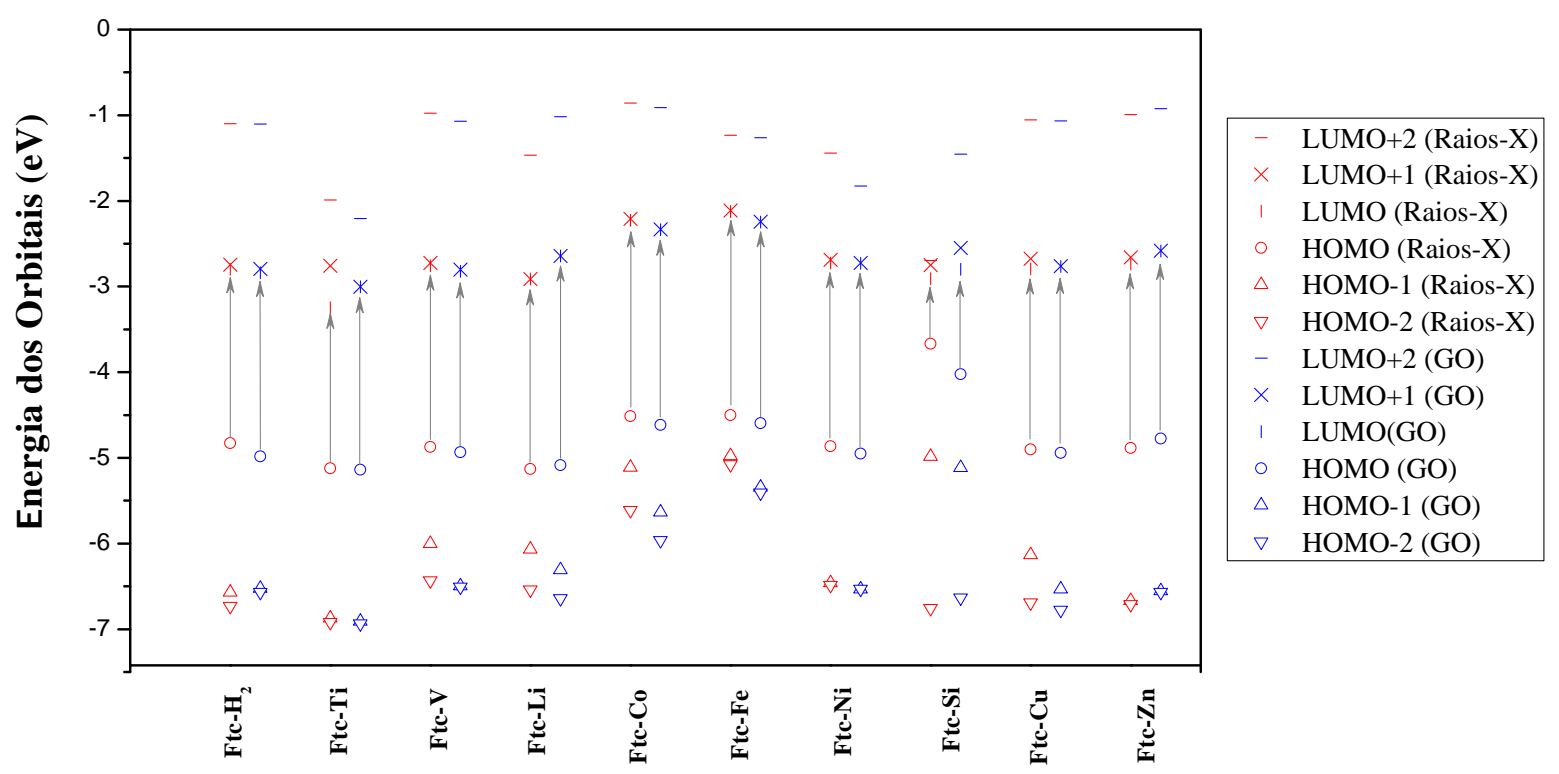

Figura 3.16: Energia dos Orbitais HOMO, HOMO-1, HOMO-2 e LUMO, LUMO+1, LUMO+2 para Raios-X e geometria otimizada.

\subsection{Espectroscopia UV-VIS}

A espectroscopia eletrônica, refere-se a absorção na região UV-VIS. Compreende a radiação eletromagnética que varia de 200 a $780 \mathrm{~nm}$. Quando átomos e moléculas estando em seu nível de energia mais baixo (ou seja, em estado fundamental), são atingidos por um feixe de luz, podem ocorrer transições eletrônicas devido a absorção de energia e eles passam a ficar em um estado de energia maior, chamado de estado excitado.

O processo de absorção de energia é específico para cada estrutura eletrônica de cada molécula. Assim, a espectroscopia de absorção na região UV-VIS pode caracterizar diversas substâncias orgânicas e inorgânicas. A energia envolvida no processo de emissão do UV-VIS, não é suficiente para promover elétrons mais internos ou próximos do núcleo. Estas transições eletrônicas, acontecem com os elétrons de ligação, onde um elétron é excitado e promovido do orbital HOMO para o orbital LUMO, decorrente da energia absorvida por este elétron.

As transições eletrônicas que ocorrem nos orbitais moleculares, dependem 
também da combinação linear dos orbitais atômicos. Por exemplo, tomemos o hidrogênio $\left(\mathrm{H}_{2}\right)$, representando cada átomo como $a$ e $b$. Temos que a combinação linear dos dois átomos de hidrogênio é dada da seguinte forma:

$$
\begin{aligned}
\Psi(\sigma) & =\left(\frac{1}{\sqrt{2}}\right)\left[c_{a} \Psi\left(1 s_{a}\right)+c_{b} \Psi\left(1 s_{b}\right)\right] \\
\Psi\left(\sigma^{*}\right) & =\left(\frac{1}{\sqrt{2}}\right)\left[c_{a} \Psi\left(1 s_{a}\right)-c_{b} \Psi\left(1 s_{b}\right)\right] .
\end{aligned}
$$

Onde 2 é o fator de normalização necessário para que a probabilidade de se encontrar o elétron em todo espaço, seja igual a 1 . Os coeficientes $c_{a}$ e $c_{b}$ são ajustáveis.

Na equação 4.2, $\sigma$ é o orbital molecular formado pela soma dos dois orbitais atômicos. Há uma maior concentração de elétrons entre os núcleos e uma energia menor que a dos orbitais atômicos que o originaram. Este é chamado de orbital molecular ligante. E na equação $4.3, \sigma^{*}$ é a diferença entre dois orbitais atômicos, tendo uma energia maior que a dos orbitais atômicos que o originaram, e é chamado de orbital molecular antiligante.

Ideia semelhante acontece para os orbitais $p$, onde a soma dos orbitais atômicos formam os orbitais moleculares ligantes e a diferença entre os orbitais moleculares, originam os orbitais moleculares antiligantes. Porém, os orbitais $p$ são formados pelos pares de orbitais $p_{x}, p_{y}$ e $p_{z}$ e devem ser tratados separadamente.

Os orbitais moleculares ligantes e antiligantes formados pelo par orbital $p_{z}$, tem a mesma simetria dos orbitais moleculares formados pelos orbitais $s$, e portanto a mesma representação $\sigma$ e $\sigma^{*}$, respectivamente. Já a combinação linear dos pares $p_{x}$ e $p_{y}$, formam os orbitais ligantes $\pi$ e os orbitais antiligantes $\pi^{*}$. Também, temos os orbitais moleculares não-ligantes (orbitais $n$ ), com energia praticamente igual à dos orbitais atômicos inicias, que podem ser promovidos tanto para o orbital $\sigma^{*}$ como para o orbital $\pi^{*}$ de mais alta energia.

Os possíveis tipos de transições eletrônicas que podem ocorrer em materiais orgânicos, respeitam alguns critérios, e estão representados na Figura 3.17. Apesar, de um orbital não-ligante ter energia maior que a dos orbitais ligantes e menores que dos antiligantes, é possível que em casos como o de moléculas que tem um alto grau de conjugação, possa ter energia do orbital $\pi$ maior que o orbital $n$. Sendo necessário, uma menor energia para a transição $\pi \rightarrow \pi^{*}$ e a banda de absorção correspondente a esta transição acontecerá em um comprimento de onda maior que a transição $n \rightarrow \pi^{*}$. 


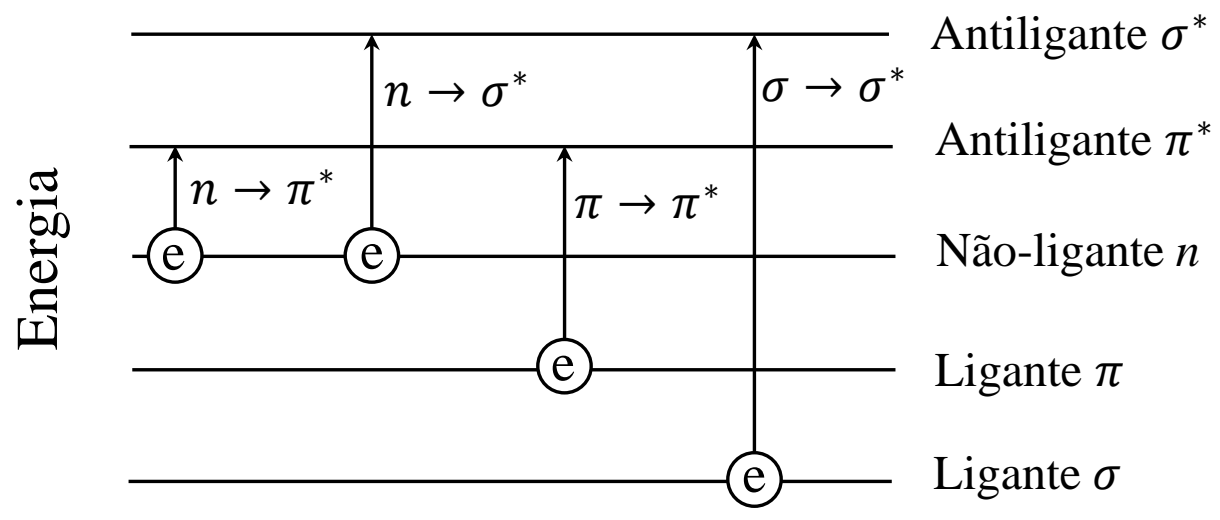

Figura 3.17: Possíveis tipos de transições eletrônicas permitidos.

A substituição dos átomos centrais de hidrogênio das Ftcs por alguns metais levam a mudanças no espectro de absorção desta molécula. Em alguns casos, aparecem novos picos de absorção, enquanto que em outros, alguns destes picos foram aniquilados.

Uma característica fundamental das Ftcs é seu espectro de absorção. Os 18 elétrons $\pi$ do anel macrocíclico favorecem uma alta densidade eletrônica, onde se pode observar uma maior intensidade de absorção, chamadas bandas Q, na região entre 550 e $800 \mathrm{~nm}$, e surge devido a transição $\pi-\pi^{*}\left(\mathrm{a}_{1 u} \rightarrow \mathrm{e}_{g}\right)$, ver Figura 3.18. Essa banda de baixa energia é responsável pela intensa cor azul das Ftcs.

Transições menos intensas e mais energéticas estão na região entre 200 e 400 nm, chamadas bandas B ou Soret, originadas de duas transições que ocorrem entre os níveis $\mathrm{b}_{2 u} \rightarrow \mathrm{e}_{g}$, chamada $\mathrm{B}_{1}$ e outra de $\mathrm{a}_{2 u} \rightarrow \mathrm{e}_{g}$ denominada $\mathrm{B}_{2}$, são de grande importância para as Ftcs. Na Figura 3.18 é mostrado o esquema dos níveis e transições de energia eletrônica das MFtcs.

Nas Tabelas 3.5 a 3.14, mostramos os primeiros cinco estados excitados, suas energias, comprimentos de onda máximo, a força de oscilador (F.O.), identificando os orbitais de maior contribuição para cada estado. Uma tabela mais completa contendo um resumo dos estados de maior contribuição das bandas de absorção está disponível no Apêndice D.

Analisando os 5 primeiros estados excitados das Ftcs, podemos observar que houve um deslocamento das bandas de absorção das MFtcs, se comparada com a Ftc- $\mathrm{H}_{2}$, visto nas Figuras de 3.19 a 3.28 . 


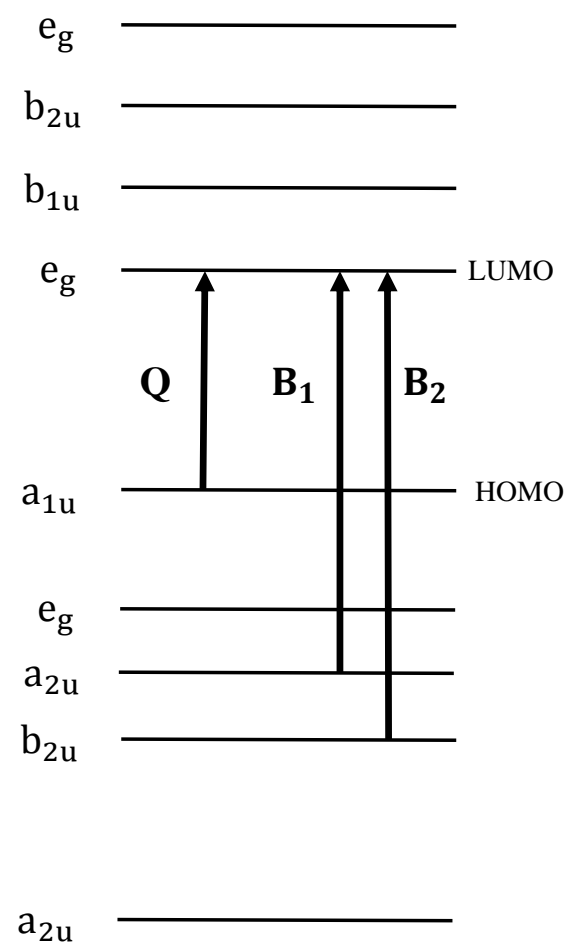

Figura 3.18: A banda Q corresponde a transição $\left(\mathrm{a}_{1 u} \rightarrow \mathbf{e}_{g}\right)$, a banda $\mathrm{B}_{1}$ corresponde a transição $\left(\mathbf{a}_{2 u} \rightarrow \mathbf{e}_{g}\right)$ e a banda $\mathbf{B}_{2}$ corresponde a transição $\left(\mathbf{b}_{2 u} \rightarrow\right.$ $\left.\mathbf{e}_{g}\right)$.

Para o primeiro estado excitado, observamos que a presença dos metais nas Ftcs provocam um deslocamento da banda de absorção. Em alguns casos, para uma região de maior comprimento de onda, como na Ftc de Ti, e outros para uma região de menor comprimento de onda, como nas Ftcs de Fe, Ni e Zn. Percebemos, também, que a presença do metal, modifica significativamente a F.O. da molécula, fazendo com que a presença do pico de absorção mostrado na $\mathrm{Ftc}^{-\mathrm{H}_{2}}$ seja drasticamente reduzido, como no caso das Ftcs de V, Li, Co, Si e Cu.

\subsubsection{Ftc- $\mathrm{H}_{2}$}

$\mathrm{Na}$ Ftc- $\mathrm{H}_{2}$, observamos três bandas de absorção (Figura 3.19), duas delas menos intensas e mais energéticas, com comprimento de onda de $338 \mathrm{~nm}$ e $404 \mathrm{~nm}$ e energias de $3.66 \mathrm{eV}$ e $3.07 \mathrm{eV}$, respectivamente. São as chamadas banda B ou Soret. A terceira banda (banda Q), encontra-se na região entre $550 \mathrm{~nm}$ e $700 \mathrm{~nm}$, com pico de 594 


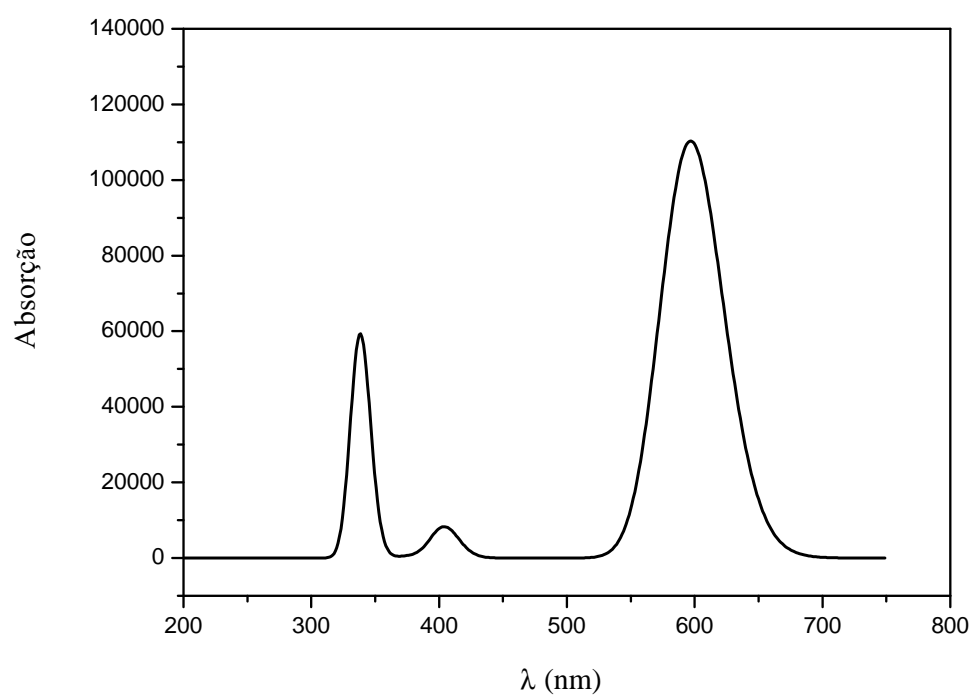

Figura 3.19: Espectro de absorção da Ftc-H $\mathrm{H}_{2}$.

nm e energia de $2.09 \mathrm{eV}$. Esta banda é responsável pela intensa cor azul da Ftc.

Na Tabela 3.5, observamos que a banda Q é decorrente das transições ocorridas nos estados excitados 1 e 2. No primeiro estado, a principal contribuição é decorrente da transição do HOMO para LUMO+1. Já no segundo estado, a transição do HOMO para LUMO, possui a transição de maior contribuição.

\begin{tabular}{|c|c|c|c|c|}
\hline \multicolumn{5}{|c|}{ Ftc-H $_{2}$} \\
\hline \hline Energia $(\mathrm{eV})$ & $\lambda_{\text {máx }}(\mathrm{nm})$ & F.O. & Contribuição & $\mathrm{N}^{\circ}$ de Estado \\
\hline 2,07 & 600 & 0,39 & $\mathrm{H} \rightarrow \mathrm{L}+1(0,67612)$ & 1 \\
2,09 & 594 & 0,44 & $\mathrm{H} \rightarrow \mathrm{L}(0,68913)$ & 2 \\
3,07 & 404 & 0,06 & $\mathrm{H}-1 \rightarrow \mathrm{L}(0,67332)$ & 3 \\
3,08 & 403 & 0,00 & $\mathrm{H}-2 \rightarrow \mathrm{L}(0,70185)$ & 4 \\
3,29 & 377 & 0,00 & $\mathrm{H}-1 \rightarrow \mathrm{L}+1(0,67083)$ & 5 \\
\hline
\end{tabular}

Tabela 3.5: Descrição dos Estados Excitados da Ftc-H . $_{2}$

A banda localizada entre $370 \mathrm{~nm}$ e $430 \mathrm{~nm}$, tem sua maior contribuição na transição do HOMO-1 para LUMO, ocorrida no terceiro estado excitado. Já no quarto e quinto estados, é visto uma F.O. nula e, portanto, não tem contribuições na formação do 
espectro de absorção da Ftc-H .

\subsubsection{Ftc-Ti}

Para a Ftc-Ti, observamos que houve um deslocamento da banda Q, sendo o comprimento de onda de $613 \mathrm{~nm}$, com energia de $2.02 \mathrm{eV}$ (Figura 3.20). Já para a faixa de $300 \mathrm{~nm}$ a $400 \mathrm{~nm}$, é apresentada apenas uma banda de absorção, com pico de 345 nm e energia de 3.59 eV. Vimos também, que o maior pico de absorção é apresentado no primeiro estado excitado. Enquanto que na Ftc- $\mathrm{H}_{2}$, isso só acontece no segundo estado excitado.

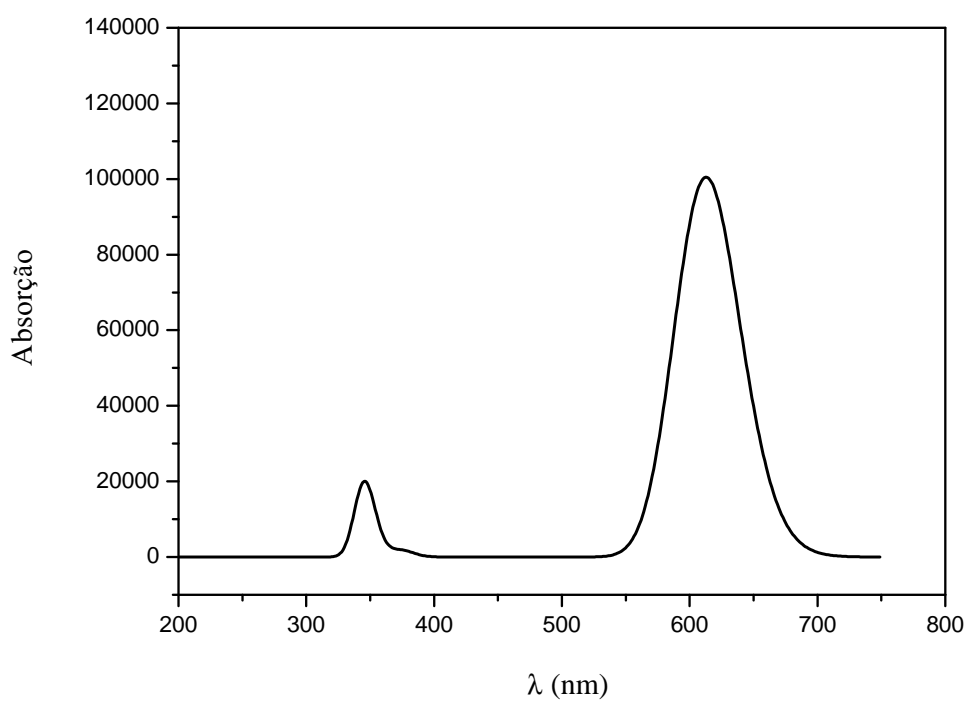

Figura 3.20: Espectro de absorção da Ftc-Ti.

Na Tabela 3.6, o deslocamento da banda Q, para a região de $613 \mathrm{~nm}$ é decorrente da transição do HOMO para o LUMO no primeiro estado excitado e da transição do HOMO para o LUMO+1, no segundo estado. Outro efeito provocado pelo Ti é o fato da F.O., presente na Ftc- $\mathrm{H}_{2}$, desaparecer para o terceiro estado de excitação. Já para os estados 4 e 5, não observamos nenhuma mudança, devido a F.O. ser nula. 


\begin{tabular}{|c|c|c|c|c|}
\hline \multicolumn{5}{|c|}{ Ftc-Ti } \\
\hline \hline Energia (eV) & $\lambda_{\text {máx }(\mathrm{nm})}$ & F.O. & Contribuição & No de Estado \\
\hline 2,02 & 613 & 0,37 & $\mathrm{H} \rightarrow \mathrm{L}(0,68883)$ & 1 \\
2,02 & 613 & 0,37 & $\mathrm{H} \rightarrow \mathrm{L}+1(0,68882)$ & 2 \\
2,16 & 575 & 0,00 & $\mathrm{H} \rightarrow \mathrm{L}+1(0,70594)$ & 3 \\
3,28 & 378 & 0,00 & $\mathrm{H}-2 \rightarrow \mathrm{L}(0,40841)$ & 4 \\
3,28 & 378 & 0,00 & $\mathrm{H}-3 \rightarrow \mathrm{L}+1(0,40625)$ & 5 \\
\hline
\end{tabular}

Tabela 3.6: Descrição dos Estados Excitados da Ftc-Ti.

\subsubsection{Ftc-V}

Enquanto que a Ftc-H $\mathrm{H}_{2}$ apresenta três bandas de absorção, a Ftc-V (Figura 3.21) apresenta apenas uma banda de absorção, que aparece deslocada para um comprimento de onda ainda maior, com $621 \mathrm{~nm}$ e uma energia de $2.00 \mathrm{eV}$. Este pico só aparece no quarto estado excitado com uma F.O. de 0.43 , sendo que uma banda B, como aparece na Ftc- $\mathrm{H}_{2}$, não foi observada.

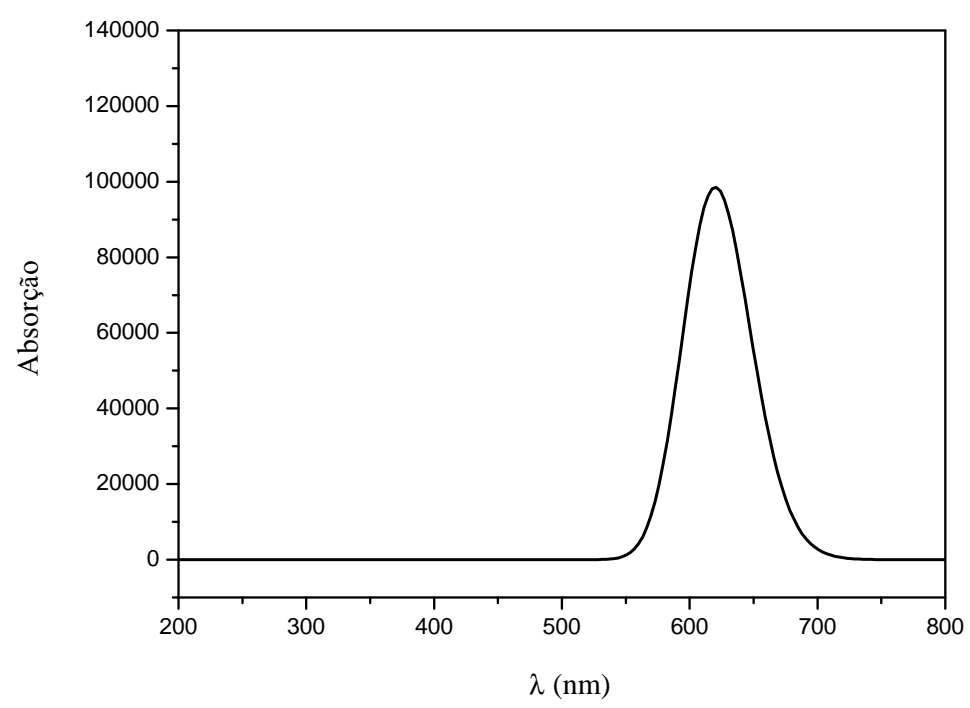

Figura 3.21: Espectro de absorção da Ftc-V.

Da Tabela 3.7, vemos que o metal de transição V na estrutura da Ftc, provoca o desaparecimento dos picos de absorção para os estados 1 e 2, devido a sua F.O. ser nula. 
Além disso, ocasiona o deslocamento da banda de $404 \mathrm{~nm}$ na Ftc- $\mathrm{H}_{2}$, para $622 \mathrm{~nm}$ no terceiro estado excitado. No quarto estado, observamos que existe uma contribuição na formação da banda de absorção na região de 621 nm. Já no quinto estado, não observamos nenhuma mudança significativa.

\begin{tabular}{|c|c|c|c|c|}
\hline \multicolumn{5}{|c|}{ Ftc-V } \\
\hline Energia $(\mathrm{eV})$ & $\lambda_{\text {máx }}(\mathrm{nm})$ & F.O. & Contribuição & $\mathrm{N}^{\circ}$ de Estado \\
\hline 1,06 & 1170 & 0,00 & $\begin{array}{c}\mathrm{H} \rightarrow \mathrm{L}(-0,71126) \\
\mathrm{H} \rightarrow \mathrm{L}(0,71424)\end{array}$ & 1 \\
\hline 1,08 & 1149 & 0,00 & $\begin{array}{l}\mathrm{H} \rightarrow \mathrm{L}+1(-0,71095) \\
\mathrm{H} \rightarrow \mathrm{L}+1(0,71380)\end{array}$ & 2 \\
\hline 1,99 & 622 & 0,35 & $\begin{array}{l}\mathrm{H} \rightarrow \mathrm{L}(0,69263) \\
\mathrm{H} \rightarrow \mathrm{L}(0,68938)\end{array}$ & 3 \\
\hline 2,00 & 621 & 0,43 & $\begin{array}{l}\mathrm{H} \rightarrow \mathrm{L}+1(0,69179) \\
\mathrm{H} \rightarrow \mathrm{L}+1(0,68865)\end{array}$ & 4 \\
\hline 2,56 & 485 & 0,00 & $\begin{array}{l}\mathrm{H}-3 \rightarrow \mathrm{L}+1(0,62944) \\
\mathrm{H}-2 \rightarrow \mathrm{L}+5(-0,61887)\end{array}$ & 5 \\
\hline
\end{tabular}

Tabela 3.7: Descrição dos Estados Excitados da Ftc-V.

\subsubsection{Ftc-Li}

A Ftc-Li, mostra duas bandas de absorção, sendo que a primeira fica entre $420 \mathrm{~nm}$ e $550 \mathrm{~nm}$, e a segunda varia de $550 \mathrm{~nm}$ a $800 \mathrm{~nm}$, ver Figura 3.22 . Foi a única que apresentou quatro picos de absorção, sendo triplamente degenerada para os estados 10-11, 2-3 e 5-6. O primeiro pico tem um comprimento de onda de $452 \mathrm{~nm}$ e energia de $2.45 \mathrm{eV}$ e o segundo pico com comprimento de onda de $452 \mathrm{~nm}$ e energia de $2.45 \mathrm{eV}$. Já a segunda banda é formada por dois picos, o primeiro tem comprimento de onda de 607 $\mathrm{nm}$ e energia correspondente de $2.05 \mathrm{eV}$. O segundo pico deslocado tem comprimento de onda de $706 \mathrm{~nm}$, com energia igual a $1.76 \mathrm{eV}$.

Na Tabela 3.8, observamos que quando a Ftc- $\mathrm{H}_{2}$ tem seus dois átomos de $\mathrm{H}$ centrais substituídos pelo átomo de Li, o pico de absorção desaparece para o primeiro 


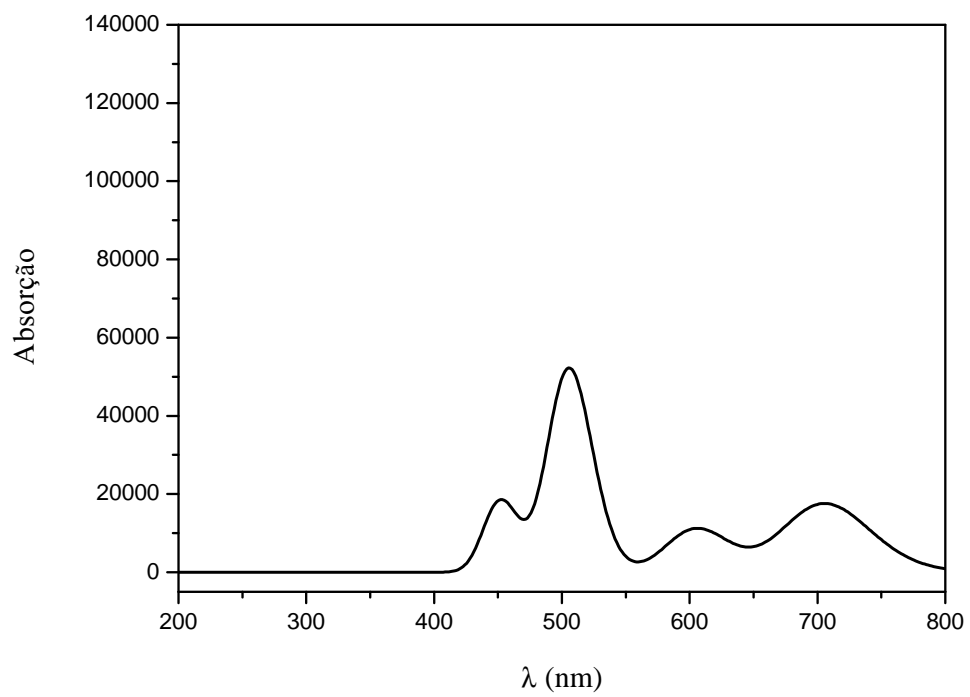

Figura 3.22: Espectro de absorção da Ftc-Li.

estado excitado, devido sua F.O. ser nula. Já no segundo e terceiro estados, observamos que mesmo com uma F.O. menor que a Ftc- $\mathrm{H}_{2}$, provoca um deslocamento da banda para 706 nm. No quarto estado, não é observado pico de absorção devido a F.O. ser nula. Porém, no quinto estado, é visto um pico de absorção na região de $606 \mathrm{~nm}$, sendo a transição do HOMO-2 para LUMO, o responsável por este pico.

\begin{tabular}{|c|c|c|c|c|}
\hline \multicolumn{5}{|c|}{ Ftc-Li } \\
\hline \hline Energia (eV) & $\lambda_{\text {máx }}(\mathrm{nm})$ & F.O. & Contribuição & $\mathrm{N}^{\circ}$ de Estado \\
\hline 1,75 & 710 & 0,00 & $\mathrm{H} \rightarrow \mathrm{L}(0,99316)$ & 1 \\
1,76 & 706 & 0,07 & $\mathrm{H} \rightarrow \mathrm{L}(-0,56737)$ & 2 \\
& & & $\mathrm{H} \rightarrow \mathrm{L}+1(0,67054)$ & \\
1,76 & 706 & 0,07 & $\mathrm{H} \rightarrow \mathrm{L}(0,67054)$ & 3 \\
& & & $\mathrm{H} \rightarrow \mathrm{L}+1(0,56737)$ & \\
1,96 & 631 & 0,00 & $\mathrm{H}-1 \rightarrow \mathrm{L}(0,96586)$ & 4 \\
2,05 & 606 & 0,04 & $\mathrm{H}-2 \rightarrow \mathrm{L}(0,68280)$ & 5 \\
\hline
\end{tabular}

Tabela 3.8: Descrição dos Estados Excitados da Ftc-Li. 


\subsubsection{Ftc-Fe}

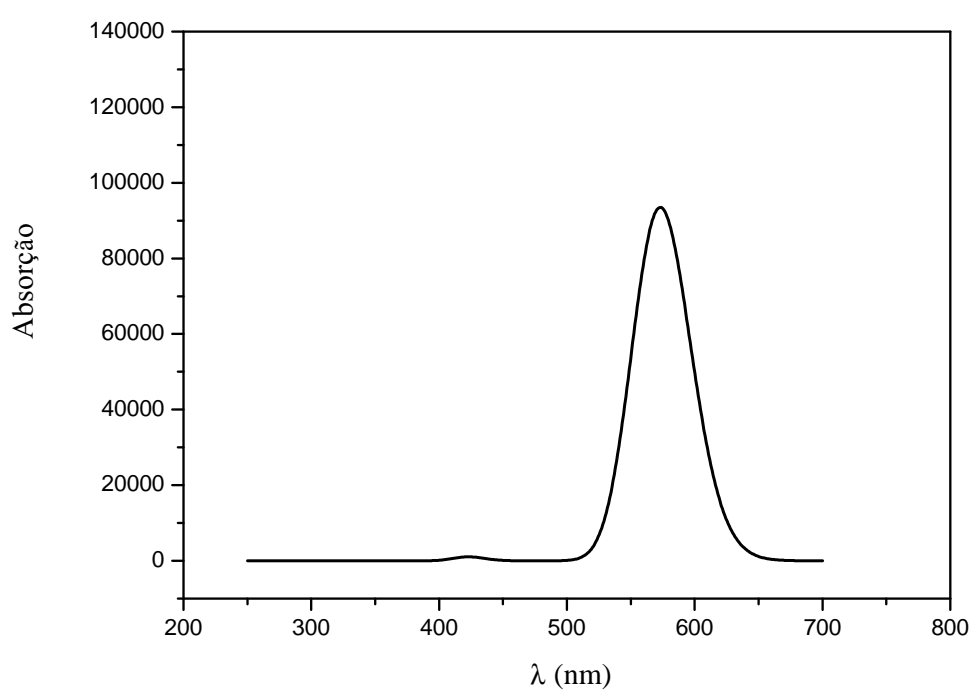

Figura 3.23: Espectro de absorção da Ftc-Fe.

Na Ftc-Fe, observamos que há uma banda de absorção na região de 520 a 650 nm, ver Figura 3.23. Esta banda é formada pelo primeiro e segundo estados excitados, sendo que o primeiro estado contribui com um comprimento de onda de $577 \mathrm{~nm}$, energia de 2.15 eV e sua F.O. é de 0.33. Já o segundo estado, tem sua contribuição na formação da banda com um comprimento de onda de $569 \mathrm{~nm}$, energia de 2.18 eV e F.O. igual a 0.38. É possível ver, também, uma banda muito pequena na região de $420 \mathrm{~nm}$, mas com F.O. de apenas 0.01, decorrente do estado 13.

\begin{tabular}{|c|c|c|c|c|}
\hline \multicolumn{5}{|c|}{ Ftc-Fe } \\
\hline \hline Energia (eV) & $\lambda_{\text {máx }}(\mathrm{nm})$ & F.O. & Contribuição & $\mathrm{N}^{\circ}$ de Estado \\
\hline 2,15 & 578 & 0,33 & $\mathrm{H} \rightarrow \mathrm{L}+1(0,68496)$ & 1 \\
2,18 & 569 & 0,38 & $\mathrm{H} \rightarrow \mathrm{L}(0,68454)$ & 2 \\
2,18 & 569 & 0,00 & $\mathrm{H}-1 \rightarrow \mathrm{L}(0,56373)$ & 3 \\
2,21 & 560 & 0,00 & $\mathrm{H}-1 \rightarrow \mathrm{L}+1(0,48979)$ & 4 \\
2,29 & 540 & 0,00 & $\mathrm{H}-2 \rightarrow \mathrm{L}+1(0,55901)$ & 5 \\
\hline
\end{tabular}

Tabela 3.9: Descrição dos Estados Excitados da Ftc-Fe. 
Na Tabela 3.9, podemos ver que a transição que acontece no primeiro estado excitado do $\mathrm{HOMO}$ para $\mathrm{LUMO}+1$, provoca um deslocamento da banda para a região de menor comprimento de onda, com pico de $578 \mathrm{~nm}$. Este deslocamento, também, acontece no segundo estado, com a transição do HOMO para o LUMO. Já no terceiro estado, acontece a aniquilação da banda $\mathrm{B}$ vista na $\mathrm{Ftc}-\mathrm{H}_{2}$, devido a F.O. ser nula após a transição HOMO-1 para LUMO. No quarto e quinto estados, nenhuma alteração foi vista no espectro de absorção.

\subsubsection{Ftc-Co}

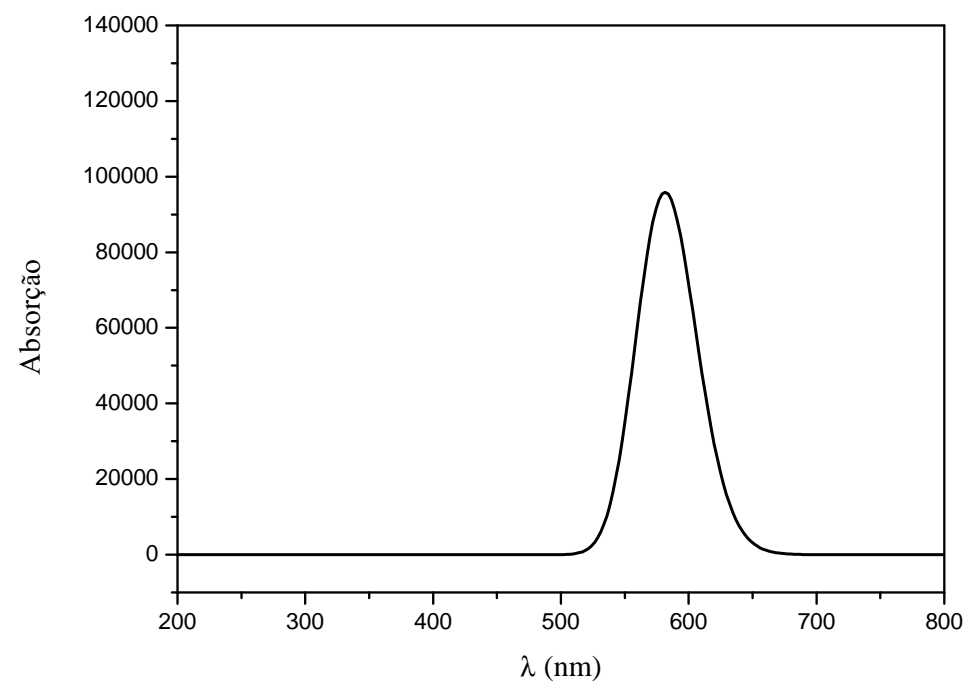

\section{Figura 3.24: Espectro de absorção da Ftc-Co.}

A Ftc-Co, possui uma única banda de absorção, formada por dois estados de excitação (9-10). Tendo o estado 9, comprimento de onda de $585 \mathrm{~nm}$ e energia $2.12 \mathrm{eV}$. Já o estado de excitação 10, contribui com um comprimento de onda de $578 \mathrm{~nm}$ e energia $2.14 \mathrm{eV}$. Uma diferença marcante entre a Ftc-Co e a Ftc- $\mathrm{H}_{2}$, é o fato de não aparecer a banda de maior energia na região entre 200 e $400 \mathrm{~nm}$ (Figura 3.24), característica da maioria das Ftcs.

Na Tabela 3.10, foi visto que o metal presente na Ftc, para os 5 primeiros estados excitados, interferiu na formação do espectro de absorção da molécula, aniquilando todos os picos visto na Ftc- $\mathrm{H}_{2}$. Com a F.O. nula nestes estados, não foi observado nenhum 


\begin{tabular}{|c|c|c|c|c|}
\hline \multicolumn{5}{|c|}{ Ftc-Co } \\
\hline \hline Energia (eV) & $\lambda_{\text {máx }}(\mathrm{nm})$ & F.O. & Contribuição & $\mathrm{N}^{\circ}$ de Estado \\
\hline 1,26 & 984 & 0,00 & $\mathrm{H} \rightarrow \mathrm{L}+1(0,68693)$ & 1 \\
& & & $\mathrm{H} \rightarrow \mathrm{L}(-0,68225)$ & \\
1,27 & 976 & 0,00 & $\mathrm{H} \rightarrow \mathrm{L}(0,68837)$ & 2 \\
& & & $\mathrm{H} \rightarrow \mathrm{L}+1(0,68055)$ & \\
1,48 & 836 & 0,00 & $\mathrm{H}-1 \rightarrow \mathrm{L}+12(0,57024)$ & 3 \\
1,49 & 832 & 0,00 & $\mathrm{H}-2 \rightarrow \mathrm{L}+12(0,56274)$ & 4 \\
1,71 & 726 & 0,00 & $\mathrm{H}-2 \rightarrow \mathrm{L}+11(-0,64281)$ & 5 \\
\hline
\end{tabular}

Tabela 3.10: Descrição dos Estados Excitados da Ftc-Co.

pico de absorção.

\subsubsection{Ftc-Ni}

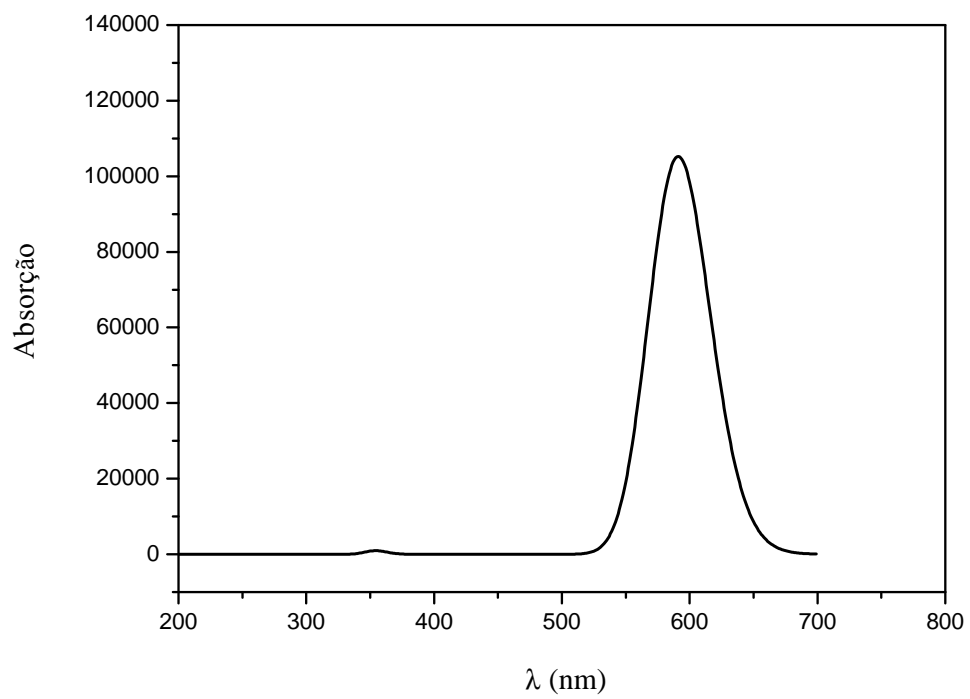

Figura 3.25: Espectro de absorção da Ftc-Ni.

Na Ftc-Ni, a banda B que aparece de forma sutil, se localiza na região próxima a $350 \mathrm{~nm}$, é formada pelos estados 14 e 15, quase degenerados, tendo comprimento de onda de $354 \mathrm{~nm}$ e energia de $3.50 \mathrm{eV}$. A F.O. responsável pelo pequeno pico do gráfico 
é de 0.0036. Na formação da banda Q, são os estados 1 e 2 que participam, sendo quase degenerados. Tem um comprimento de onda de $591 \mathrm{~nm}$, energia de $2.10 \mathrm{eV}$ e sua F.O. mede 0.39, caracterizando sua amplitude, ver Figura 3.25.

Na Tabela 3.11, podemos ver que a banda Q, identificada no primeiro estado excitado da $\mathrm{Ftc}-\mathrm{H}_{2}$, sofre um deslocamento para uma região de menor comprimento de onda, na presença do Ni, isto ocorre na transição HOMO para LUMO. Uma interferência que acontece causada pelo metal, é o desaparecimento das bandas existentes na Ftc- $\mathrm{H}_{2}$, geradas pelos estados 2 e 3. Já para o quarto e quinto estados, não vimos nenhuma alteração.

\begin{tabular}{|c|c|c|c|c|}
\hline \multicolumn{5}{|c|}{ Ftc-Ni } \\
\hline \hline Energia (eV) & $\lambda_{\text {máx }}(\mathrm{nm})$ & F.O. & Contribuição & $\mathrm{N}^{\circ}$ de Estado \\
\hline 2,10 & 591 & 0,39 & $\mathrm{H} \rightarrow \mathrm{L}(0,69173)$ & 1 \\
2,10 & 591 & 0,00 & $\mathrm{H} \rightarrow \mathrm{L}+1(0,69169)$ & 2 \\
2,31 & 537 & 0,00 & $\mathrm{H} \rightarrow \mathrm{L}+2(0,70596)$ & 3 \\
2,32 & 533 & 0,00 & $\mathrm{H}-8 \rightarrow \mathrm{L}+2(0,69997)$ & 4 \\
2,45 & 506 & 0,00 & $\mathrm{H}-1 \rightarrow \mathrm{L}+2(0,53903)$ & 5 \\
\hline
\end{tabular}

Tabela 3.11: Descrição dos Estados Excitados da Ftc-Ni.

\subsubsection{Ftc-Si}

Na Ftc-Si, observamos três bandas de absorção, estas são formadas por cinco excitações. A primeira banda na região de 340 a $400 \mathrm{~nm}$, é formada pelo estado 11, com um comprimento de onda de $390 \mathrm{~nm}$, energia de 3.18 eV e uma F.O. de apenas 0.02. Já o estado 14, possui um comprimento de onda de $361 \mathrm{~nm}$ e energia de $3.43 \mathrm{eV}$, sendo sua F.O. de 0.25. A segunda banda formada entre 440 e $530 \mathrm{~nm}$, é formada pelos estados 6 e 7 . O estado de excitação 6 tem um comprimento de onda de $482 \mathrm{~nm}$ e energia de $2.57 \mathrm{eV}$. O estado 7 apresenta uma F.O. de 0.68, com um comprimento de onda de $476 \mathrm{~nm}$ e energia igual a $2.60 \mathrm{eV}$. Já a terceira banda é formada pelo estado 5, com um comprimento de onda de $629 \mathrm{~nm}$ e energia de $1.97 \mathrm{eV}$, ver Figura 3.26.

Na Tabela 3.12, observamos que o átomo de Si provoca o desaparecimento das 


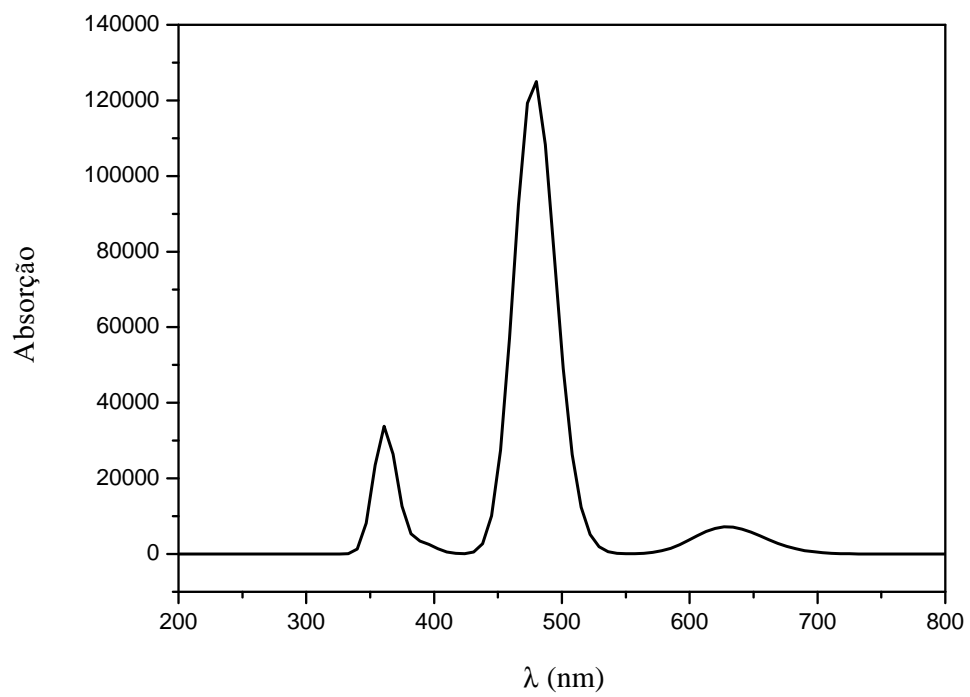

Figura 3.26: Espectro de absorção da Ftc-Si.

bandas de absorção existente na Ftc- $\mathrm{H}_{2}$, para os três primeiros estados de excitação, no quarto estado a F.O. também é nula e não aparece nenhum pico nesta região. Apenas no quinto estado excitado, observamos um pequeno pico de absorção, com uma F.O. de 0,05 na região de 629 nm. A transição deste estado ocorre entre o HOMO-1 e o LUMO.

\begin{tabular}{|c|c|c|c|c|}
\hline \multicolumn{5}{|c|}{ Ftc-Si } \\
\hline \hline Energia (eV) & $\lambda_{\text {máx }(\mathrm{nm})}$ & F.O. & Contribuição & $\mathrm{N}^{\circ}$ de Estado \\
\hline 0,59 & 2118 & 0,00 & $\mathrm{H} \rightarrow \mathrm{L}(0,70922)$ & 1 \\
0,74 & 1674 & 0,00 & $\mathrm{H} \rightarrow \mathrm{L}+1(0,70544)$ & 2 \\
1,74 & 713 & 0,00 & $\mathrm{H} \rightarrow \mathrm{L}+2(0,70604)$ & 3 \\
1,85 & 669 & 0,00 & $\mathrm{H}-1 \rightarrow \mathrm{L}+1(0,70517)$ & 4 \\
1,97 & 629 & 0,05 & $\mathrm{H}-1 \rightarrow \mathrm{L}(0,58188)$ & 5 \\
\hline
\end{tabular}

Tabela 3.12: Descrição dos Estados Excitados da Ftc-Si. 


\subsubsection{Ftc-Cu}

$\mathrm{Na} \mathrm{Ftc-Cu,} \mathrm{podemos} \mathrm{observar} \mathrm{que} \mathrm{aparece} \mathrm{apenas} \mathrm{uma} \mathrm{banda} \mathrm{de} \mathrm{absorção,}$ na região de 550 a 670 nm (Figura 3.27), gerada a partir do estado de excitação 4, com comprimento de onda de $596 \mathrm{~nm}$ e energia de $2.08 \mathrm{eV}$. Observamos que, apesar da Ftc-Cu ter esta banda muito parecida com a banda $\mathrm{Q}$ da $\mathrm{Ftc}_{-} \mathrm{H}_{2}$, elas se diferenciam pelo fato de não aparecer nenhuma outra banda de absorção na Ftc-Cu.

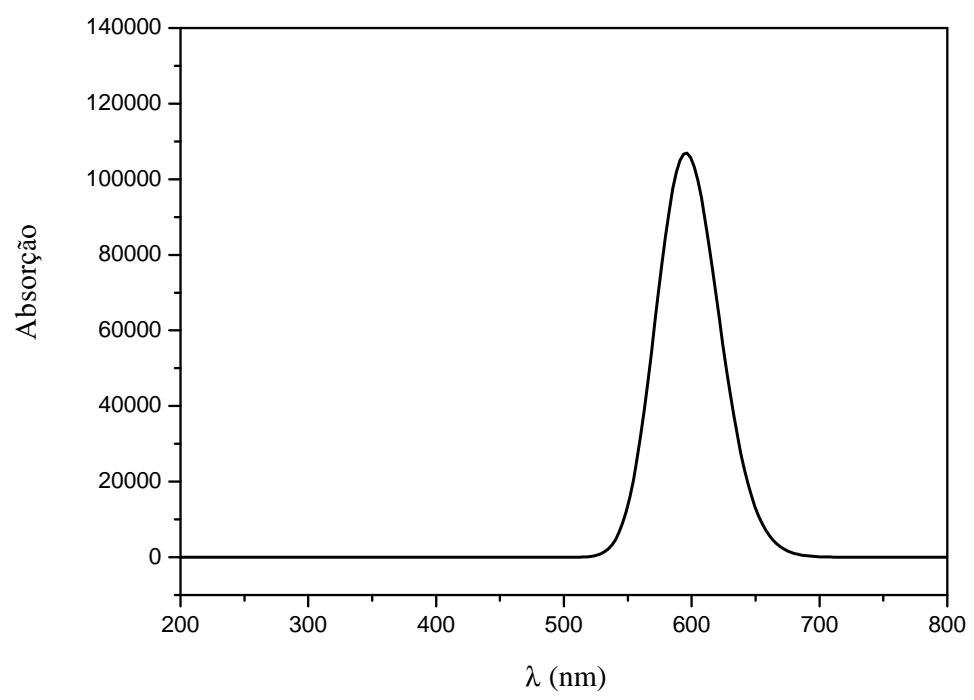

Figura 3.27: Espectro de absorção da Ftc-Cu.

Na Ftc-Cu, observamos que o metal destrói as bandas de absorção que aparecem na Ftc- $\mathrm{H}_{2}$, decorrentes dos estados excitados 1,2 e 3. Porém, vimos que aparece uma banda de absorção na região próxima de $600 \mathrm{~nm}$, com contribuições do quarto estado excitado, com transição alfa decorrente do HOMO para o LUMO, e da transição beta decorrente do HOMO para o LUMO. O quinto estado, também, contribui na formação desta banda, com transição alfa do HOMO para LUMO+1 e transição beta do HOMO para o LUMO+1. 


\begin{tabular}{|c|c|c|c|c|}
\hline \multicolumn{5}{|c|}{ Ftc-Cu } \\
\hline \hline Energia (eV) & $\lambda_{\text {máx }(\mathrm{nm})}$ & F.O. & Contribuição & $\mathrm{N}^{\circ}$ de Estado \\
\hline 1,14 & 1085 & 0,00 & $\mathrm{H} \rightarrow \mathrm{L}(0,72114)$ & 1 \\
1,14 & 1084 & 0,00 & $\mathrm{H} \rightarrow \mathrm{L}+1(0,72111)$ & 2 \\
& & & $\mathrm{H} \rightarrow \mathrm{L}+1(-0,70072)$ & \\
1,57 & 788 & 0,00 & $\mathrm{H} \rightarrow \mathrm{L}+2(0,99840)$ & 3 \\
2,08 & 596 & 0,40 & $\mathrm{H} \rightarrow \mathrm{L}(-0,67936)$ & 4 \\
& & & $\mathrm{H} \rightarrow \mathrm{L}(0,69902)$ & \\
2,08 & 595 & 0,40 & $\mathrm{H} \rightarrow \mathrm{L}+1(0,67929)$ & 5 \\
\hline \hline
\end{tabular}

Tabela 3.13: Descrição dos Estados Excitados da Ftc-Cu.

\subsubsection{Ftc-Zn}

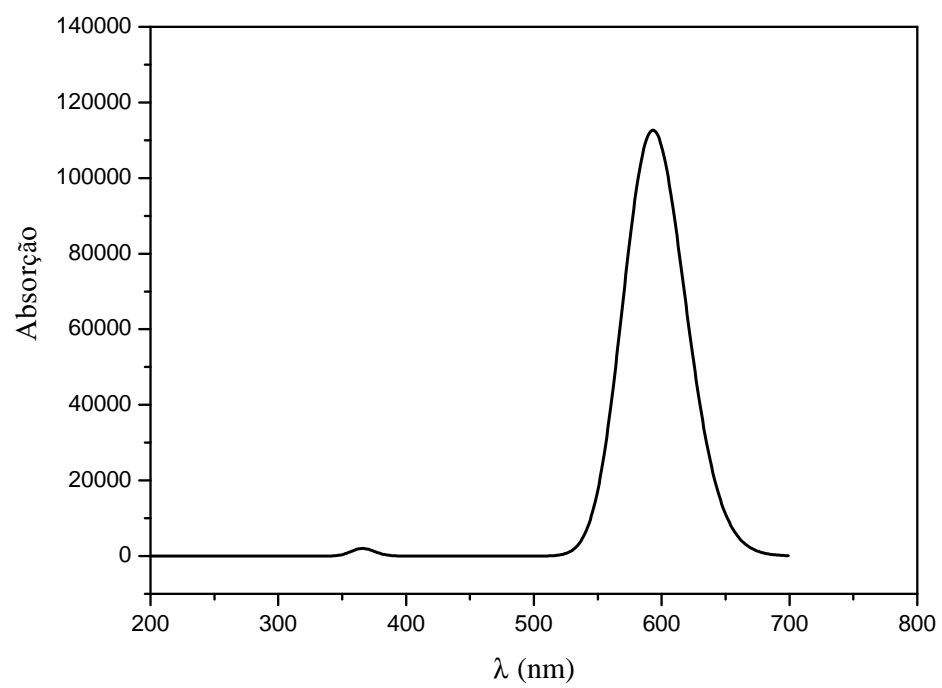

Figura 3.28: Espectro de absorção da Ftc-Zn.

Na Ftc-Zn, observamos duas bandas de absorção, sendo que, a primeira se encontra entre 340 e $390 \mathrm{~nm}$, ver Figura 3.28. Os principais estados envolvidos nesta banda de absorção são: estado 4, com um comprimento de onda de $367.73 \mathrm{~nm}$, energia com 3.37 eV e sua F.O. de 0.02; e o estado 5, com uma maior contribuição na largura 
da banda, com apenas uma F.O. de 0.01. Para a banda situada entre 540 e $680 \mathrm{~nm}$, os estados quase degenerados 1 e 2, são os envolvidos nesta formação, tendo um comprimento de onda de $594.10 \mathrm{~nm}$, energia de $2.09 \mathrm{eV}$ e F.O. de 0.41.

Na Ftc-Zn, observamos que para o primeiro estado excitado, ocorre um deslocamento da banda para uma região de menor comprimento de onda (ver Tabela 3.14). Já para o segundo estado excitado, vimos que o pico ficou no mesmo lugar. Porém, no terceiro estado, houve um deslocamento da banda de $404 \mathrm{~nm}$ para $369 \mathrm{~nm}$, mas com uma F.O. muito pequena. Nesta mesma região, temos a contribuição do quarto estado, gerado pela transição HOMO-1 para LUMO e do quinto estado, com a transição HOMO-3 para LUMO+1, ambos com uma pequena F.O.

\begin{tabular}{|c|c|c|c|c|}
\hline \multicolumn{5}{|c|}{ Ftc-Zn } \\
\hline \hline Energia (eV) & $\lambda_{\text {máx }}(\mathrm{nm})$ & F.O. & Contribuição & $\mathrm{N}^{\circ}$ de Estado \\
\hline 2,08 & 595 & 0,42 & $\mathrm{H} \rightarrow \mathrm{L}(0,68735)$ & 1 \\
2,08 & 595 & 0,42 & $\mathrm{H} \rightarrow \mathrm{L}+1(0,68735)$ & 2 \\
3,37 & 368 & 0,00 & $\mathrm{H}-2 \rightarrow \mathrm{L}(0,48637)$ & 3 \\
3,37 & 368 & 0,00 & $\mathrm{H}-3 \rightarrow \mathrm{L}+1(0,47143)$ & 4 \\
3,38 & 367 & 0,01 & $\mathrm{H}-1 \rightarrow \mathrm{L}(0,67561)$ & 5 \\
\hline
\end{tabular}

Tabela 3.14: Descrição dos Estados Excitados da Ftc-Zn.

Na Figura 3.29, mostramos o gráfico de absorção de todas as Ftcs juntas, para termos uma visão mais clara do deslocamento das bandas, que ocorre com a presença dos metais. Como foi dito anteriormente, a cor das Ftcs que observamos, está diretamente relacionada com o deslocamento das bandas de absorção destas moléculas.

A banda Q do espectro de absorção é a responsável pela intensa cor azul da Ftc- $\mathrm{H}_{2}$. Porém, com a substituição dos dois átomos de hidrogênio da gaiola da $\mathrm{Ftc}-\mathrm{H}_{2}$, por determinados átomos, leva ao deslocamento desta banda, para comprimentos de ondas maiores ou menores, a depender da substituição feita.

Se compararmos o pico de absorção da Ftc-H ${ }_{2}$, com a Ftc-Ti (com pico de absorção em $613 \mathrm{~nm}$ ), veremos que o deslocamento de $19 \mathrm{~nm}$ da banda, não é suficiente para que haja mudanças significativas na absorção da luz, que caracteriza a sua intensa 


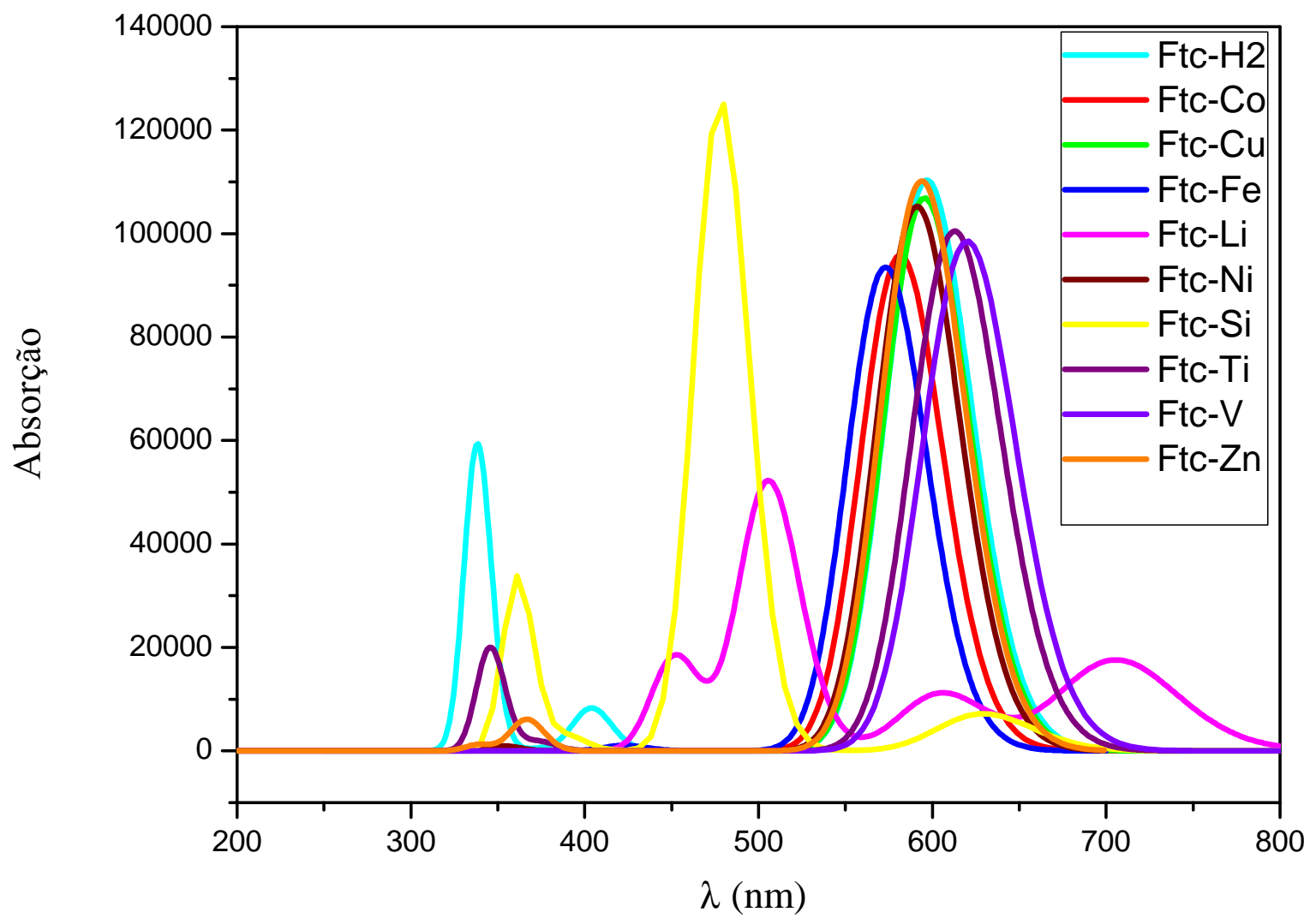

Figura 3.29: Espectro de absorção das MFtcs e da Ftc-H $\mathrm{H}_{2}$.

cor azul.

Na Ftc-V, observamos que houve um deslocamento da banda Q, para uma região de maior comprimento de onda, centrada em $621 \mathrm{~nm}$. Com este deslocamento, a intensa cor azul observada na Ftc- $\mathrm{H}_{2}$, passa a ser vista com uma cor azul esverdeada.

Dentre as bandas na região do visível, que aparece no espectro de absorção da Ftc-Li, uma se destaca com pico de 506 nm. Esta banda de absorção, deslocada para uma região de menor comprimento de onda, é responsável pela cor púrpura característica desta Ftc.

O deslocamento da banda de absorção da Ftc-Fe, para uma região de menor comprimento de onda, com um pico de absorção em $570 \mathrm{~nm}$, interfere diretamente na cor violeta azulada desta Ftc. Este deslocamento, comparado com a Ftc- $\mathrm{H}_{2}$ chega a uma diferença de $24 \mathrm{~nm}$. 
Com uma cor azul-violeta, a Ftc-Co tem um deslocamento da banda de absorção para $578 \mathrm{~nm}$. Este deslocamento, se assemelha bastante com a Ftc-Fe, tendo um deslocamento considerável, se comparado com a Ftc- $\mathrm{H}_{2}$.

Devido a presença do átomo de Ni na estrutura da Ftc-Ni, observamos o deslocamento da banda de absorção para uma região de menor comprimento de onda, centrada em $591 \mathrm{~nm}$. Como o deslocamento é pequeno, permanece na região que caracteriza sua cor azul.

Apesar do Silício não ser um metal, ocorre um deslocamento da banda de absorção para uma região de menor comprimento de onda centrada em $477 \mathrm{~nm}$. Com isso, a Ftc-Si é vista na cor vermelha, ao invés da típica cor azul das Ftcs.

$\mathrm{Na}$ Ftc-Cu, o deslocamento da banda de absorção ocorre de forma moderada para uma região de maior comprimento de onda, centrada em $596 \mathrm{~nm}$. Por ser pequeno o deslocamento da banda, a cor azul continua sendo uma característica da Ftc-Cu.

Na Ftc-Zn, observamos que praticamente não houve deslocamento na banda de absorção responsável pela cor da Ftc, sendo esta banda localizada na região centrada com um pico de absorção de $594 \mathrm{~nm}$. Valor igual ao da Ftc- $\mathrm{H}_{2}$, se desconsiderar os valores de aproximação, com isto, vimos que o azul é a cor definida da Ftc-Zn.

Na Figura 3.29, podemos ver que na região dos $600 \mathrm{~nm}$ as Ftcs de Zn, Cu e $\mathrm{Ni}$ praticamente permaneceram inalteradas em relação a $\mathrm{Ftc}-\mathrm{H}_{2}$, tanto para a banda de absorção quanto a intensidade do pico. Já para as Ftcs de Co, Fe, Ti e V houve um pequeno deslocamento da banda de absorção comparado a Ftc- $\mathrm{H}_{2}$, como também uma pequena diminuição do pico de absorção. Já para as Ftcs de Si e Li não foi visto a mesma intensidade do pico de absorção em relação a $\mathrm{Ftc}-\mathrm{H}_{2}$, mesmo estando na região dos 600 nm.

Nas bandas na região dos $300 \mathrm{~nm}$ e $400 \mathrm{~nm}$, há grandes deslocamentos e diferença de intensidade da absorção para as Ftcs de Si, Ti e Zn. Para as demais MFtcs não foram observados picos de absorção nesta região.

Portanto, a presença do metal no interior da cavidade central tem influência no sistema de uma maneira que leva a uma maior simetria e com isto, o espectro de absorção das MFtcs exibem apenas um pico para a banda Q de cada molécula [19]. 


\section{Considerações Finais}

Nesta dissertação, nosso objetivo foi analisar os efeitos causados pela substituição de átomos de metal nas propriedades eletrônicas e ópticas das Ftcs. Sendo usado em nossos cálculos o funcional B3LYP com a base 6-31G**, disponível no Gaussian 09.

Concluímos que para a estrutura geométrica, estes metais interferem na planaridade da molécula causando distorções em sua estrutura. Para os casos em que o metal substituinte ficou para fora do plano, como o Ti e o V, a molécula sofreu um arqueamento, devido ao tamanho do metal ser maior que a gaiola central da Ftc. Já em outros casos em que o átomo coube no centro da gaiola, como o $\mathrm{Li}$, o $\mathrm{Co}$, o $\mathrm{Fe}$, o $\mathrm{Ni}$, o $\mathrm{Si}$, o $\mathrm{Cu}$ e o Zn, não foi observado nenhuma alteração na planaridade das Ftcs.

Além da deformação do plano da molécula, outra consequência da presença destes átomos é o alargamento da gaiola central da Ftc. Também foi vista uma contração desta gaiola que se ajustou ao átomo de Si, por ser um átomo menor que a gaiola da Ftc.

Analisamos a contribuição dos orbitais $d$ dos metais de transição na formação dos orbitais moleculares. Notamos que as maiores contribuições para os orbitais HOMO-1 aconteceram para as Ftcs de V e de Fe, com $63 \%$ e $65 \%$, respectivamente.

Os menores gaps de energia entre HOMO e HOMO-1, ocorreram nas Ftcs de $\mathrm{Fe}$ e de Co com energias de $0,48 \mathrm{eV}$ e 0,60 eV, respectivamente. Não foram vistas as contribuições para os orbitais LUMO+1, pois em nossas análises só estudamos as contribuições acima de 10\% e estes orbitais tiveram uma contribuição menor que este valor. Porém, o metal que teve uma maior contribuição do orbital $d$ acima de $10 \%$ que esteja próximo ao LUMO, foi o Ni com 40\% localizado no orbital LUMO+2.

Uma terceira análise feita foi o impacto do átomo central no espectro de absorção das Ftcs. Observando o primeiro estado de excitação, o efeito causado pela presença dos átomos de V, Li, Co, Si e Cu foi o desaparecimento da F.O. que existe na Ftc-H. Já 
para os átomos de Ti e Fe houve uma redução na amplitude da F.O., enquanto que para o Ni e o Zn a interferência fez com que aumentasse sua amplitude.

Para a primeira energia de excitação vertical (verificada para as moléculas em estudo) verificamos que sua energia é de aproximadamente $2 \mathrm{eV}$, que está de acordo com a literatura [19].

A presença do metal na gaiola da Ftc é um dos responsáveis pela simetria da molécula e com isto é observado que no espectro de absorção das MFtcs só é identificado um pico para a banda $\mathrm{Q}$ de cada molécula [19].

Na região dos $600 \mathrm{~nm}$, usando a $\mathrm{Ftc}-\mathrm{H}_{2}$ como referência, observamos que o deslocamento das bandas das MFtcs permaneceram praticamente inalteradas e os picos de absorção tiveram pequenas variações. Porém, para a região de 300 nm a 400 nm houve grande deslocamento e diferença de intensidade da absorção para algumas MFtcs e em outras não foi observado o pico de absorção.

São várias as influências que ocasionam o deslocamento da banda Q e a depender do tamanho do metal, pode ter um deslocamento pequeno desta banda. Átomos de camada aberta interagem fortemente com o anel da Ftc provocando um menor deslocamento da banda Q [15]. Comparando as MFtcs com a Ftc- $\mathrm{H}_{2}$ é observado que o pico de absorção responsável pela formação da banda Q sofre um deslocamento devido à substituição destes átomos [46].

Portanto, devido à grande absorção das Ftcs na região UV-VIS há considerável interesse na funcionalização da estrutura eletrônica destas moléculas. Assim, o papel do átomo de metal é de interesse em vários campos onde as Ftcs podem ser usadas, como por exemplo as Ftcs de Zn e $\mathrm{Cu}$ podem ser usadas em dispositivo OPV [65] e em células solares fotovoltaicas [66] e a Ftc-Li em transistores de efeito de campo [67], fazendo uso deste composto interessante.

Como perspectiva para trabalhos futuros, sugerimos o uso do parâmetro $\omega$ (parâmetro de separação de curto e longo-alcance) a fim de melhorar a descrição do sistema, pois erros de auto-interação dos funcionais híbridos convencionais podem levalos a terem dificuldades na descrição de algumas propriedades consideradas neste estudo. 


\section{Referências Bibliográficas}

[1] Mendez, M . L. R., Saja, J. A., Journal of Porphyrins and Phthalocyanines 13, 606-615 (2009).

[2] Blochwitz, J., Pfeiffer, M., Fritz, T., Leo, K., Applied Physics Letters, 73, 729-731 (1998)

[3] Horowitz, G., Advanced Materials, 10, 365-377 (1998).

[4] Guillaud, G., Simon, J., Chemical Physics Letter, 219, 123-126 (1994).

[5] Armstrong, N. R., Wang, W., Alloway, D. M., Placencia, D., Ratcliff, E., Brumbach, M., Macromolecular Rapid Communications, 30, 717-731 (2009).

[6] D’Souza, F., Journal of Porphyrins and Phthalocyanines, 6, 285-288 (2002).

[7] Guillaud, G., Chaabane, R. B., Jouve, C., Gamoudi, M., Thin Solid Films, 258, 279-282 (1995).

[8] Lever, A. B. P., Hempstead, M. R., Leznoff, C. C., Llu, W., Melnik, M., Nevln, W. A., Seymour, P., Pure and Applied Chemistry, 58, 1467-1476 (1986).

[9] Poldi, G., Caglio, S., Optics and Spectroscopy, 1, 929-935 (2013).

[10] Linstead, R. P., Journal of the Chemical Society, 0, 1016-1017 (1934).

[11] Ruan, C., Mastryukov, V., Fink, M., Journal of Chemical Physics, 111, 3035-3041 (1999).

[12] de la Torre, G., Torres, T., Journal of Porphyrins and Phthalocyanines, 6, 274-284 (2002).

[13] Bian, Y., Li, L., Dou, J., Cheng, D. Y. Y., Li, R., Ma, C., Ng, D. K. P., Kobayashi, N., Jiang, J., Inorganic Chemistry, 43, 7539-7544 (2004). 
[14] de la Torre, G., Bottari, G., Hahn, U., Torres, T., Structure and Bonding, 135, 1-44 (2010).

[15] Leznoff, C. C., Lever, A. B. P., Phthalocyanines Properties and Applications, VCH Publishers (1989).

[16] Filho, D. A. S., Coropceanu, V., Gruhn, N. E., Neto, P. H. O., Brédas, J. L., Chemical Communications., 49, 6069-6071 (2013).

[17] Wöhrle, D., Schnurpfeil, G., Makarov, S. G., Kazarin, A., Suvorovab, O. N., Journal Macroheterocycles, 5, 191-202 (2012).

[18] Kamloth, K. P., Chemical Reviews, 108, 367-399 (2008).

[19] Claessens, C. G., Hahn, U., Torres, T., The Chemical Record, 8, 75-97 (2008).

[20] Zagal, J. H., Coordination Chemistry Reviews, 119, 89-136 (1992).

[21] Nascimento, F. B., Manieri, T. M., Cerchiaro, G., Ribeiro, A. O., Dyes and Pigments, 99, 316-322 (2013).

[22] Ranta, J., Kumpulainen, T., Lemmetyinen, H., Efimov, A., The Journal of Organic Chemistry, 75, 5178-5194 (2010).

[23] Mihill, A., Buell, W., Fink, M., Journal of Chemical Physics, 99, 6416-6420 (1993).

[24] de Oliveira, K. T., de Souza, J. M., Gobo, N. R. S., de Assis, F. F., Brocksom, T. J., Revista Virtual de Química, 7(1), 310-335 (2015).

[25] Frisch, M. J., Trucks, G. W., Schlegel, H. B., Scuseria, G. E., Robb, M. A., Cheeseman, J. R., Scalmani, G., Barone, V., Mennucci, B., Petersson, G. A., Nakatsuji, H., Caricato, M.; Li, X.; Hratchian, H. P., Izmaylov, A. F., Bloino, J., Zheng, G., Sonnenberg, J. L., Hada, M.; Ehara, M., Toyota, K., Fukuda, R., Hasegawa, J., Ishida, M., Nakajima, T., Honda, Y., Kitao, O., Nakai, H., Vreven, T., Montgomery Jr, J. A., Peralta, J. E., Ogliaro, F., Bearpark, M., Heyd, J. J., Brothers, E., Kudin, K. N., Staroverov, V. N., Kobayashi, R., Normand, J., Raghavachari, K., Rendell, A., Burant, J. C., Iyengar, S. S., Tomasi, J., Cossi, M., Rega, N., Millam, J. M., Klene, M., Knox, J. E., Cross, J. B., Bakken, V., Adamo, C., Jaramillo, J., Gomperts, R., 
Stratmann, R. E., Yazyev, O., Austin, A. J., Cammi, R., Pomelli, C., Ochterski, J. W., Martin, R. L., Morokuma, K., Zakrzewski, V. G., Voth, G. A., Salvador, P., Dannenberg, J. J., Dapprich, S., Daniels, A. D., Farkas, O., Foresman, J. B., Ortiz, J. V., Cioslowski, J., Fox, D. J., Gaussian Inc., Wallingford C. T., (2009).

[26] Norton, J. E., Brédas, J. L., The Journal of Chemical Physics, 128, 034701-1-0347017 (2008).

[27] Cambridge Crystallographic Data Centre. Disponível em: http://http://www.ccdc.cam.ac.uk/. Acesso em: 27 de abr. 2015.

[28] Martins, R. A., Revista Brasileira de Ensino de Física, 20, 373-391 (1998).

[29] Cullity, B. D., Elements of X-Ray Diffraction, Addison-Wesley Publishing Company (1956).

[30] Klug, H. P., Alexander, L.E., X-Ray Diffraction Procedures For Polycrystalline and Amorphous Materials, John Wiley \& Sons (1902).

[31] Shackelford, J. F., Ciência dos Materiais, Pearson Prentice Hall (2008).

[32] Szabo, A., Ostlund, N.S., Modern Quantum Chemistry: Introducion to Advanced Electronic Structure Theory, Dover Publications (1989).

[33] Born, M., Oppenheimer, R., Annalen der Physik (Leipzig), 84, 457 (1927).

[34] Morgon, N. H., Coutinho,K., Métodos Químicos Teóricos e Modelagem Molecular, Livraria da Física (2007).

[35] Cramer, C. J., Essentials of Computational Chemistry, John Wiley \& Sons Ltd (2002).

[36] Levine, I. N., Quantum Chemistry, Pretice Hall International, New Jersey (1991).

[37] Marques, M. A. L., Botti, S., Gazeta de Física, 29, 10-15 (2006).

[38] Morgan, N. H., Custodio, R., Química Nova, 18, 44-55 (1995).

[39] Casida, M. E., Journal of Molecular Estructure: THEOCHEM, 914, 3-18 (2009). 
[40] Becke, A. D., The Journal of Chemical Physics, 98, 5648-5652 (1993).

[41] Hussein, M. S., Salinas, S. R. A., 100 Anos de Física Quântica, Livraria da Física (2002).

[42] Wilter, A. Estudo por modelagem e dinâmica molecular da protease de variantes do vírus da imunodeficiência humana tipo 1 resistentes a drogas antivirais. Universidade Federal do Rio de Janeiro. Centro de Ciências da Saúde. Instituto de Biofísica Carlos Chagas Filho, 2003.

[43] Alvarez, S., Dalton Transactions, 42, 8617-8636 (2013).

[44] McDowell, J. L., Belcher, J., Today's Chemist at Work, 51-52 (2002).

[45] Pereira, D. H., La Porta, F. A., Santiago, R. T., Garcia, D. R., Ramalho, T. C., Revista Virtual de Química, 8(2), no prelo (2016).

[46] Davidson, A. T., The Journal of Chemical Physics, 77, 168-172 (1982).

[47] Matsumoto, S., Matsuhama, K., Mizuguchi, J., Acta Crystallographica, C55, 131-133 (1999).

[48] Paoletti, A. M., Pennesi, G., Rossi, G., Generosi, A., Paci, B., Albertini, V. R., Sensors, 9, 5277-5297 (2009).

[49] Sugimoto, H., Mori, M., Masuda, H., Tagab, T., Journal of the Chemical Society, Chemical Communications, 12, 962-963 (1986).

[50] Dinguizli, M., Jeumont, S., Beghein, N., Hea, J., Walczak, T., Lesniewski, P. N., Houb, H., Grinberg, O. Y., Sucheta, A., Swartz, H. M., Gallez, B., Biosensors and Bioelectronics, 21, 1015-1022 (2006).

[51] Liu, K. J., Gast, P., Moussavi, M., Norby, S. W., Vahidi, N., Walczak, T., Wu, M. Swartz, H. M., Proceedings of the National Academy of Sciences, 90, 5438-5442 (1993).

[52] Vasseur, K., Broch, K., Ayzner, A. L., Rand, B. P., Cheyns, D., Frank, C., Schreiber, F., Toney, M. F., Froyen, L., Heremans, P., ACS Applied Materials and Interfaces, 5(17), 8505-8515 (2013). 
[53] Janczak, J., Kubiak, R., Inorganica Chimica Acta, 342, 64-76 (2003).

[54] Fujiwara, S. T., Gushikem, Y., Journal of the Brazilian Chemical Society, 10, 389-393 (1999).

[55] Shahrokhiana, S., Ghalkhania, M., Amini, M. K., Sensors and Actuators B: Chemical, 137, 669-675 (2009).

[56] Fischer, M. S., Templeton, D. H., Zalkin, A., Calvin, M., Journal of the American Chemical Society, 93:11, 2622-2628 (1971).

[57] Mi, J., Guo, L., Liu, Y., Liu, W., You, G., Qian, S., Physics Letters A, 310, 486-492 (2003).

[58] Robertson, J. M., Woodward, I., Journal of the Chemical Society, 0, 219-230 (1937).

[59] Ghammamy, S., Azimi, M., Sedaghat, S., Scientific Research and Essays, 7(43), 3751-3757 (2012).

[60] Morishige, K., Araki, K., Journal of the Chemical Society, Dalton Transactions, 22, 4303-4305 (1996).

[61] Kubiak, R., Janczak, J., Journal of Alloys and Compounds, 189, 107-111 (1992).

[62] Cui, L Y., Yang, J., Fu, Q., Zhao, B. Z., Tian, L., Yu, H. L., Journal of Molecular Structure, 827, 149-154 (2007).

[63] Senthilarasu, S., Velumani, S., Sathyamoorthy, R., Subbarayan, A., Ascencio, J. A., Canizal, G., Sebastian, P. J., Chavez, J. A., Perez, R., Applied Physics A - Materials Science and Processing, 77, 383-389 (2003).

[64] Moon, H. K., Son, M., Park, J. E., Yoon, S. M., Lee, S. H., Choi, H. C., NPG Asia Materials, 4, 1-8 (2012).

[65] Lin, C. F., Zhang, M., Liu, S. W., Chiu, T. L., Lee, J. H., International Journal of Molecular Sciences, 12, 476-505 (2011).

[66] Walter, M. G., Rudine, A. B., Wamser, C. C., Journal of Porphyrins and Phthalocyanines, 14, 759-792 (2010). 
[67] de la Torre, G., Claessens, C. G., Torres, t., Chemical Communications, 2000-2015 (2007). 


\section{A Ftalocianinas}

\section{A.1 Ftalocianina de Base Livre}

Ftalocianina de base livre $\left(\mathrm{C}_{32} \mathrm{H}_{18} \mathrm{~N}_{8}\right)$ [47], Figura A.1, é um composto policíclico orgânico formado por quatro anéis de benzeno ligados por nitrogênios na posição $a z a$. Dentre suas características, merece destaque sua estabilidade térmica e química, simetria e estrutura eletrônica altamente conjugadas conferidas pelos seus 18 elétrons $\pi$ [12]. O espectro de absorção da Ftc na região do visível apresenta um pico entre 600 e $700 \mathrm{~nm}$ $[12,14,15]$. Devido a sua intensa cor azul, tem aplicação na fabricação de corantes para coloração de couros, tecidos entre outros [17].

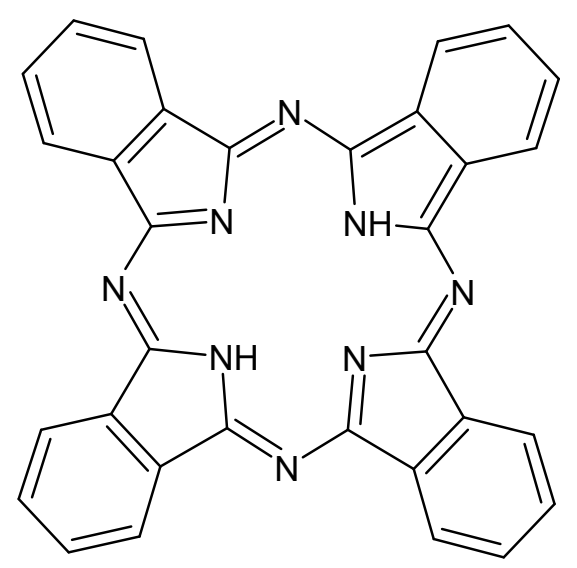

Figura A.1: Ftc- $\mathrm{H}_{2}$.

A seguir são apresentadas várias moléculas obtidas do banco de dados CCDC. Utilizamos o código da estrutura obtida da CCDC para nomear a Ftc que foi analisada. Note que algumas estruturas foram modificadas para melhor se adaptar aos objetivos do trabalho. 


\section{A.2 BITSAY02}

Ftalocianina de titânio $\left(\mathrm{C}_{32} \mathrm{H}_{17} \mathrm{~N}_{8} \mathrm{OTi}\right)$, Figura A.2, possui um único metal ligado a dois macro ciclos, o que a diferencia da maioria das Ftcs tipo sanduíche, onde cada macro ciclo tem um metal em sua estrutura [48].

Tem aplicabilidade como fotocondutor orgânico, com características interessantes: não é tóxico, apresenta baixo custo de produção e alta fotocondutividade.

Em alguns casos, as moléculas encontradas na CCDC não possuem átomos de hidrogênio algum. Este foi um dos casos. Os átomos de hidrogênio tiveram que ser acrescentados manualmente.

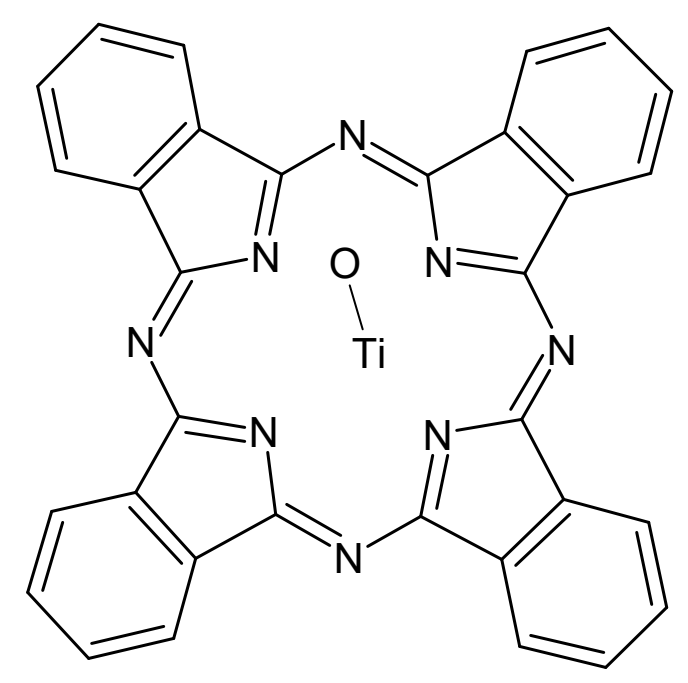

Figura A.2: BITSAY02 (Ftc-Ti.) 


\section{A.3 CIDDAW}

A ftalocianina de vanádio $\left(\mathrm{C}_{36} \mathrm{H}_{26} \mathrm{~N}_{8} \mathrm{OV}\right)$ tem características discóticas que são de grande importância para aplicações na Eletrônica Orgânica. Esta Ftc tem sido aplicada com sucesso na confecção de dispositivos eletrônicos impressos como, por exemplo, na confecção de transistores orgânicos de efeito de campo (OFETs). Essas moléculas podem formar nanoestruturas em forma de pilha, onde há uma superposição dos orbitais $\pi$, favorecendo um transporte de carga eficiente.

Na Ftc-V, Figura A.3, foram substituídas as cadeias saturadas por $\mathrm{CH}_{3}$, para simplificação dos cálculos teóricos. Esta substituição não alterará significativamente os resultados de interesse.

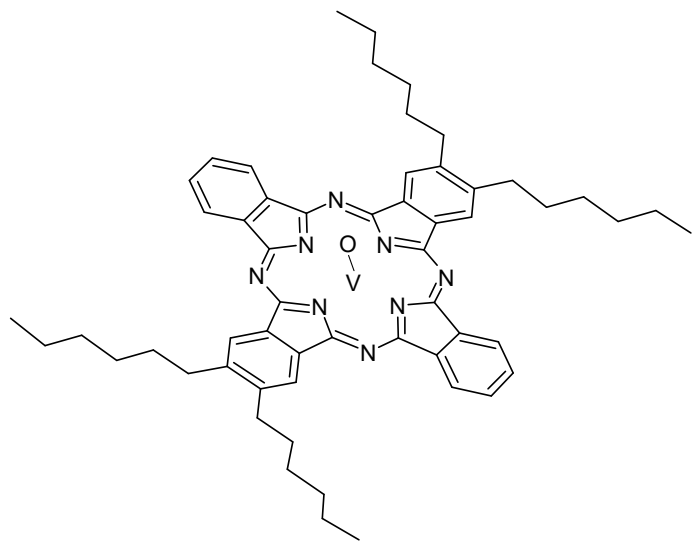

(a) Original

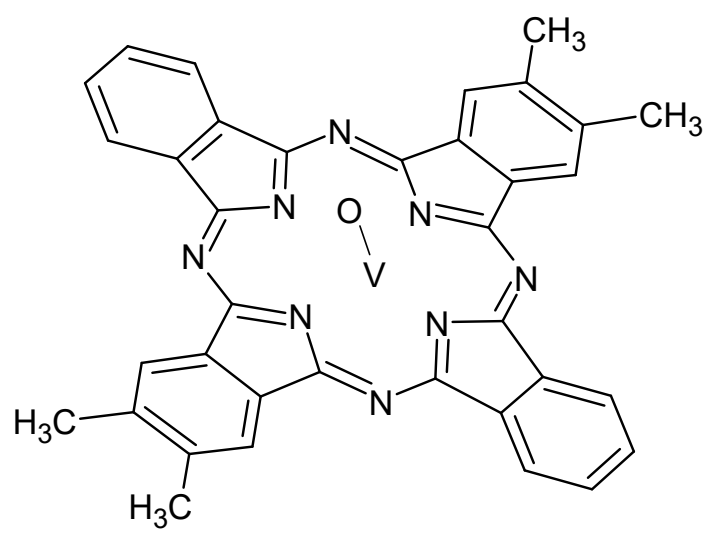

(b) Adaptada

Figura A.3: CIDDAW (Ftc-V). 


\section{A.4 DIXNIH02}

A Ftc de lítio $\left(\mathrm{C}_{32} \mathrm{H}_{16} \mathrm{~N}_{8} \mathrm{Li}\right)$, Figura A.4, é uma molécula quase plana com simetria $\mathrm{S}_{4}$ (giro de $90^{\circ}$ seguido de reflexão no plano central da molécula), em que o metal encontra-se no centro dos quatro átomos de nitrogênio. Em seu empilhamento ocorre a sobreposição dos metais, de forma que seus planos moleculares médios fiquem perpendiculares ao eixo cristalográfico $c$. Sua distância média inter planar é relativamente pequena $(3,25 \AA)$, se comparado com os compostos aromáticos neutros, a exemplo dos derivados de benzeno ou grafite $(3,35-3,5 \AA)$. Sua distância planar é muito parecida com as Ftcs de níquel e cobalto, ambas normalmente condutoras. Isto sugere que a Ftc de lítio (Ftc-Li) também deve ser condutora [49].

A Ftc-Li é muito estável e sensível a presença de oxigênio [50]. Uma aplicação desta molécula é a utilização na ressonância paramagnética eletrônica, uma tecnologia usada para medir a oxigenação nos tecidos de seres vivos [51].

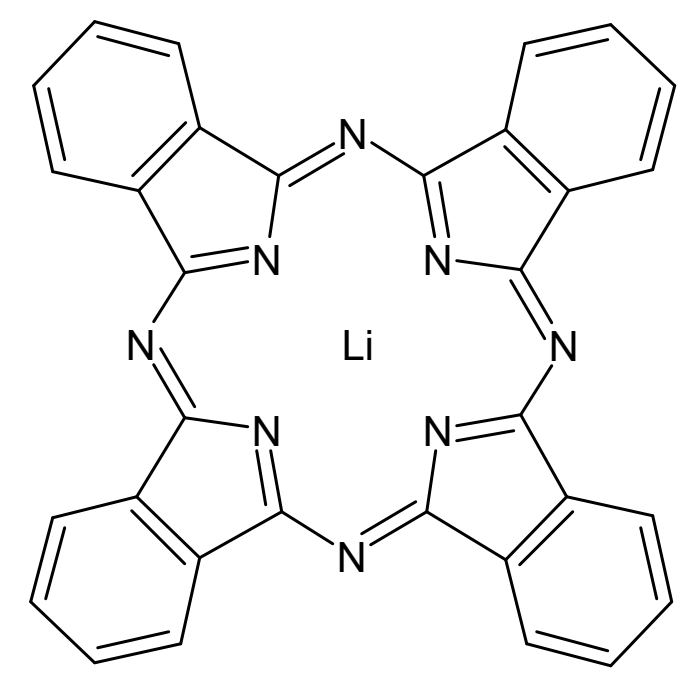

Figura A.4: DIXNIH02 (Ftc-Li). 


\section{A.5 LUWNUM}

Esse complexo é formado por uma ftalocianina de cobalto $\left(\mathrm{C}_{32} \mathrm{H}_{16} \mathrm{~N}_{8} \mathrm{Co}\right)$ e duas moléculas de piridina $\left(\mathrm{C}_{5} \mathrm{H}_{5} \mathrm{~N}\right)$, Figura A.5, retirada do CCDC sem alterações. Tem uma estrutura centrossimétrica onde as moléculas de piridina axiais são ligadas ao seu centro metálico pelo átomo de nitrogênio. Uma das suas características é ser plana e que o metal se encaixa completamente na gaiola central formada pelos quatro átomos de nitrogênio e é estável em condições normais.

$\mathrm{Na}$ formação do cristal, as moléculas se organizam em folhas onde os planos dos macrociclos são paralelos um ao outro e as moléculas vizinhas são sobrepostas pelo seus dois anéis de fenil, e as folhas são perpendiculares entre si [53].

A Ftc-Co pode ser aplicada na eletrólise da oxidação do ácido oxálico, e associado a alta estabilidade química, é utilizado na elaboração de sensores químicos [54].

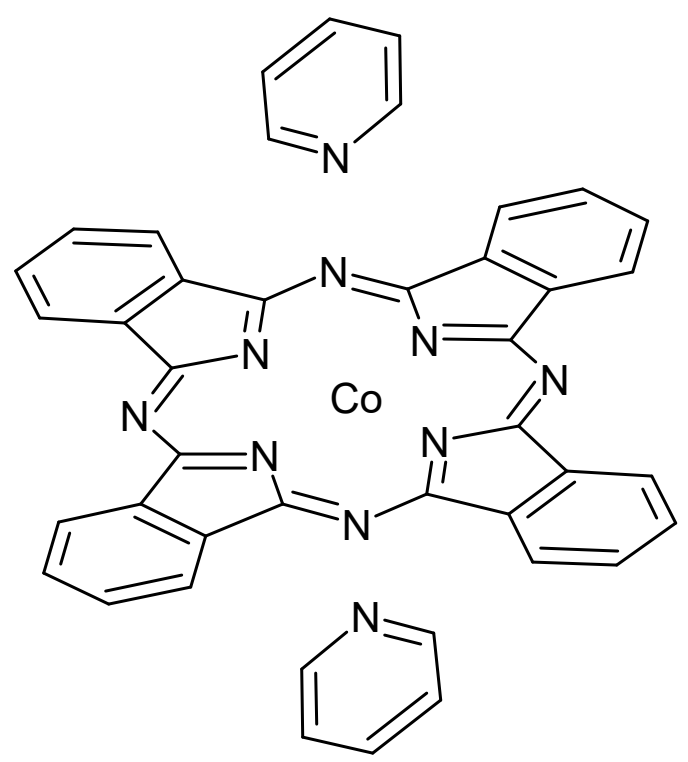

Figura A.5: LUWNUM (Ftc-Co). 


\section{A.6 LUWPAU}

Com características e estrutura muito parecidas com a Ftc de cobalto, o complexo LUWPAU é constituído por uma molécula de ftalocianina de ferro $\left(\mathrm{C}_{32} \mathrm{H}_{16} \mathrm{~N}_{8} \mathrm{Fe}\right)$ e duas de piridina $\left(\mathrm{C}_{5} \mathrm{H}_{5} \mathrm{~N}\right)$, Figura A.6. É um macrociclo planar, onde as moléculas de piridina axiais são ligadas a ele por coordenação, sendo o raio atômico do ferro de dimensão razoavelmente pequeno, pode ser acomodado na gaiola central da Ftc, essa estrutura favorece a uma boa estabilidade em condições normais. O seu arranjo de empacotamento, é feito em folhas onde as moléculas são paralelas para cada uma delas, porém entre as folhas são posicionadas de forma perpendicular [53].

A Ftc de ferro tem sido utilizada em preparações farmacêuticas e clínicas para a determinação da epinefrina (adrenalina), é um dos mais importantes neurotransmissores em sistemas nervosos centrais de mamíferos [55].

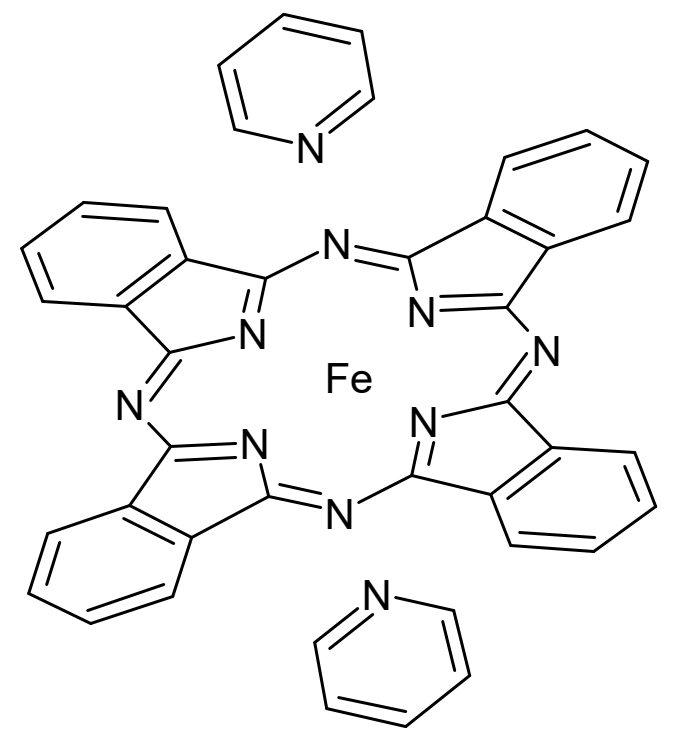

Figura A.6: LUWPAU (Ftc-Fe). 


\section{A.7 NIPHTC}

A ftalocianina de níquel $\left(\mathrm{C}_{32} \mathrm{H}_{16} \mathrm{~N}_{8} \mathrm{Ni}\right)$, Figura A.7, é uma molécula com característica planar, e seu metal se encontra completamente dentro da gaiola central da molécula. Tem características parecidas com a Ftc- $\mathrm{H}_{2}$, inclusive em sua orientação. Seu plano molecular faz um ângulo de $44,2^{\circ}$ com o seu plano de projeção, (010). Seus anéis de benzeno são hexágonos ligados ao centro da molécula de carbono-nitrogênio por ligações C-C [58].

As propriedades biológicas antitumorais e antibacterianas da NiFtc faz dela uma grande aliada no tratamento contra o câncer do cólon [59]. Uma outra aplicação prática é sua utilização em células solares orgânicas [60].

Para a realização dos cálculos dessa molécula foram acrescentados átomos de hidrogênio em sua estrutura.

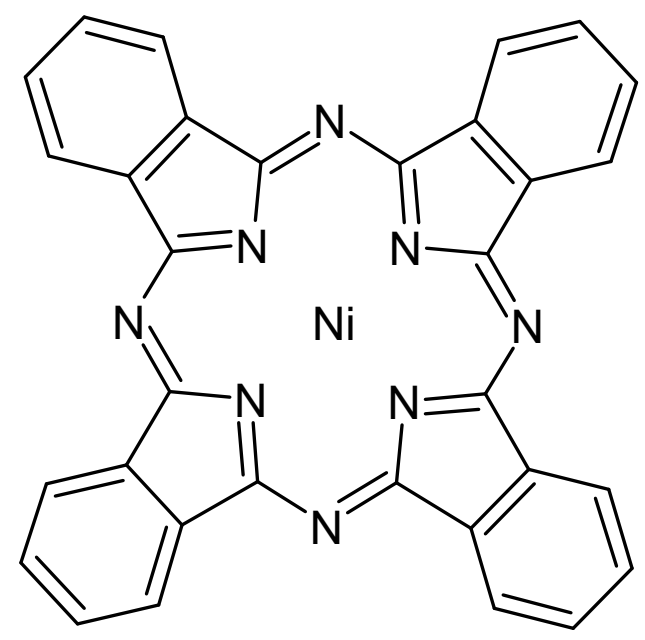

Figura A.7: NIPHTC (Ftc-Ni). 


\section{A.8 RADPIV}

A Ftalocianina de cobre $\left(\mathrm{C}_{32} \mathrm{H}_{16} \mathrm{~N}_{8} \mathrm{Cu}\right)$, Figura A.8, foi a primeira das metaloftalocianinas descobertas no início do século XX. Devido a sua importância e baixo custo de produção, é muito utilizada na indústria de corantes. São moléculas onde seu empilhamento se dá dentro do plano $a b$, formando uma superfície bidimensional [60]. Anidrido de ácido ftálico é um dos reagentes de partida para a síntese econômica de CuFtc.

A ftalocianina de cobre é um pigmento azul de grande importância em sua classe. Com algumas modificações pode se conseguir uma variação de cores, como: verde, verde-azulado e verde-amarelado. Este pigmento ser utilizado na preparação de tintas de impressão, tintas comuns, revestimentos, plásticos, têxteis, etc [60].

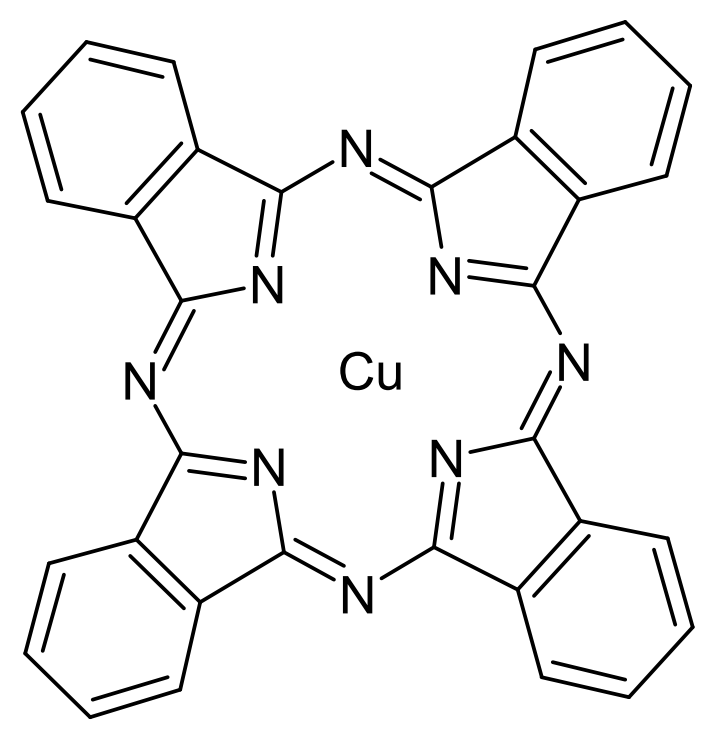

Figura A.8: RADPIV (Ftc-Cu). 


\section{A.9 YEXJOB}

Esse composto é formado por uma ftalocianina de zinco $\left(\mathrm{C}_{32} \mathrm{H}_{18} \mathrm{~N}_{8} \mathrm{OZn}\right)$, com característica coplanar, uma molécula de água e duas moléculas de dimetilformamida (DMF), Figura A.9. Seu metal localizado no centro da Ftc é ligado a quatro nitrogênios e ao oxigênio da molécula de água. Sua ligação C-N é tipicamente conjugada no sistema $\pi-$ elétrons. Seu empilhamento se dá em forma de espinha ao longo do seu eixo cristalográfico $b[62]$.

Neste composto foram feitas algumas adaptações para facilitar os cálculos teóricos, com o objetivo de analisar os efeitos do átomo de zinco na Ftc. Essas adaptações foram feitas de forma que não interferisse significativamente no cálculo de interesse. Nela foram retiradas as duas moléculas de DMF e a molécula de água.

As Ftcs de zinco tem aplicações em semicondutores fotovoltaicos orgânicos, seu uso em células solares é de grande interesse por ser facilmente sintetizada e não tóxica para o meio ambiente [63]. A sua utilização no tratamento do câncer na terapia fotodinâmica (PDT - do inglês, Photodynamic therapy), é bem aceita por se tratar de uma metodologia não-invasiva capaz de destruir as células cancerígenas com poucos efeitos colaterais $[15,64]$.

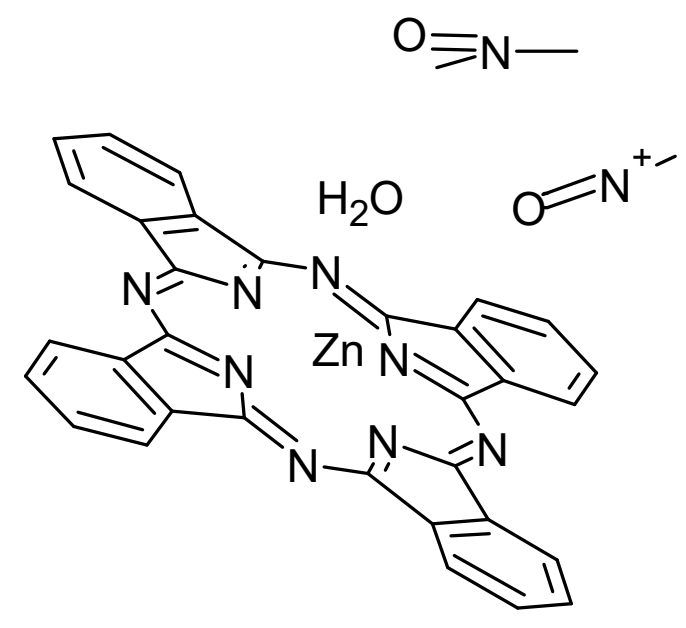

(a) Original

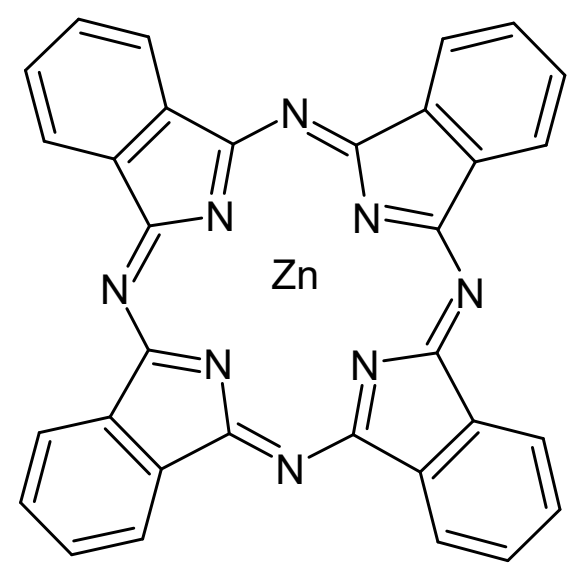

(b) Adaptada

Figura A.9: YEXJOB (Ftc-Zn). 


\section{B Script para o Cálculo das Contribuições do Orbital d}

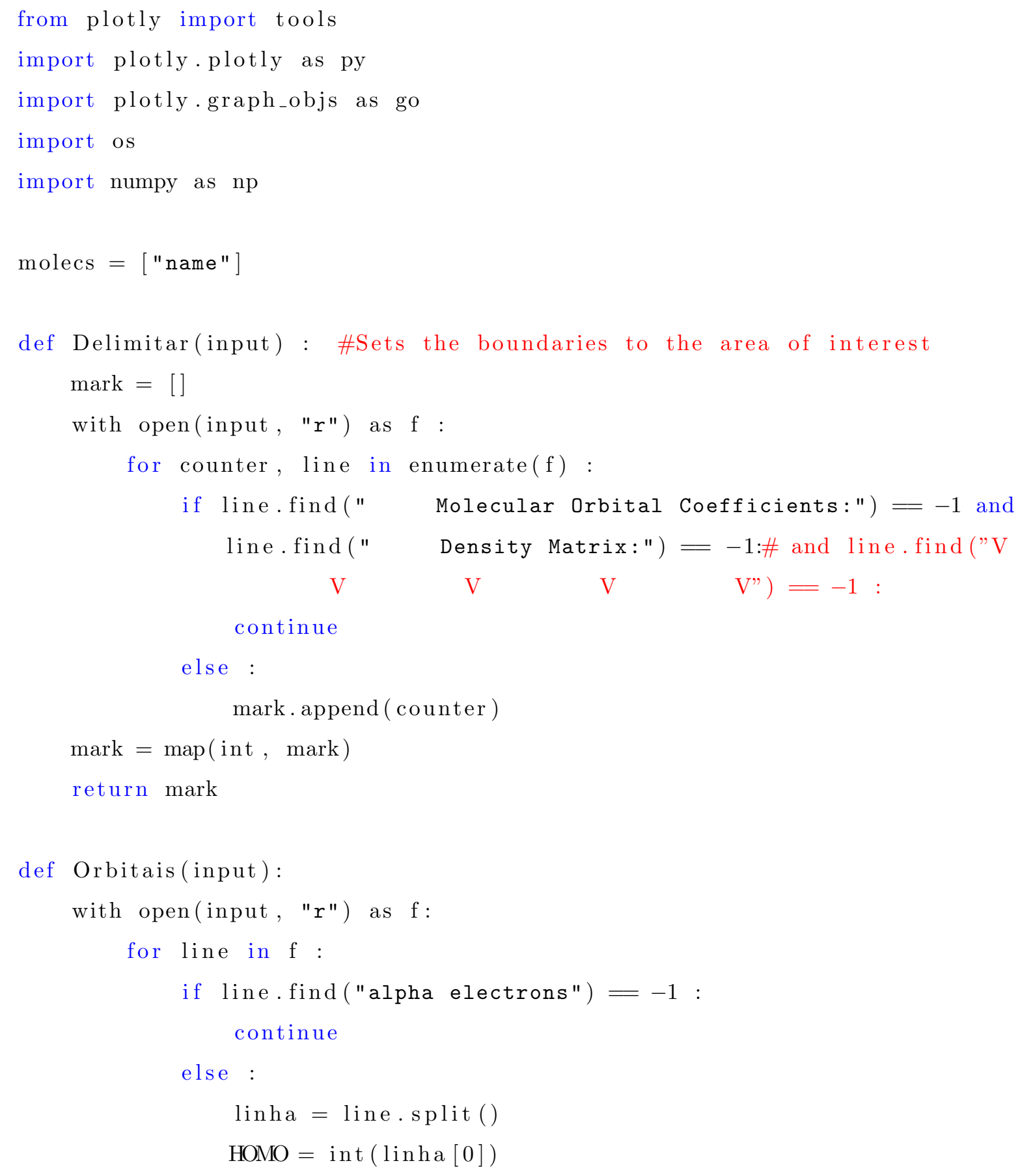




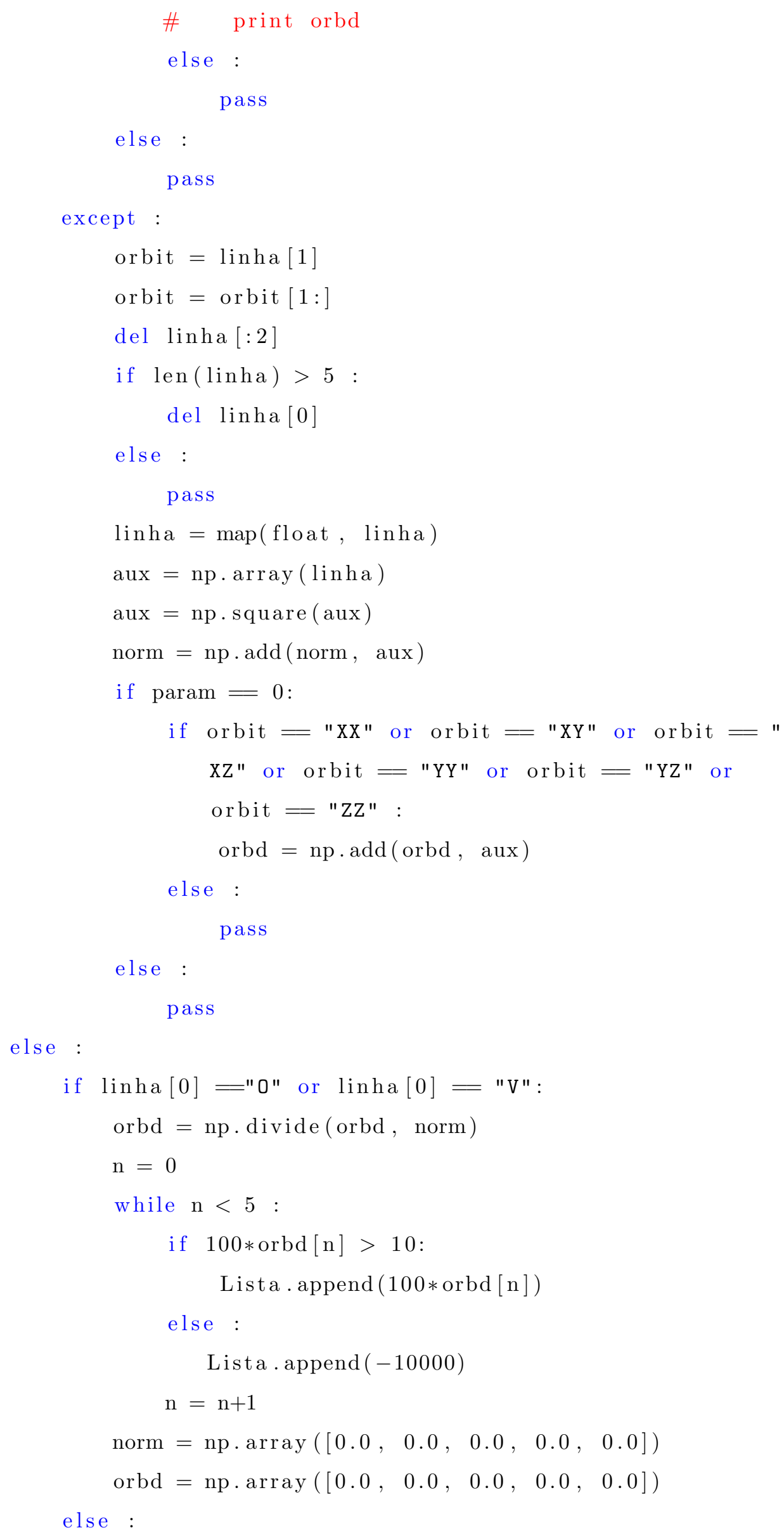


pass

else

$$
\text { pass }
$$

\#print len(Energias)

\#print len( Lista)

return Energias, Lista

for molec in molecs:

os . chdir (molec)

$\mathrm{HOMO}=$ Orbitais (molec+" . log" )

mark $=$ Delimitar (molec+".log")

En, Prob $=$ Teste $($ molec+".log", mark $)$

En $=\operatorname{map}($ float, En $)$

$\mathrm{i}=0$

while $\mathrm{i}<\operatorname{len}(\mathrm{En}):$

$\operatorname{En}[\mathrm{i}]=\operatorname{En}[\mathrm{i}] *(27.2114)$

$\mathrm{i}=\mathrm{i}+1$

trace 1 go. Scatter (name="Probabilidade Orbitais d", $\mathrm{x}=$ En, $\mathrm{y}=$ Prob, mode $="$ markers", marker $=\operatorname{dict}($ symbol $=$ "line-ns-open", size $=5))$

$\mathrm{j}=0$

$\mathrm{Y}=[]$

$\mathrm{DATA}=[]$

while $\mathrm{j}<\operatorname{len}($ En $)$ :

Y. append ( "-3.5")

$\mathrm{j}=\mathrm{j}+1$

trace $2=$ go. Scatter $(\mathrm{x}=\mathrm{En}, \mathrm{y}=\mathrm{Y}$, mode="markers", name="Orbitais", marker= $\operatorname{dict}($ symbol= "line-ns-open", size=10))

$\mathrm{X} 1=[]$

$\mathrm{X} 1$. append (En $[\mathrm{HOMO}-1])$

$\mathrm{X} 1$. append (En [HOMO])

trace $3=$ go. Scatter $(\mathrm{x}=\mathrm{X} 1, \mathrm{y}=\mathrm{Y}$, mode='markers', name="HOMO e LUMO", marker $=\operatorname{dict}($ symbol $=$ "line-ns-open", size $=20))$

DATA. append ( trace 1 )

DATA. append ( trace 2 )

DATA. append ( trace 3 )

layout $=$ go. Layout $($ title $=" F t c-T i \quad$ Orbitais $d "$, xaxis=dict (title="

Energia", range $=[-10,5]$, zeroline $=$ False, showline $=$ True, mirror $=$ True ) , yaxis $=$ dict $($ title $=$ "Probabilidade $(\%) "$, range $=[-7,100]$, zeroline $=$ True , showline $=$ True, mirror=True)) 
134

135

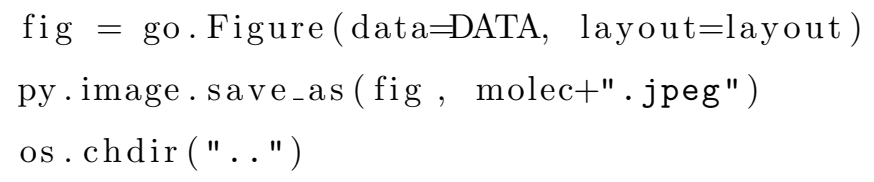




\section{Contribuições do Orbital d}

\begin{tabular}{ccc}
\hline Orbital & Energia eV & Porcentagem \\
\hline HOMO-15 & $-8,46$ & 26 \\
\hline LUMO+2 & $-1,99$ & 65 \\
\hline LUMO+8 & 0,27 & 38 \\
\hline LUMO+9 & 0,38 & 49 \\
\hline LUMO+10 & 0,53 & 19 \\
\hline LUMO+11 & 0,59 & 12 \\
\hline LUMO+12 & 0,64 & 1 \\
\hline LUMO+19 & 1,73 & 14 \\
\hline
\end{tabular}

Tabela C.1: Ftc-Ti

\begin{tabular}{ccc}
\hline Orbital & Energia eV & Porcentagem \\
\hline \hline HOMO-30 & $-9,98$ & 27 \\
\hline HOMO-28 & $-9,85$ & 48 \\
\hline HOMO-26 & $-9,84$ & 26 \\
\hline HOMO-23 & $-9,61$ & 62 \\
\hline HOMO-22 & $-9,57$ & 63 \\
\hline HOMO-17 & $-8,94$ & 74 \\
\hline HOMO-16 & $-8,58$ & 26 \\
\hline HOMO-15 & $-8,50$ & 23 \\
\hline HOMO-1 & $-6,13$ & 31 \\
\hline
\end{tabular}

Tabela C.2: Ftc-Cu 


\begin{tabular}{ccc}
\hline Orbital & Energia eV & Porcentagem \\
\hline \hline HOMO-21 & $-9,09$ & 65 \\
\hline HOMO-19 & $-8,94$ & 19 \\
\hline HOMO-17 & $-8,87$ & 22 \\
\hline HOMO-15 & $-7,89$ & 43 \\
\hline HOMO-14 & $-7,85$ & 42 \\
\hline HOMO-9 & $-7,16$ & 14 \\
\hline HOMO-8 & $-7,03$ & 71 \\
\hline HOMO-2 & $-6,49$ & 41 \\
\hline HOMO-1 & $-6,46$ & 40 \\
\hline LUMO+2 & $-1,44$ & 44 \\
\hline
\end{tabular}

Tabela C.3: Ftc-Ni

\begin{tabular}{ccc}
\hline Orbital & Energia eV & Porcentagem \\
\hline HOMO-21 & 9,16 & 11 \\
\hline HOMO-20 & $-9,08$ & 22 \\
\hline HOMO-10 & $-7,34$ & 14 \\
\hline HOMO-1 & $-5,60$ & 63 \\
\hline LUMO+4 & $-0,69$ & 16 \\
\hline LUMO+5 & $-0,68$ & 14 \\
\hline LUMO+6 & $-0,62$ & 30 \\
\hline LUMO+7 & $-0,28$ & 35 \\
\hline LUMO+8 & $-0,19$ & 26 \\
\hline LUMO+9 & 0,44 & 22 \\
\hline LUMO+10 & 0,63 & 41 \\
\hline LUMO+16 & 1,86 & 20 \\
\hline
\end{tabular}

Tabela C.4: Ftc-V 


\begin{tabular}{ccc}
\hline Orbital & Energia eV & Porcentagem \\
\hline \hline HOMO-37 & $-9,81$ & 13 \\
\hline HOMO-27 & $-8,84$ & 22 \\
\hline HOMO-26 & $-8,81$ & 13 \\
\hline HOMO-23 & $-8,42$ & 10 \\
\hline HOMO-18 & $-7,42$ & 39 \\
\hline HOMO-12 & $-7,01$ & 43 \\
\hline HOMO-11 & $-6,93$ & 35 \\
\hline HOMO-5 & $-6,40$ & 37 \\
\hline HOMO-3 & $-5,63$ & 61 \\
\hline HOMO-2 & $-5,61$ & 60 \\
\hline HOMO-1 & $-5,12$ & 50 \\
\hline LUMO+9 & $-0,20$ & 20 \\
\hline LUMO+10 & $-0,20$ & 20 \\
\hline
\end{tabular}

Tabela C.5: Ftc-Co

\begin{tabular}{ccc}
\hline Orbital & Energia eV & Porcentagem \\
\hline \hline HOMO-28 & $-9,17$ & 12 \\
\hline HOMO-12 & $-6,91$ & 11 \\
\hline HOMO-11 & $-6,80$ & 26 \\
\hline HOMO-9 & $-6,64$ & 11 \\
\hline HOMO-3 & $-5,35$ & 53 \\
\hline HOMO-2 & $-5,08$ & 65 \\
\hline HOMO-1 & $-4,98$ & 65 \\
\hline LUMO+11 & 0,48 & 50 \\
\hline LUMO+14 & 1,26 & 34 \\
\hline LUMO+15 & 1,29 & 13 \\
\hline
\end{tabular}

Tabela C.6: Ftc-Fe 


\begin{tabular}{|c|c|c|}
\hline Orbital & Energia eV & Porcentagem \\
\hline HOMO-67 & $-15,61$ & 12 \\
\hline HOMO-63 & $-14,47$ & 10 \\
\hline HOMO-59 & $-13,00$ & 54 \\
\hline HOMO-57 & $-13,00$ & 52 \\
\hline HOMO-56 & $-13,00$ & 44 \\
\hline HOMO-55 & $-12,96$ & 13 \\
\hline HOMO-53 & $-12,84$ & 56 \\
\hline HOMO-51 & $-12,64$ & 18 \\
\hline HOMO-50 & $-12,57$ & 19 \\
\hline HOMO-48 & $-12,34$ & 17 \\
\hline HOMO-47 & $-12,27$ & 35 \\
\hline HOMO-46 & $-12,19$ & 64 \\
\hline HOMO-45 & $-12,01$ & 22 \\
\hline HOMO-44 & $-11,98$ & 22 \\
\hline HOMO-43 & $-11,97$ & 24 \\
\hline HOMO-35 & $-11,24$ & 12 \\
\hline HOMO-34 & $-11,20$ & 14 \\
\hline HOMO-4 & $-6,80$ & 12 \\
\hline
\end{tabular}

Tabela C.7: Ftc-Zn 


\section{Descrição dos Estados Excitados das Ftcs}

\begin{tabular}{|c|c|c|c|c|}
\hline Molécula & Energia $(\mathrm{eV})$ & $\lambda_{\text {máx }}(\mathrm{nm})$ & F.O. & $\mathrm{N}^{\circ}$ de Estado \\
\hline \multirow{3}{*}{ Ftc- $\mathrm{H}_{2}$} & 2.09 & 593.86 & 0.4399 & 2 \\
\hline & 3.66 & 338.43 & 0.2695 & 12 \\
\hline & 3.07 & 404.04 & 0.0613 & 3 \\
\hline \multirow{2}{*}{ Ftc-Ti } & 2.02 & 612.87 & 0.3726 & 1 \\
\hline & 3.59 & 345.54 & 0.1452 & 15 \\
\hline Ftc-V & 1.20 & 620.61 & 0.4260 & 4 \\
\hline \multirow{4}{*}{ Ftc-Li } & 2.45 & 505.73 & 0.1936 & $10-11$ \\
\hline & 2.74 & 452.24 & 0.1369 & 15 \\
\hline & 1.76 & 705.73 & 0.0651 & $2-3$ \\
\hline & 2.05 & 605.73 & 0.0415 & $5-6$ \\
\hline \multirow{3}{*}{ Ftc-Fe } & 2.18 & 569.33 & 0.3800 & 2 \\
\hline & 2.15 & 577.62 & 0.3251 & 1 \\
\hline & 2.93 & 422.92 & 0.0078 & 13 \\
\hline \multirow{2}{*}{ Ftc-Co } & 2.14 & 578.45 & 0.3812 & 10 \\
\hline & 2.12 & 585.09 & 0.3371 & 9 \\
\hline \multirow{3}{*}{ Ftc-Mg } & 2.08 & 595.38 & 0.4107 & 1 \\
\hline & 2.08 & 594.87 & 0.4111 & 2 \\
\hline & 3.36 & 369.00 & 0.0233 & 4 \\
\hline \multirow{2}{*}{ Ftc-Ni } & 2.10 & 591.15 & 0.3903 & 1 \\
\hline & 3.50 & 354.28 & 0.0036 & 14 \\
\hline
\end{tabular}




\begin{tabular}{|c|c|c|c|c|}
\hline Molécula & Energia $(\mathrm{eV})$ & $\lambda_{\text {máx }}(\mathrm{nm})$ & F.O. & $\mathrm{N}^{\circ}$ de Estado \\
\hline \hline \multirow{5}{*}{ Ftc-Si } & 2.60 & 476.57 & 0.6789 & 7 \\
& 2.57 & 482.32 & 0.2667 & 6 \\
& 3.43 & 361.48 & 0.2506 & 14 \\
& 3.18 & 390.15 & 0.0216 & 11 \\
\hline \multirow{2}{*}{ Ftc-Cu } & 1.97 & 629.42 & 0.0536 & 5 \\
\hline \multirow{3}{*}{ Ftc-Zn } & 2.08 & 595.62 & 0.3968 & 4 \\
& 2.09 & 594.10 & 0.4086 & 1 \\
& 3.40 & 364.97 & 0.0084 & 5 \\
& 3.37 & 367.73 & 0.0151 & 4 \\
\hline
\end{tabular}

Tabela D.1: Descrição dos Estados Excitados das Ftcs 